\title{
Prehistoria de las islas Baleares
}

\author{
Lluis Plantalamor ${ }^{*}$ Massanet
}

\begin{abstract}
RESUMEN
RÉSUMÉ

La discontinuidad territorial de las Islas

Baleares queda reflejada enla distinta incidencia que tienen en cada isla los elementos culturales que se observan en el Mediterráneo Occidental.

En este marco geográfico se presentan las bases para una visión global de la prehistoria balear (calcolítico-edad del bronce) antes del I milenio a.C., con la introducción del hierro y la progresiva influencia colonial.

Los restos paleontológicos permiten suponer cierta presión humana ya en el $V$ milenio a.C., aunque carecemos

de restos de cultura material que permitan una definición de grupos cuiturales.

A partir de la fase calcolítica, los sepulcros megalíticos, hipogeos, $y$ hábitats, permiten ya definir grupos culturales en cada ámbito insular. Los megalitos de las Pitiusas podrian estar relacionados con los del levante insular y el Languedoc Occidental, en una fase

tardía del grupo de Veraza, mientras que los sepulcros e hipogeos de

Mallorca y Menorca parece que guardan relación con el Languedoc

Oriental-Ródano y Cerdeña, especialmente con los grupos de

La discontinuité territorial des îles Baléares vient réfléchie à la différent incidence qu'ont, dans chaque île, les éléments culturels qu'on observe à la Méditerranée Occidental. C'est dans ce cadre géographique qu'on présente les fondements pour une vision global de la préhistoire Baléare (chalcolithique-âge du bronze) avant du I millénaire a.C., avec l'introduction du fer et la progressive influence colonial. Les débris paléontologiques permettent de supposer une pression humaine vers le $V$ millénaire a.C., bien que nous n'avons pas des débris de culture matériel qui permettent une définition des groupes culturels.

Dés la phase chalcolithique, les sépulcres mégalithiques, les hypogées et les habitats permettent déjà de définir des groupes culturels dans chaque domaine insulaire. Les mégalithes des Pitiuses pourraient se mettre en rapport avec les mégalithes de l'est péninsulaire et le Languedoc occidental, dans une phase tardive du groupe de Veraza, trandis que les sépulcres et les hypogées de Majorque et Minorque semblent se rattacher au Languedoc Oriental-Rhône et la Sardaigne,
\end{abstract}

* Director-Conservador del Museo de Menorca. 
Ferrières, Fontbouisse, Subozieri, Monteclaro i Bonnanaro $A$. A partir del bronce antiguo-medio se iniciará en Menorca Oriental la influencia del grupo de Bonnanaro $B y$ de otros grupos culturales del

Mediterráneo Central, que progresivamente se extenderán al resto de Menorca y a Mallorca, dando lugar a la cultura talaiótica.

En las Islas Pitiusas, en cambio, es dificil por el momento, constatar este tipo de relaciones extra insulares. Con la edad del hierro se integrarán en el ámbito cultural fenicio púnico al tiempo que las Baleares propiamente dichas entrarán en un proceso de aculturalización. notamment avec les groupes de Ferrières, Fontbouisse, Subozieri, Monteclaro et Bonnanaro $A$. À partir du bronze ancien-moyen va commencer, à la partie oriental de lîle de Minorque, linfluence du groupe de Bonnanaro $B$ et d'autres groupes culturels de la Méditerranée Central, que progressivement s'étendra au reste de Minorque et à Majorque, en donnant lieu à la culture talaiotique.

Aux Îles Pitiuses, autrement, est difficile à ce moment de constater ce type de relations extra-insulaires. Avec l'âge du fer, elles vont entrer dans le domaine culturel phénicien- punique, au même temps que les Baléares entreront dans un processus d'acculturation.

\section{INTRODUCCIÓN}

La unidad geográfica conocida como Comunidad de las Islas Baleares no siempre ha presentado una evolución idéntica y unitaria, tal como podría deducirse de la imagen hoy generalizada fuera del ámbito insular. La discontinuidad territorial, ya observada en la historiografía clásica, ha influido de forma determinante en las líneas actuales de investigación (Blanes, C.; Bonet, J.; Font, A., y Roselló, A.M., 1990).

No es objeto del presente estudio profundizar en las distintas fases y corrientes de las investigaciones realizadas hasta la actualidad, aspecto por otra parte tratado ya ampliamente (Pericot García, L., 1972). Simplemente destacamos que, salvo en contadas ocasiones, las investigaciones realizadas no abarcan un ámbito mayor del delimitado por una isla y sólo excepcionalmente observamos estudios que abarcan las dos agrupaciones culturales clásicas: las Baleares propiamente dichas o Gimnesias (Mallorca y Menorca) y las Pitiusas (Ibiza i Formentera).

A grandes rasgos el interés de las investigaciones ha sido desigual: mientras que la existencia de talaiots en Mallorca y Menorca ha propiciado un interés hacia la prehistoria, los hallazgos de ricas necrópolis han determinado los estudios hacia la cultura púnica en las Pitiusas (Román, C., 1813).

El inicio temprano de las investigaciones en Mallorca (Binimelis, J., 1927) y Menorca (Ramis i Ramis, J. 1818) propiciaron una ya tradicional 
historiografía mediterránea (Cartailhac, E., 1892) sobre la que ha incidido la dependencia de los avances realizados en la Península lbérica (especialmente en el entorno de las Universidades de Barcelona y Madrid) (Bosch Gimpera, P., 1932, Almagro Gorbea, M., 1941). Este hecho contrasta con los escasos documentos referidos a la prehistoria pitiusa anteriores al redescubrimiento del sepulcro megalítico de $\mathrm{Ca} \mathrm{Na}$ Costa (Formentera) (Fernández, J.H., Plantalamor, L. y Topp, C., 1976).

A grandes rasgos observamos un primer período, que coincide con la expansión neolítica en el Mediterráneo Occidental, del que no tenemos elementos que permitan definir mínimamente un grupo cultural.

Ya en la fase calcolítica observamos una progresiva ocupación territorial en Mallorca y Menorca, donde el gran número de datos permite definir dos fases culturales sucesivas: la pretalaiótica y la talaiótica, que presentan características insulares, regionales y temporales concretas. En cambio, la escasez de datos referentes a lbiza y Formentera no permiten una periodización de su prehistoria hasta que entran en el área de la cultura fenicio-púnica.

\section{PRIMEROS INDICIOS DE POBLACIÓN EN LAS BALEARES Y PITIUSAS}

La asociación de huesos humanos y el antilópido conocido con el nombre de «myotragus Balearicus» en la cueva de Muleta evidenció la coexistencia del hombre y la fauna autóctona en una fecha que se remonta al $\checkmark$ milenio A.C. (Waldren, W.H., 1994). Es más problemática la asociación de estos restos con los sílex, de clasificación incierta, hallados en una zona próxima y que se conservan en el Museo de Sóller.

Indicios de hechos similares parecen desprenderse de algunas informaciones referentes a Sa Cova Murada (Ciutadella) de Menorca (Mercadal, B., 1959) aunque los datos deben tratarse con cierta precaución dada la metodología empleada.

Los resultados de la excavación de Son Matge en sus niveles inferiores permitieron documentar un intento de domesticación del Myotragus, observándose la acumulación de coprolitos y el corte selectivo de las cornamentas (Waldren, W., 1994). Nuevos datos procedentes de excavaciones paleontológicas tanto en Mallorca como en Menorca parecen confirmar estos resultados (Encinas, J. A. i Alcover, J.A., 1997) (fig. 1).

Pocos son los datos conocidos respecto a lbiza. Los resultados de la excavación de Es Pouàs (Sant Antoni) permiten documentar un cambio de fauna en torno al $V$ milenio, difícil de explicar sin la intervención humana (Alcover, 1994). 


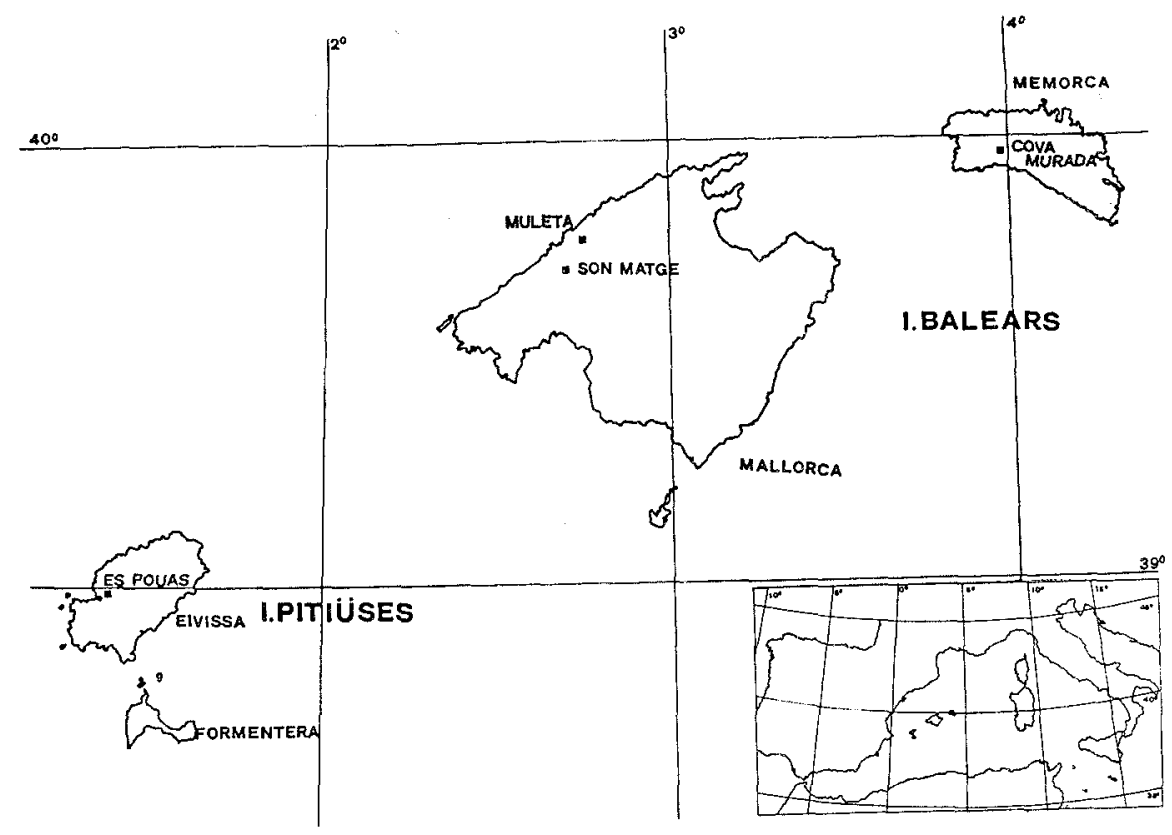

Figura 1. Primeras ocupaciones humanas en las Baleares y las Pitiusas.

De lo expuesto podría intuirse cierta presión humana sobre las Baleares y las Pitiusas parejo al inicio del neolítico en el norte del Mediterráneo Occidental y del Levante Ibérico respectivamente, si bien carecemos de elementos que permitan definir grupos culturales.

\section{ELEMENTOS PARA UNA PREHISTORIA DE IBIZA Y FORMENTERA}

Ya hace tiempo eran conocidos algunos fragmentos de cerámica procedentes de Sa Cova des Cuïram (Vives, A., 1917). Nuevos hallazgos, como los de Sa Cova des Fum (Trías, M. y Roca, L., 1975), Cova es Riuets, y Cova Xives (Trías, M., 1977), permiten documentar el uso arcaico de espacios naturales en un contexto poco definido.

La excavación del Cap de Berberia (Formentera) (Topp, C., Fernández, J.H., y Plantalamor, L., 1979) puso al descubierto un tipo de casa circular compartimentada a la que pueden adosarse ambientes absidales (Costa, B. y Fernández, J.H., 1992) (fig. 2). Es posible que nos encontremos frente a un tipo de estructura con características diferentes al de las cabañas circulares como la de Es Puig de ses Torretes, posiblemente ya de la edad 


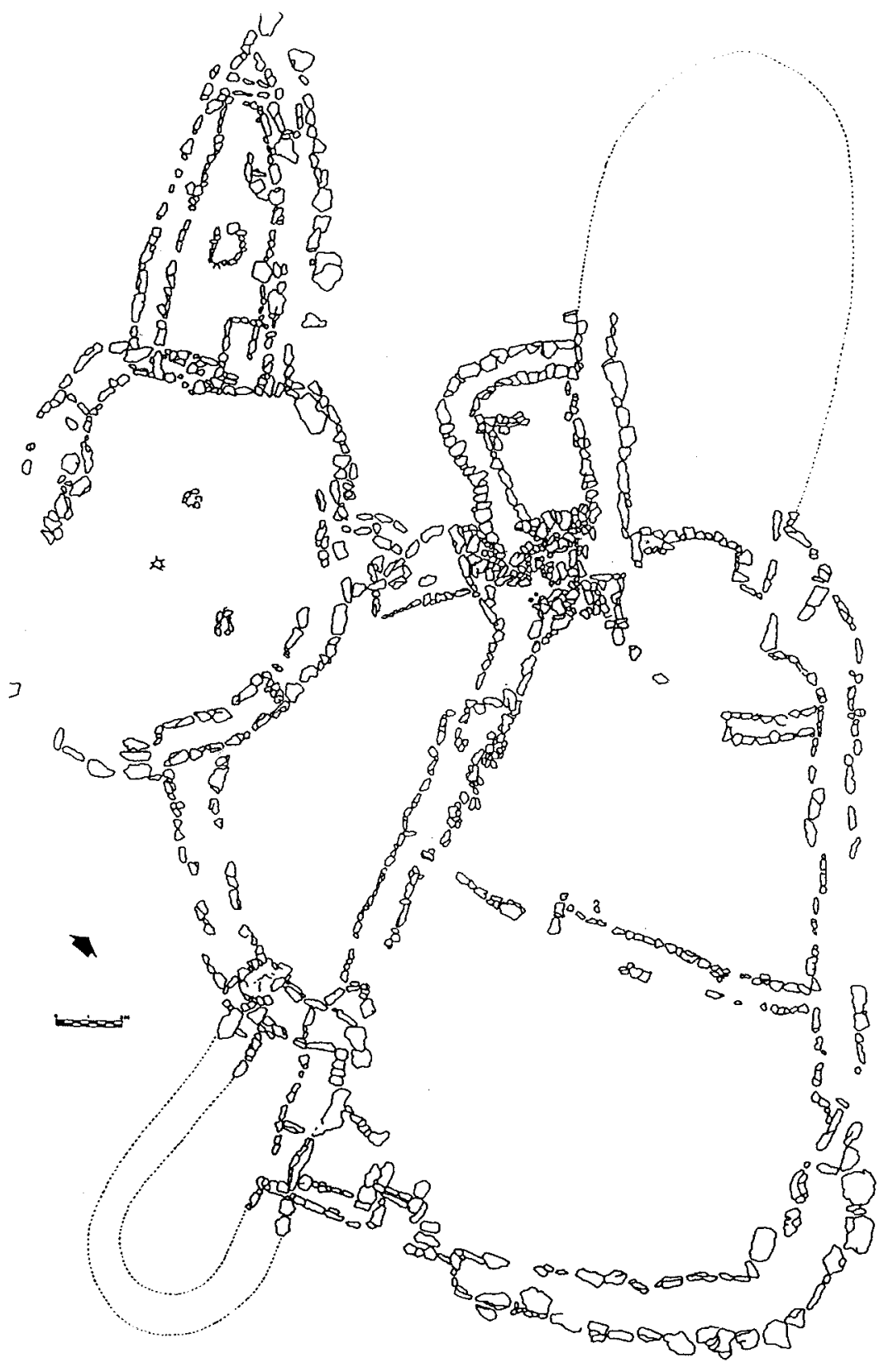

Figura 2. Cap de Barberia (Formentera)(según B. Costa y J.H. Fernandez). 
del bronce. En este último período podría hipotéticamente situarse el murallón costero de la Mola de Formentera (Fernández, J.H., 1975).

La excavación del sepulcro megalítico de $\mathrm{Ca} \mathrm{Na}$ Costa (Formentera) (Fernández, J.H., Plantalamor, L., y Topp, C., 1987), y posteriormente Can Sergent (Sant Josep-lbiza) (Topp, C., Fernández Gómez, J.C. y Plantalamor, L., 1979) permitieron identificar este tipo de estructuras prehistóricas singulares.

Especial interés presenta el conjunto de $\mathrm{Ca} \mathrm{Na}$ Costa. En este monumento, la estructura de corredor y cámara circular con losa perforada interpuesta está reforzada por un muro de contención anular en el que se apoyan bloques a modo de ortostatos radiales que delimitan un segundo anillo sobre una plataforma (fig. 3).

El contexto cultural (cerámicas generalmente lisas, salvo dos fragmentos incisos, botones piramidales con perforación en $\mathrm{V}$, lascas de sílex, un pequeño puñal con orificio de remaches) indica un estadio calcolítico bronce inicial que contrasta con las dataciones no calibradas, tal vez erróneas o correspondientes al último momento de ocupación (1320 \pm 80 A.C para Ca Na Costa, $550 \pm 100$, y $720 \pm 60$ A.C. para Can Sergent) (fig. 4).

Conocemos también varias hachas de bronce de formas muy diversas (planas, de filo semilunar, tubulares, de talón) que junto a lingotes de modo de torta sugieren un comercio que indudablemente se remonta a la edad del bronce, pero que muy bien podría prolongarse hasta ya entrado el primer milenio (Fernández Gómez, J.H., 1973, Fernández Gómez, J.H., 1974).

\section{EL HÁBITAT PRETALAIÓTICO DE MALLORCA Y MENORCA}

La utilización como hábitat de espacios naturales protegidos es común en todas las culturas. En Menorca, abrigos como el de Morellet (Maó) (Rita Larrucea, M.C., 1986), Montgofre Nou (Maó) (López Pons, A., 1997) y Son Boter (Migjorn) fueron ocupados ya en época pretalaiótica. También en Mallorca este hecho ha sido comprobado en Sa Canova (fig. 7) (Cañigueral, J., 1951) y Son Matge (Rosselló, G. y Waldren, W.H., 1973), en los que se documentan los grupos cerámicos conocidos por incisas $B$ y A respectivamente.

Esta asociación también es conocida en hábitats al aire libre, como Ca $\mathrm{Na}$ Cotxera (Muro) (Cantarellas Camps, C., 1972) y Son Ferrandell-Son Oleza (Waldren, W.H., Ensenyat, J. y Cubí C., 1994). La excavación de este último yacimiento ha permitido documentar estructuras de planta alargada de cierta complejidad (fig. 6). 

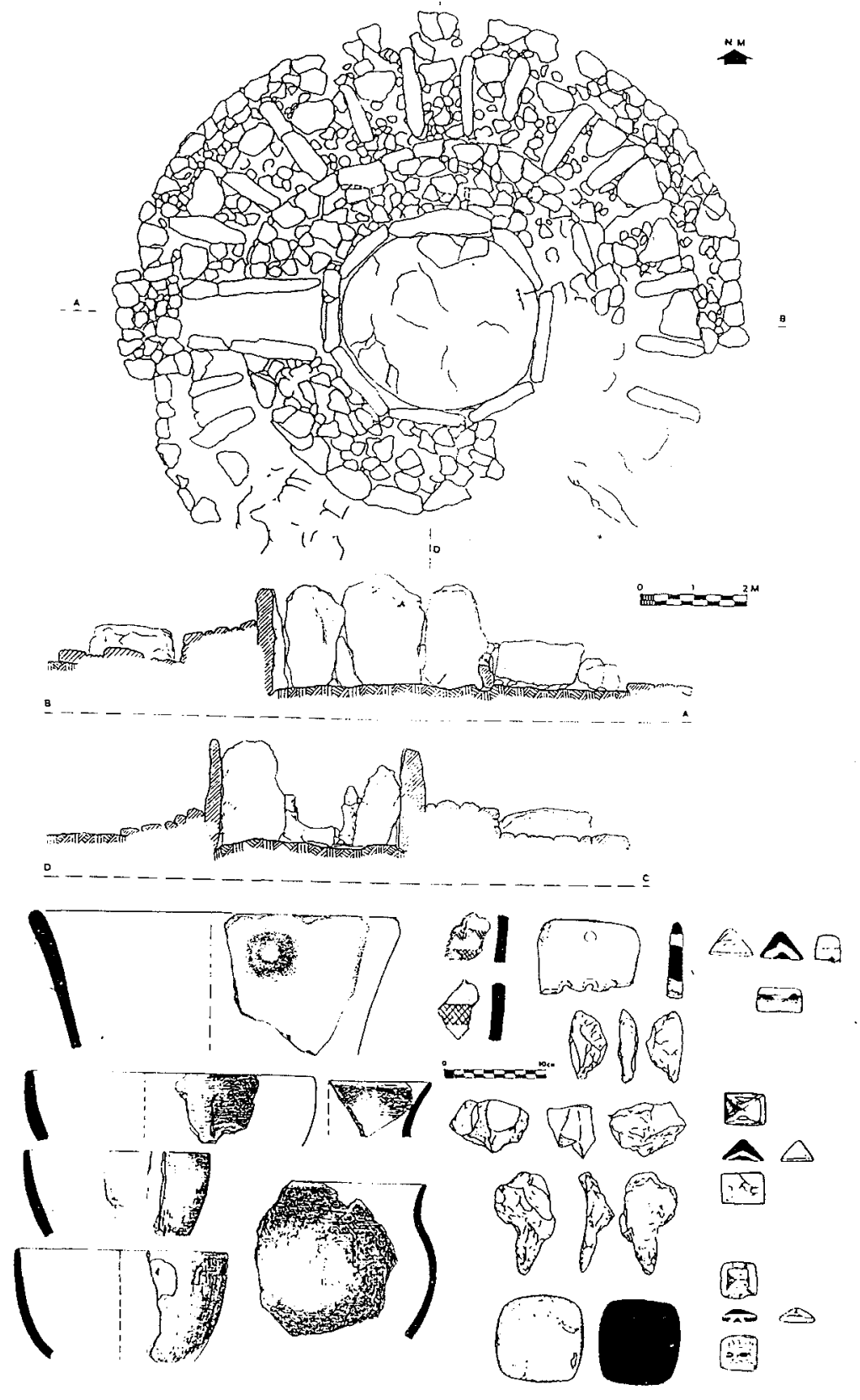

Figura 3. Ca Na Costa (Formentera) (según J.H. Fernandez, L. Plantalamor y C. Topp). 

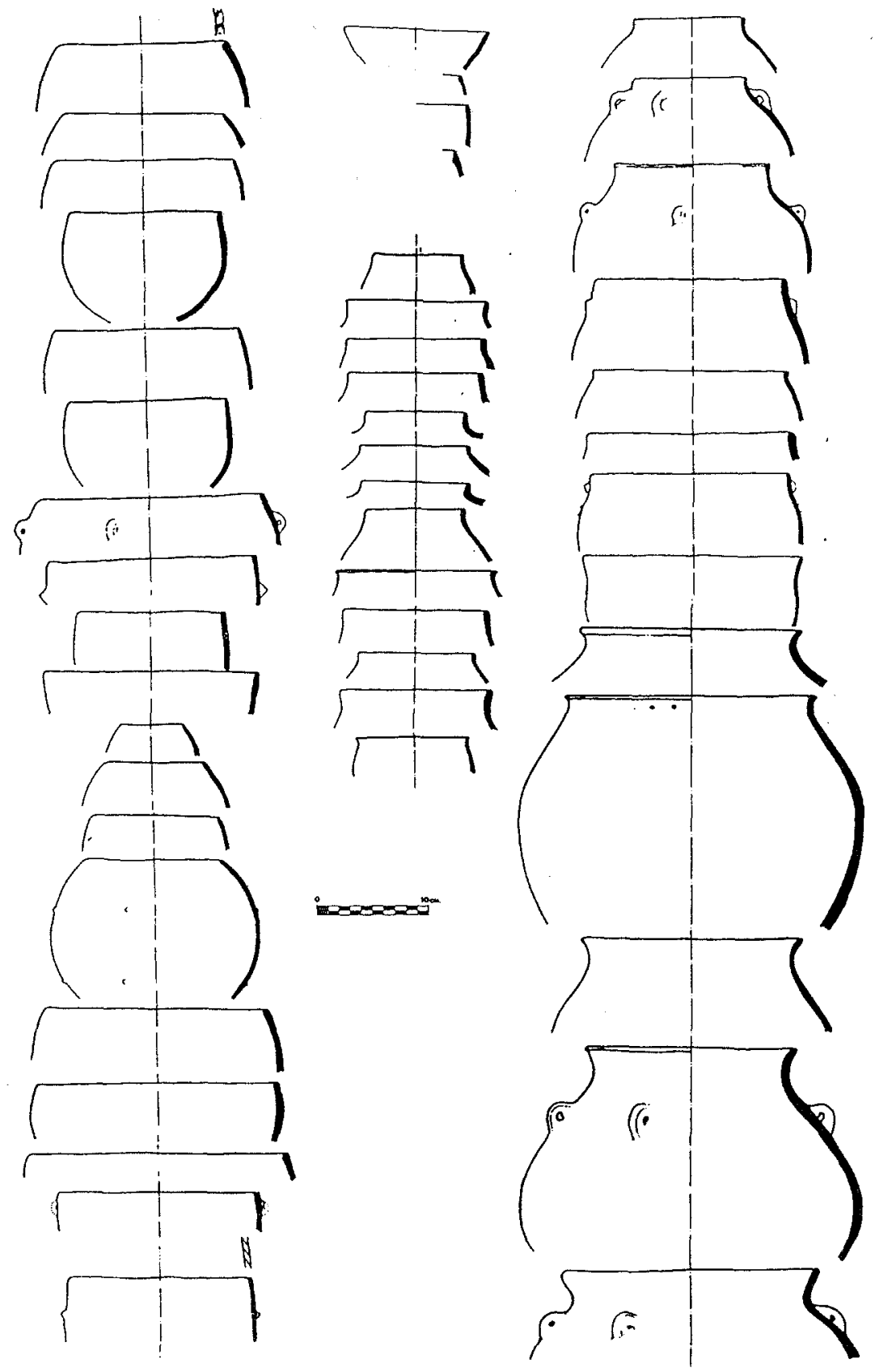

Figura 4. Materiales de la Cova des Rivets (Formentera) (según M. Tries y LI. Roca). 


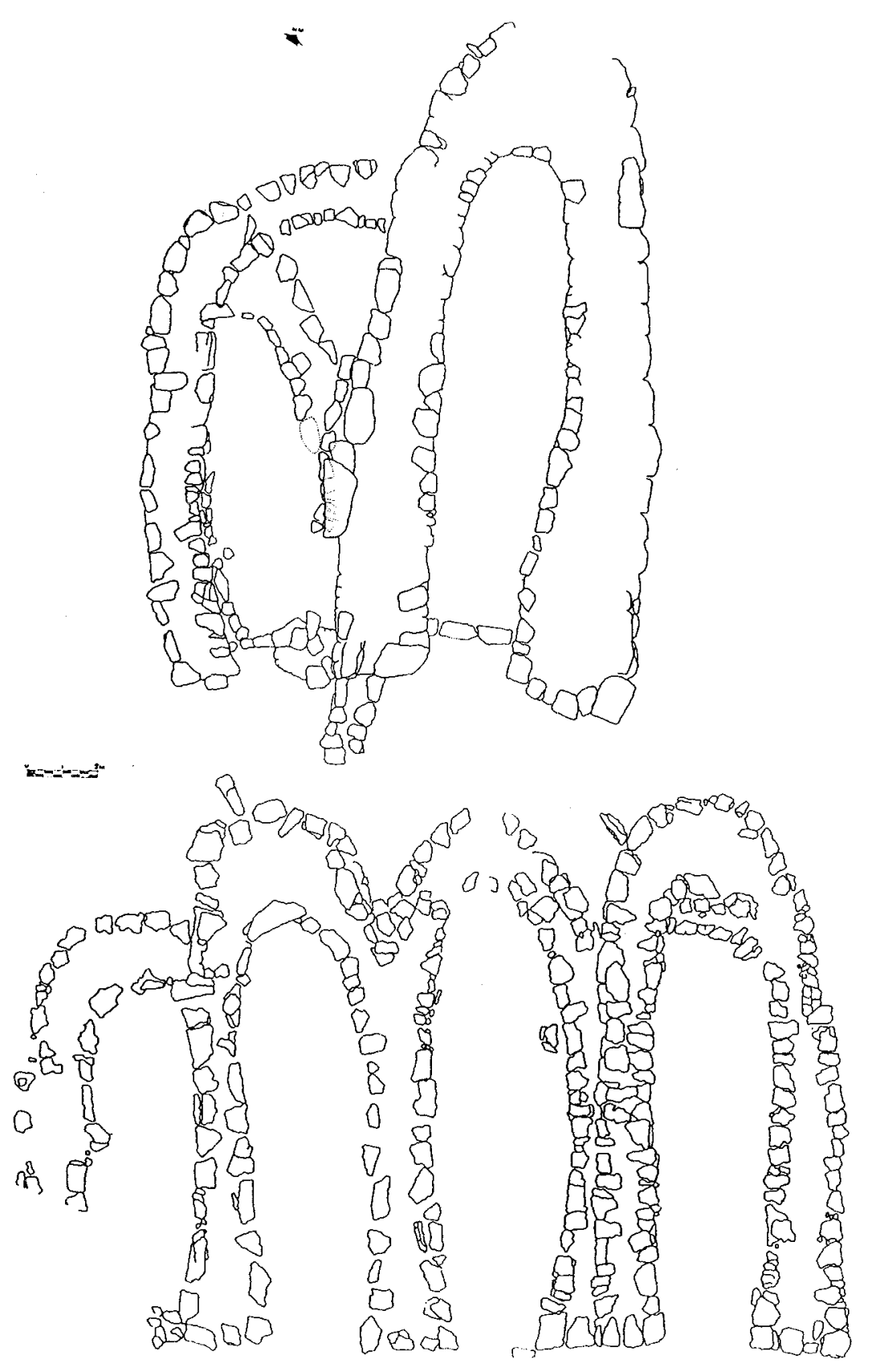

Figura 5. Navetas de Canyamel (Artà) (según G. Rosselló Bordoy). 


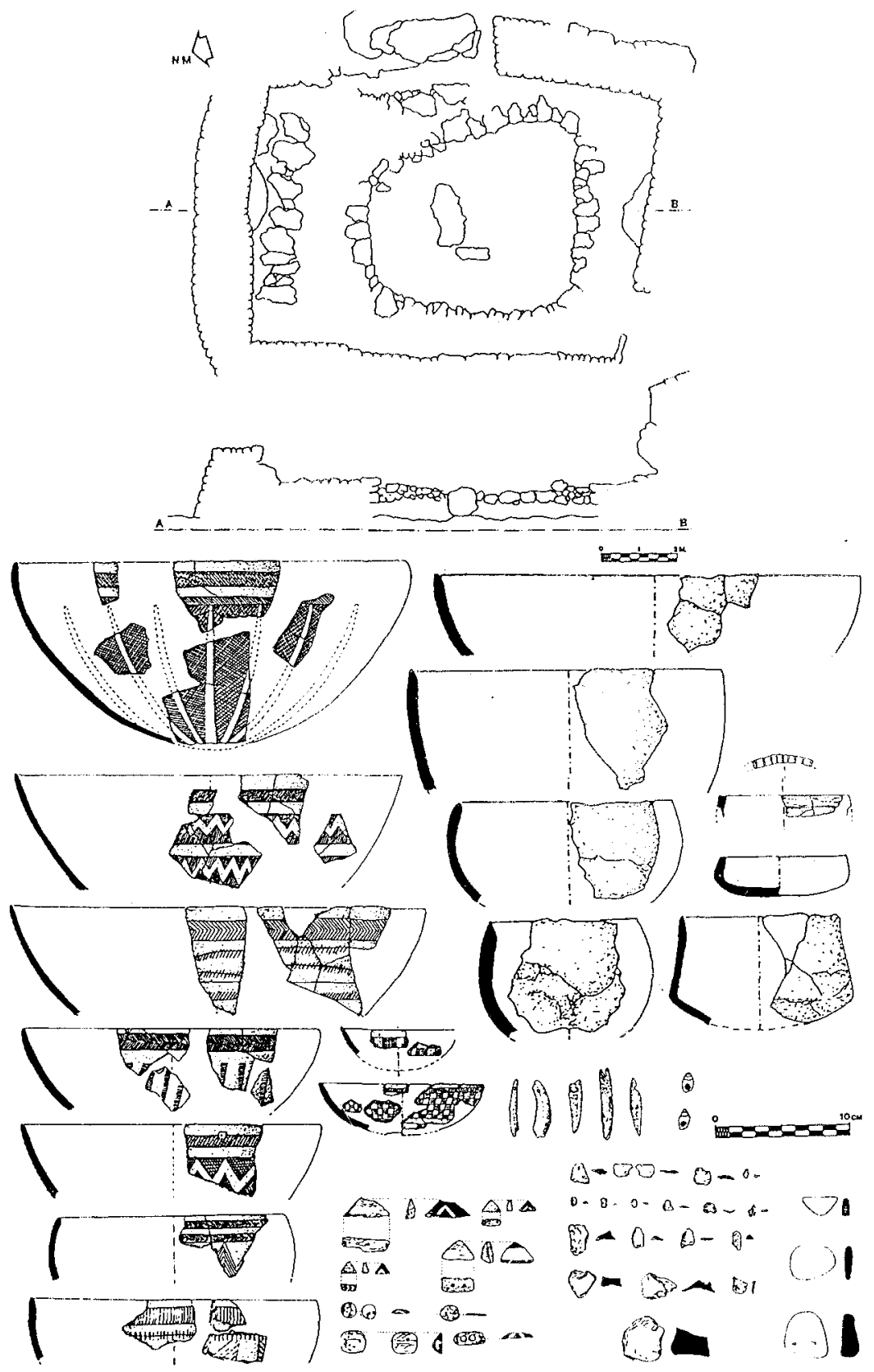

Figura 6. Ca Na Cotxera (Muro) (según C. Cantarellas, dibujo de M. Tries y L. Plantalamor). 


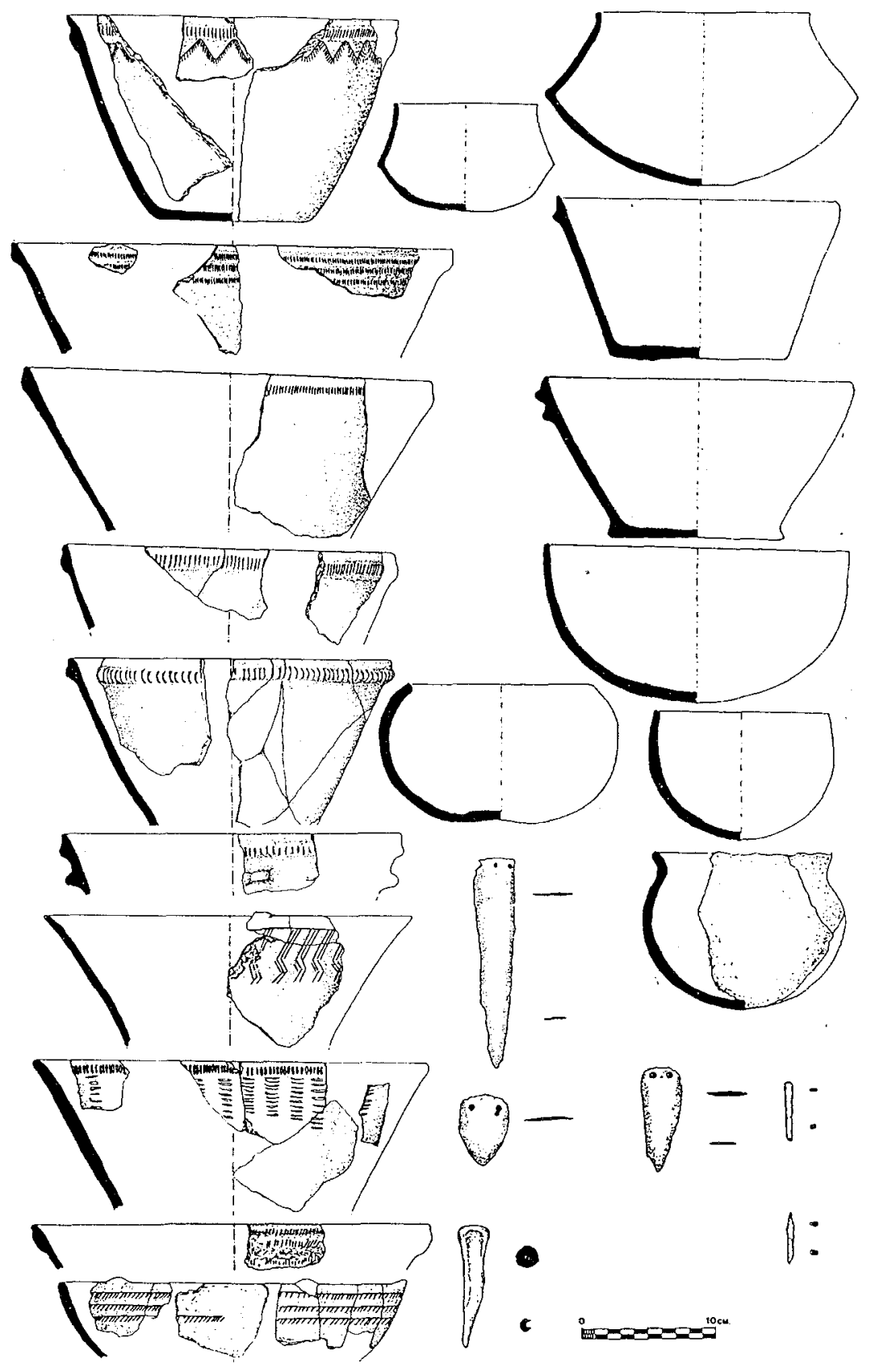

Figura 7. Sa Canova (Ariany) (según C. Cantarelles, dibujo de L. Plantalamor). 
También deben situarse en la fase pretalaiótica algunos pequeños recintos cerrados por un muro, como el de Filicomís (Lloseta-Mallorca) (fig. 8) (asociado con el hipogeo de Can Patos), o los de Trebalúger (Es Castell) (Gual, J., López, A. y Plantalamor, L., 1991) y Curnia (Maó) (Plantalamor, L., 1991) (sobre los que se han construido estructuras talaióticas).

Las estructuras de defensa próximas a la costa de Es Puig de S'Áliga (Capdepera-Mallorca) o de Es Cap de Cala Morell (Ciutadella-Menorca) (fig. 12) (Juan Benejam, G. y Plantalamor, L.) son similares a las anteriores. Las plantas de las casas que se encuentran en el interior de estos recintos son

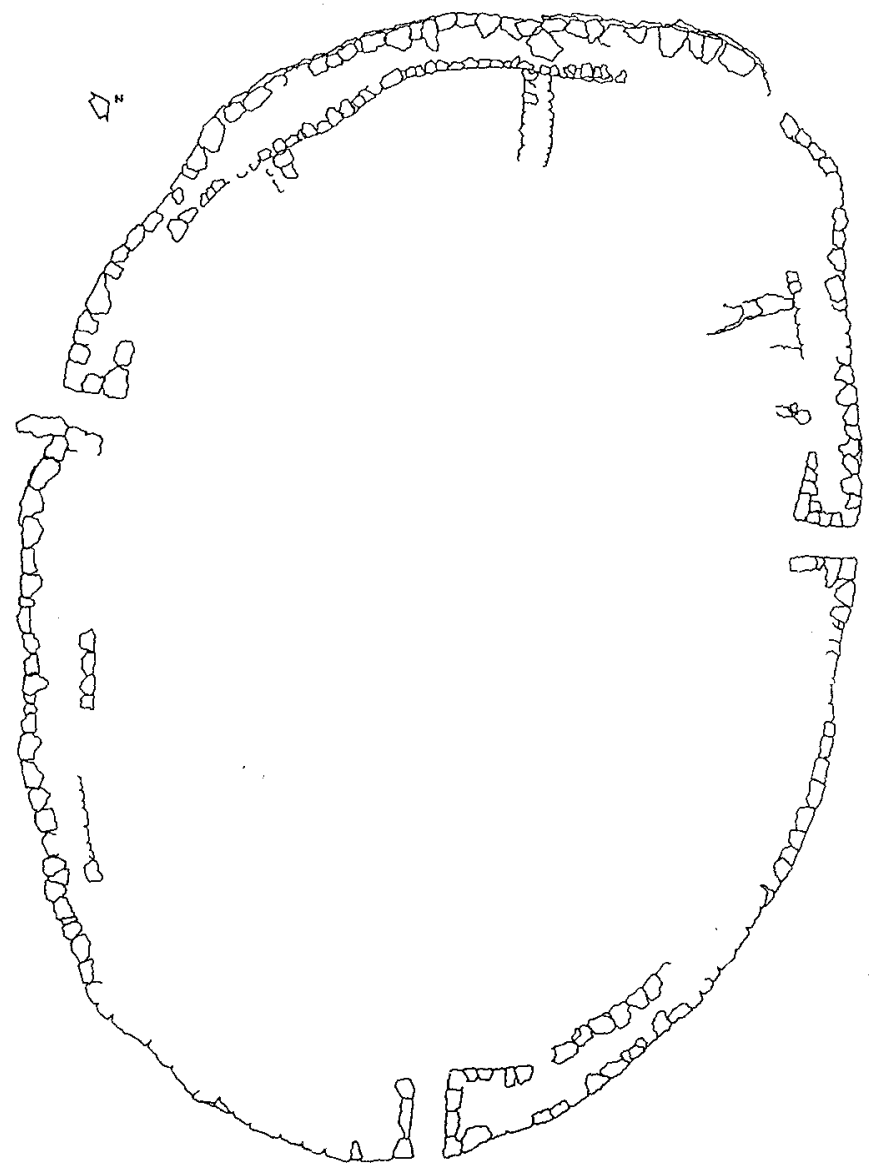

Figura 8. Es Filicomís (Lloseta) (según L. Plantalamor, J. Murillo y T. Salvà). 


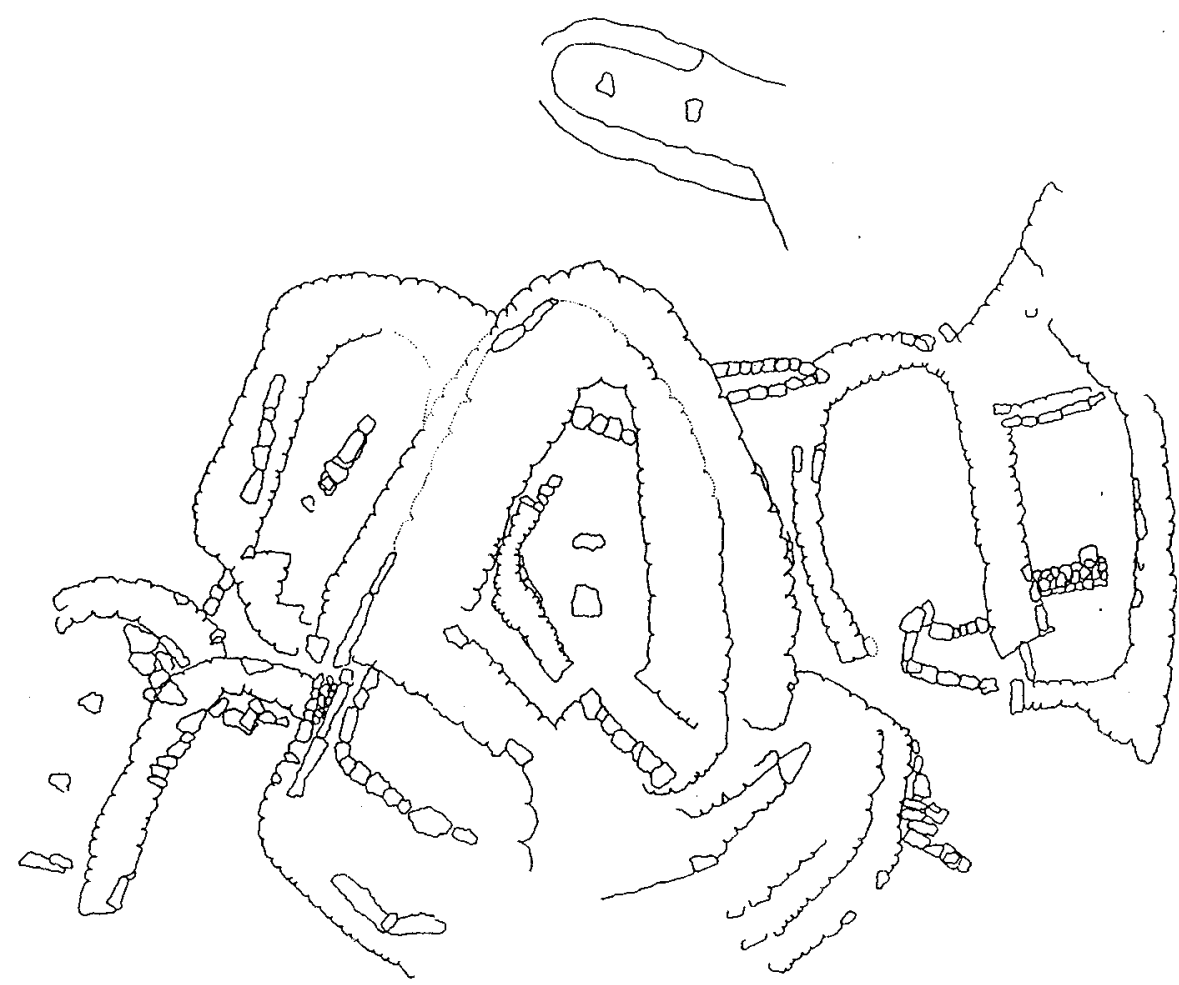

Figura 9. Navetas de Es Figueral de Son Real (Santa Margalida) (según J. Camps y G. Rosselló Bordoy).

absidales y similares a las de las navetas de habitación, aunque de menores proporciones, y están construidas con piedras de tamaño reducido.

Las excavaciones en las navetas de habitación Alemany (Mallorca) (Enseñat, C., 1971), Clariana (Ciutadella-Menorca) (Plantalamor, L. y Anglada, J., 1978), Son Mercer de Baix (Rita Larrucea, M.C., 1986) y Cala Blanca (Ciutadella) (fig. 10) (Juan Benejam, G. y Plantalamor, L., 1997) han puesto de manifiesto el uso generalizado de este tipo de hábitat en la fase pretalaiótica, como ya apuntó Rosselló Bordoy (Rosselló Bordoy, G., 1973).

Se trata de un tipo de hábitat de planta alargada, con muros sólidos de grosor superior a un metro, con entrada en uno de los extremos, ábside semicircular o apuntado y hogar central, que frecuentemente se adosa a otras estructuras similares (Es Figueral de Son Real (Santa Margalida) (fig. 9) (Rosselló Bordoy, G. I Camps Coll, J. (1972), Canyamel (Artà) (fig. 5) [Rosselló Bordoy, G. y Camps Coll, J. (1976), Son Oms (Palma de 
Mallorca) (Rosselló Bordoy, G., 1973)] llegando a concentraciones importantes [Es Clossos de Can Gaià (Felanitx) (Rosselló Bordoy, G. i Frey, O.H., 1967) o Bóquer (Pollença)].

También en Menorca se observan estas concentraciones de navetas [Clariana (Ciutadelia) (fig. 11), Son Mercer de Baix 1 y 2 (Ferreries), Sant Jordi (Mercadal)], aunque sin alcanzar la densidad de Mallorca.

Nos hallamos indudablemente ante estructuras de hábitat permanente y de economía mixta, en las que la agricultura es la forma básica de explotación del territorio en toda la isla de Mallorca y que en Menorca tendría especial incidencia en la mitad occidental (estudios recientes apuntan algunos posibles casos en la mitad oriental de la isla).

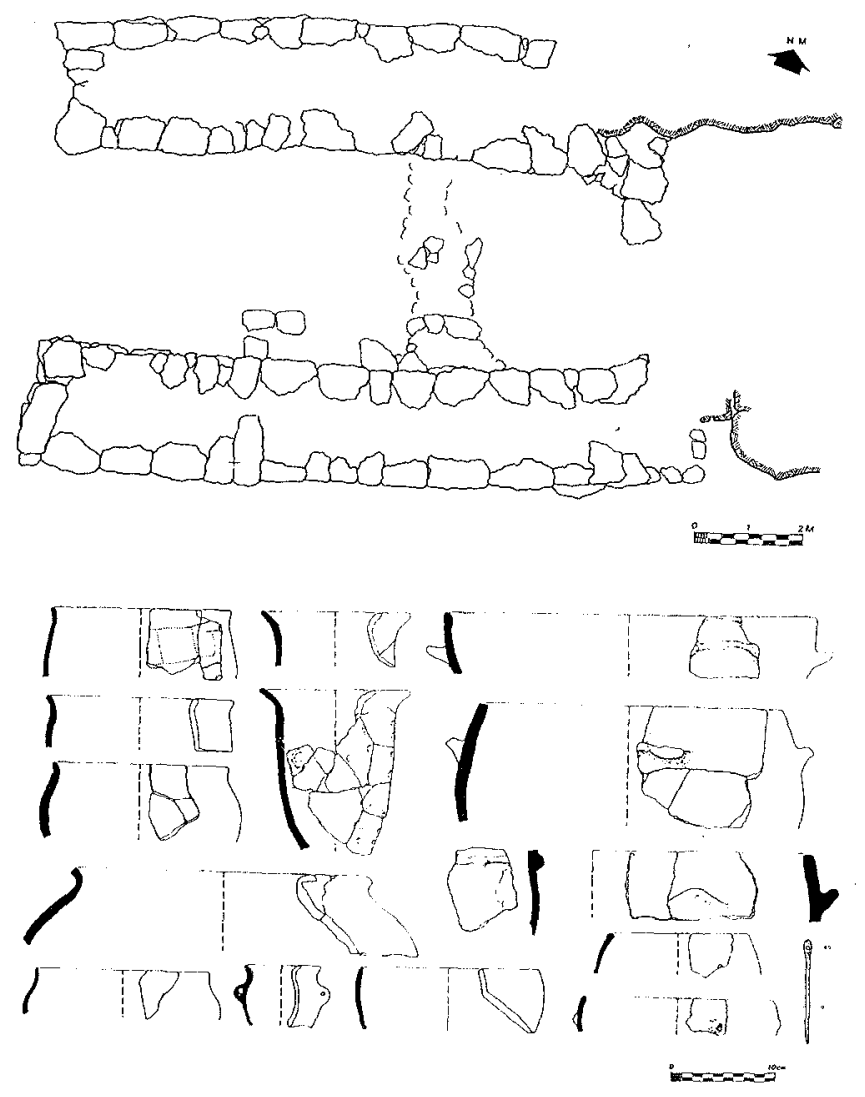

Figura 10. Naveta de Sa Cala Blanca (Ciutadella) (según G. Juan y L. Plantalamor). 

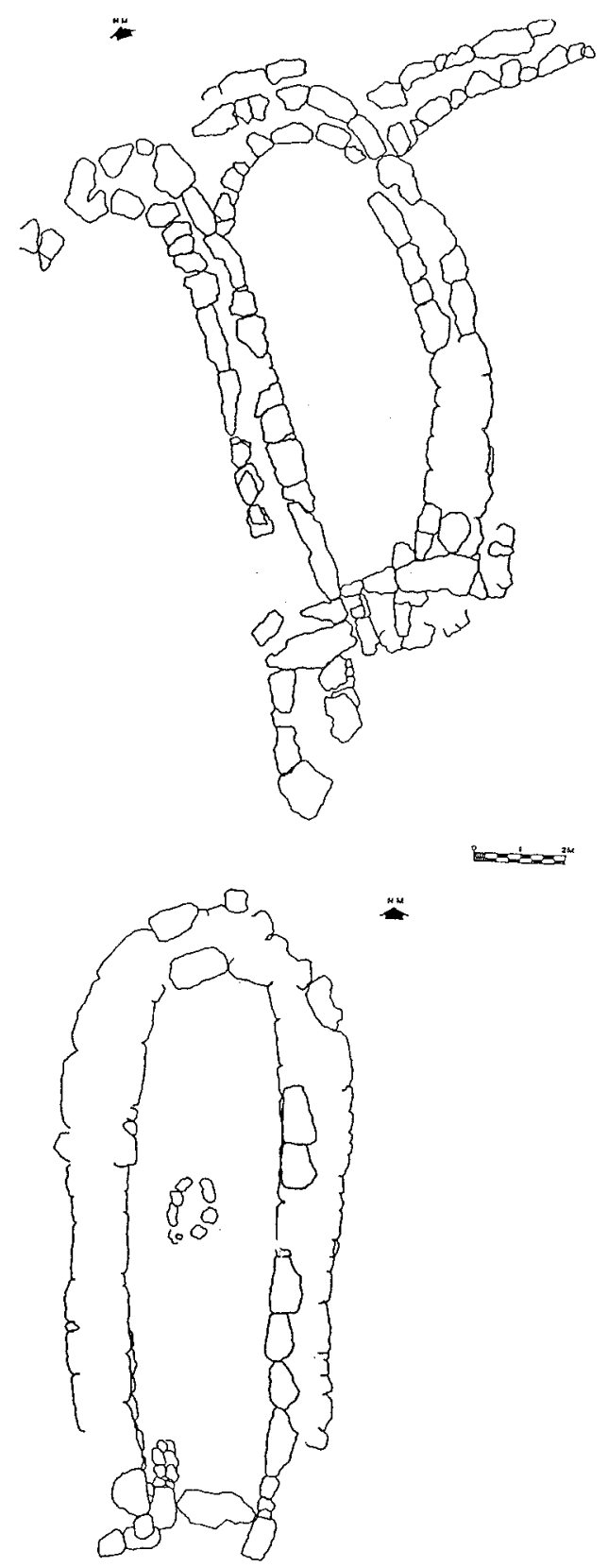

Figura 11. Navetas de Clariana (Ciutadella) (según J. Anglada y L. Plantalamor). 


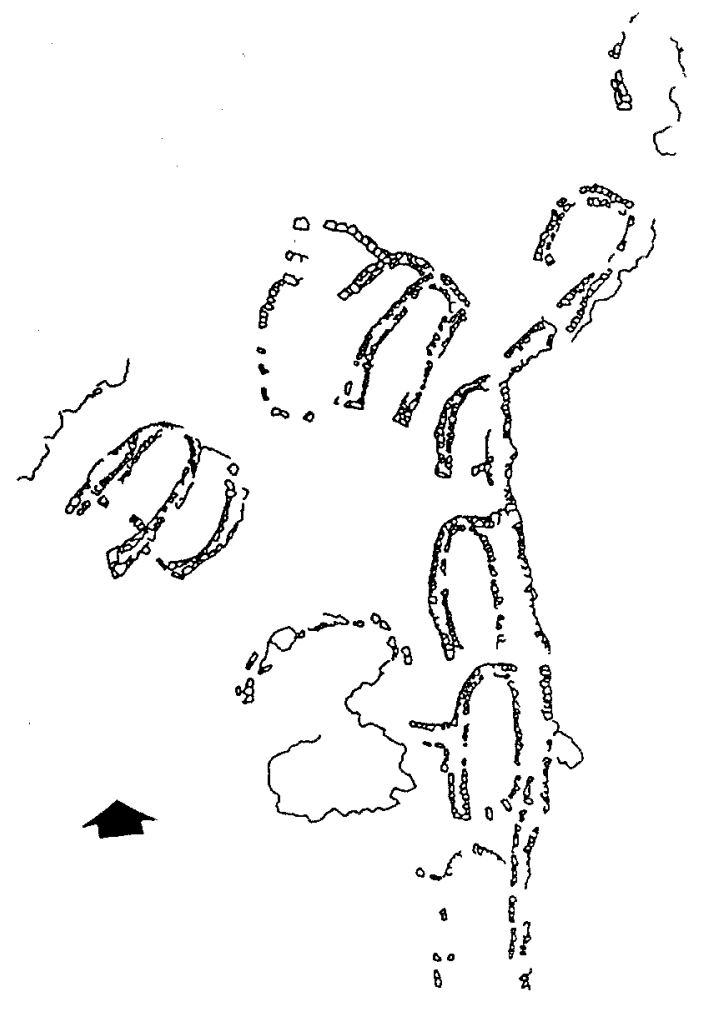

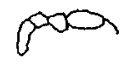
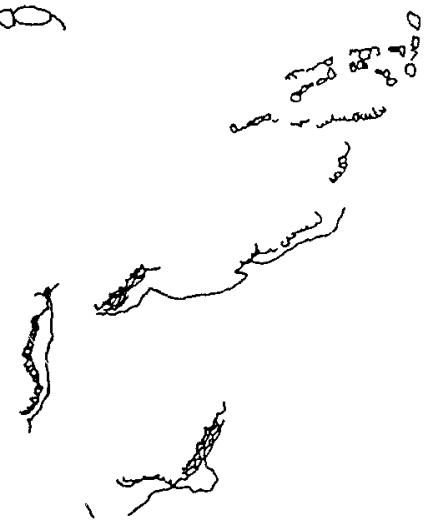

Figura 12. Asentamiento Costero de Cala Morell (Ciutadella) (según G. Juan y L. Plantalamor). 
Se encuentran también otras estructuras que presentan planta absidal de gran tamaño, pero en las que el grosor de los muros, mucho más estrechos, y el pequeño tamaño de las piedras utilizadas en su construcción permiten suponer que corresponderían a algún tipo de hábitat con cubierta de elementos vegetales, tal vez asociado a una economía básicamente ganadera [Cotaina, Alaior (Menorca) (Plantalamor, L., 1991)].

\section{LA INHUMACIÓN EN LA FASE PRETALAIÓTICA EN MALLORCA Y MENORCA}

El uso de espacios naturales como lugares funerarios en la fase pretalaiótica abarca todo el ámbito insular (Mallorca y Menorca). Este hecho es bien conocido en Mallorca, donde en diversos yacimientos se han documentado depósitos funerarios con cerámicas lisas y escasamente incisas del llamado grupo B: Son Maiol (Palma de Mallorca) (fig. 13) (Rosselló Bordoy, G., 1962, Plantalamor, L., 1974) Canova d'Ariany (Escorca) (Topp, C. y Plantalamor, L., 1992), Es Tossals Verds (Escorca), Es Corral des Porcs (Lloseta) y más recientemente Can Martorellet (Pollensa). En Menorca es evidente la existencia de casos similares, como en La Mola (Alaior), si bien estos casos no se han estudiado en profundidad.

La abundancia de terrenos cársticos, en especial calcoarenitas terciarias y cuaternarias, han facilitado la excavación de hipogeos funerarios en la práctica totalidad de la isla de Mallorca (no se conocen casos en la sierra norte) y en la zona occidental de Menorca.

En general estos hipogeos, excavados en zonas llanas o en las pendientes montañosas, presentan cámara alargada y excepcionalmente oval o circular. Los accesos (mediante corredor, rampa, o pozo) comunican con el interior directamente o a través de una antecámara, y presentan frecuentemente un trabajo refinado. Es común el uso de cámaras secundarias o adjetivas y las subdivisiones de la cámara interior, lo que permite suponer un complejo ritual de inhumaciones primarias y secundarias.

Con cierta frecuencia se observa la utilización de elementos constructivos estructurales en la cubierta de los accesos (Torre del Ram I, Son Vivó (Ciutadella) (fig. 14), Can Patos-Filicomís (Lloseta) (fig. 15) y excepcionalmente en la de la cámara (Torre del Ram II (Ciutadella).

Es frecuente, en Mallorca, la concentración de varios hipogeos en un espacio delimitado, formando autenticas necrópolis: Son Sunyer (Palma de Mallorca) (Rosselló Bordoy, G., 1962), Cala Sant Vicenç (Pollença) (fig. 


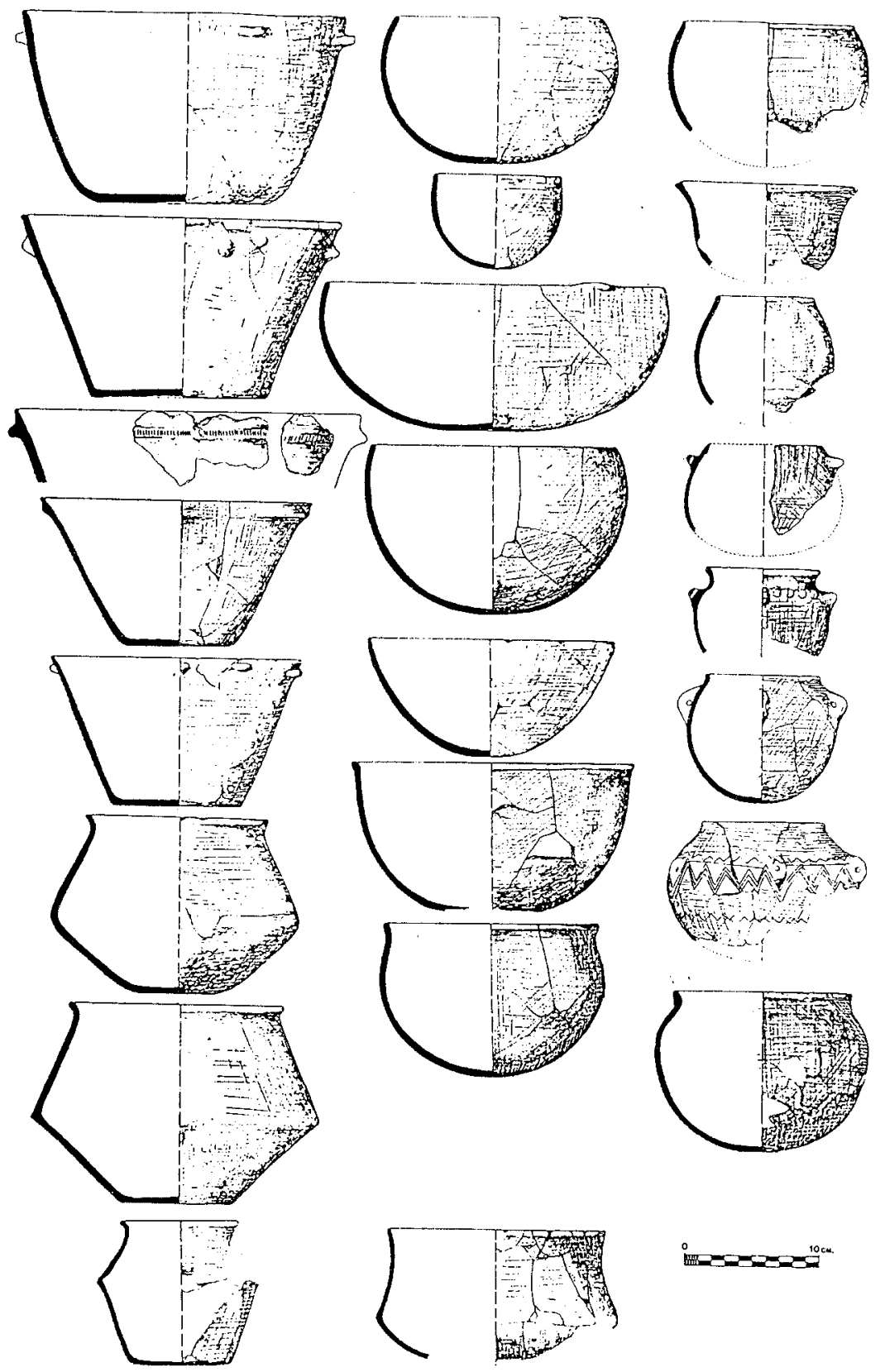

Figura 13. Materiales pretalaióticos de Son Maiol. 

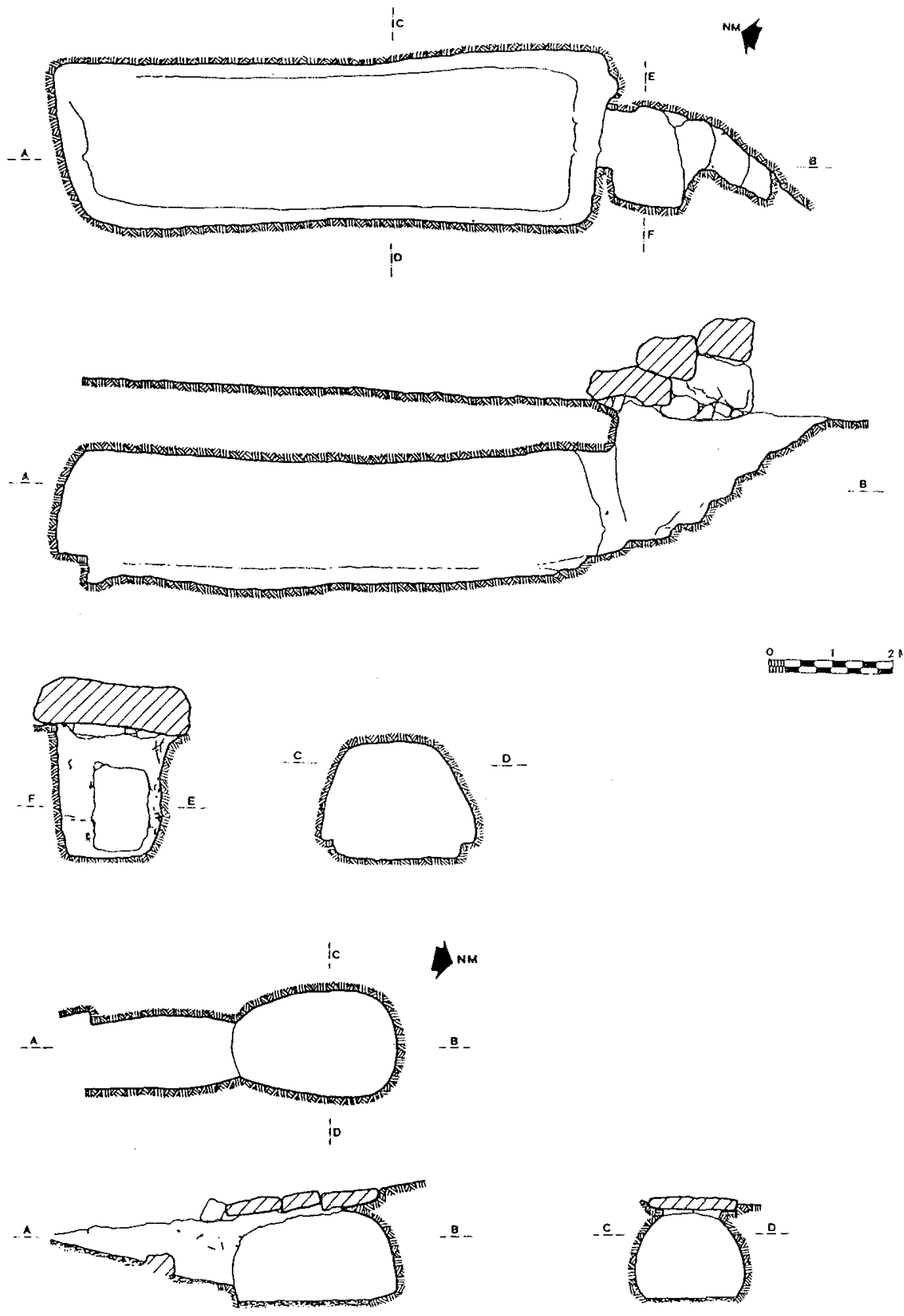

Figura 14. Hipogeos I y // de Torre del Ram (Ciutadella). 

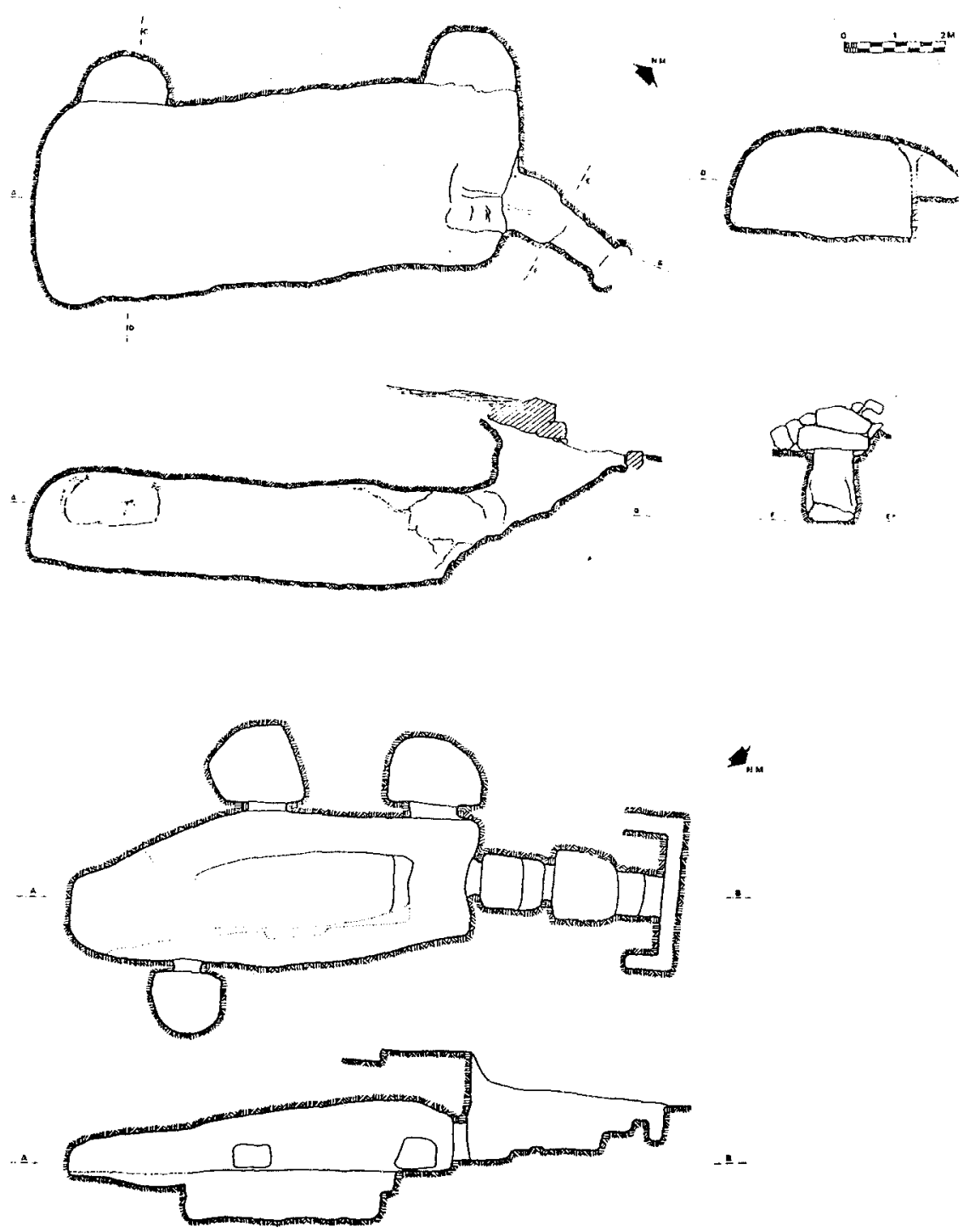

iximing

Figura 15. Can Patos-Filicomís (Lloseta) (según L. Plantalamor, A. Murillo y T. Salvà). Hipogeo 4 de Son Sunyer (Palma de Mallorca) (según G. Rosselló Bordoy). 

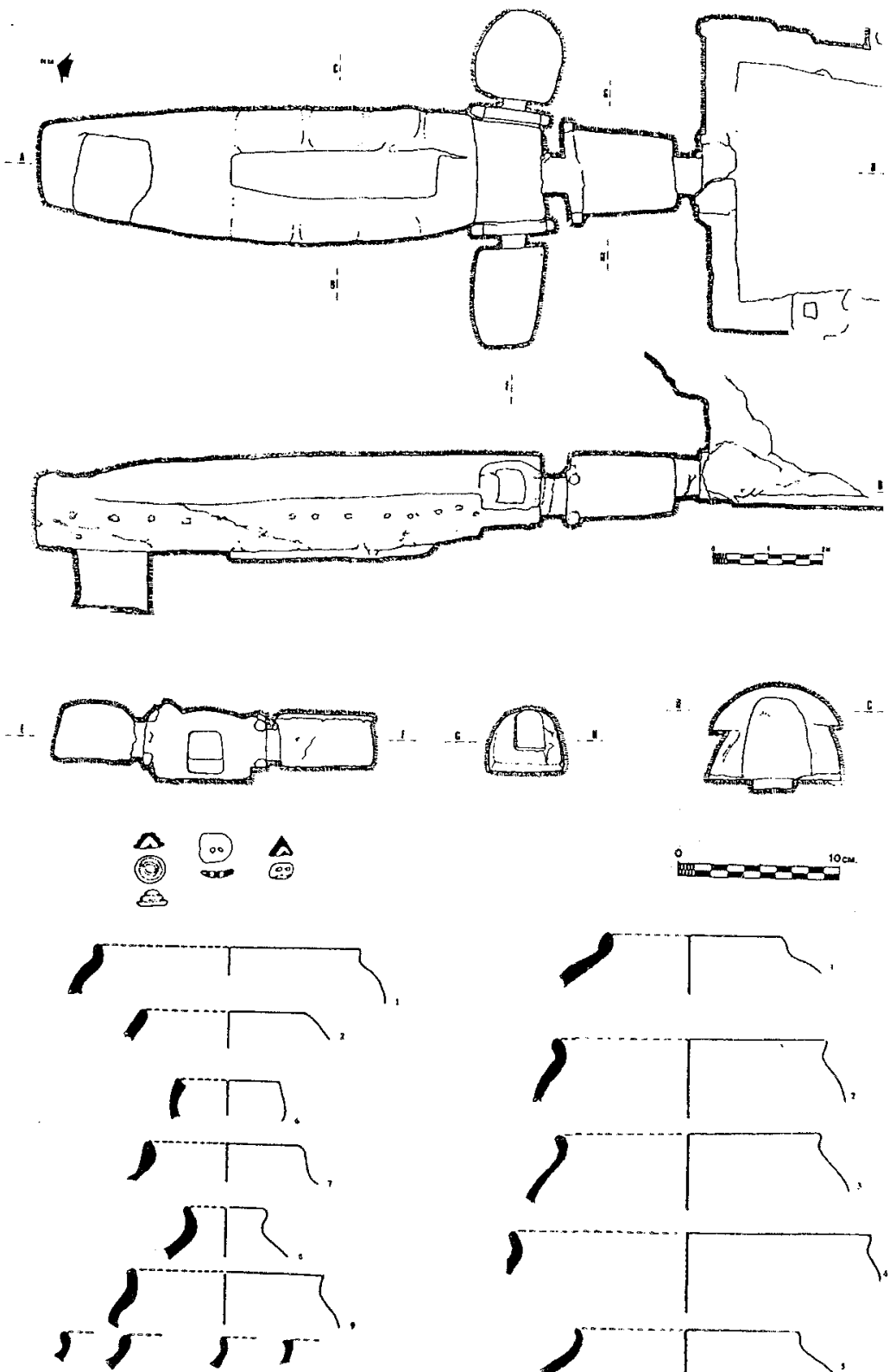

(6)

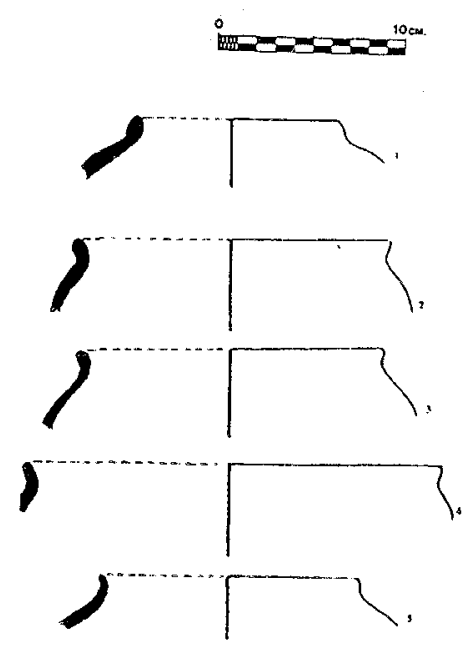

Figura 16. Hipogeo 7 de Cala Sant Vicenç (Pollença) (según G. Rosselló Bordoy, L. Plantalamor, y J. Murillo). 
16) (Rosselló Bordoy, G., Plantalamor, L., y Murillo, J., 1995), Son Toni Amer (Campos) (Veny, C., 1968).

El ajuar funerario en general está formado por pequeñas piezas cerámicas de formas diversas (esféricas, semiesféricas, globulares, carenadas y troncocónicas de base plana) y sólo excepcionalmente alguna pieza presenta decoración incisa simple (Veny, C., 1968). En su conjunto, este ajuar pre-
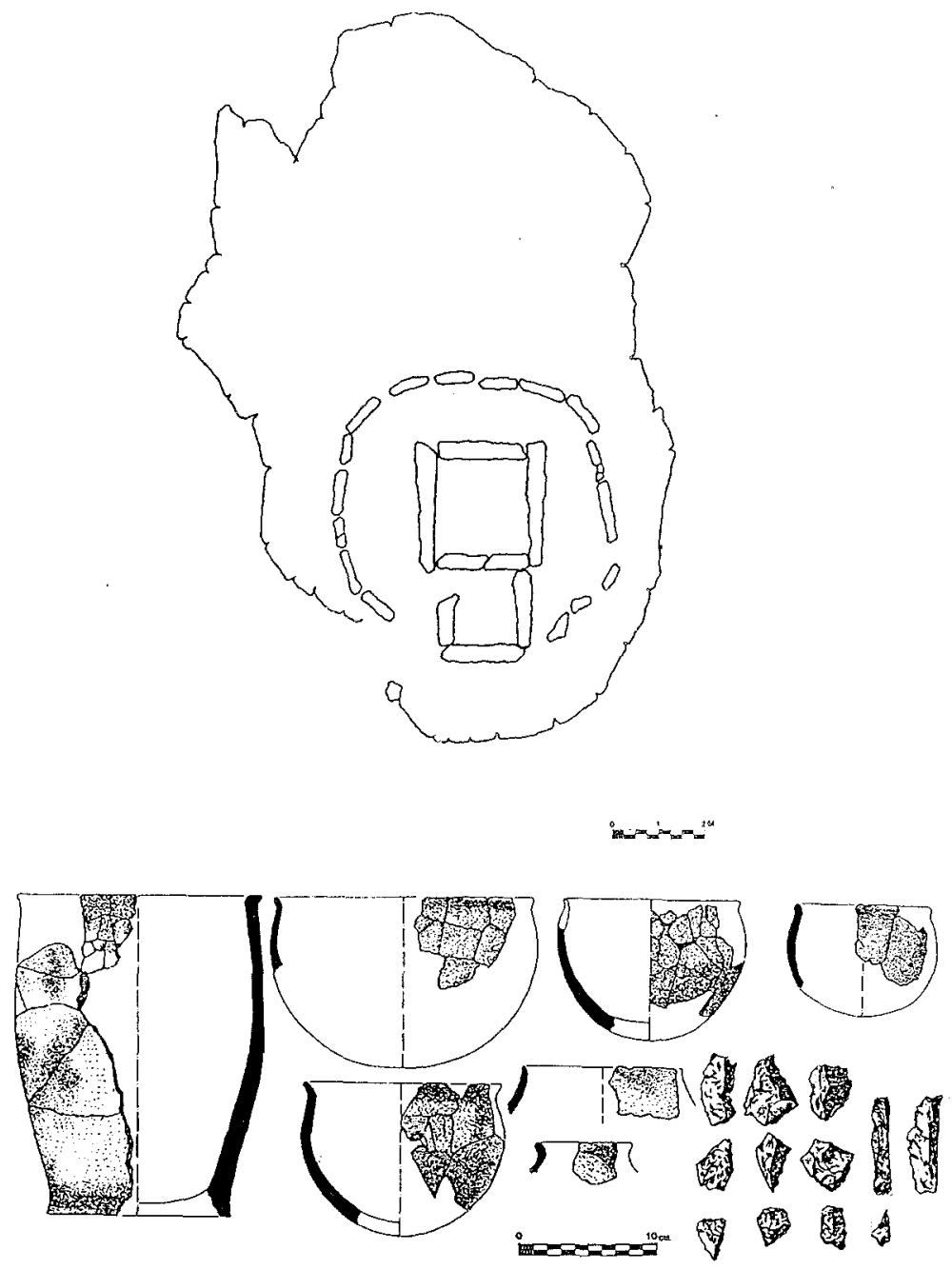

Figura 17. Sepulcro megalítico de Son Bauló de Dalt (Muro) (según G. Rosselló Bordoy). 

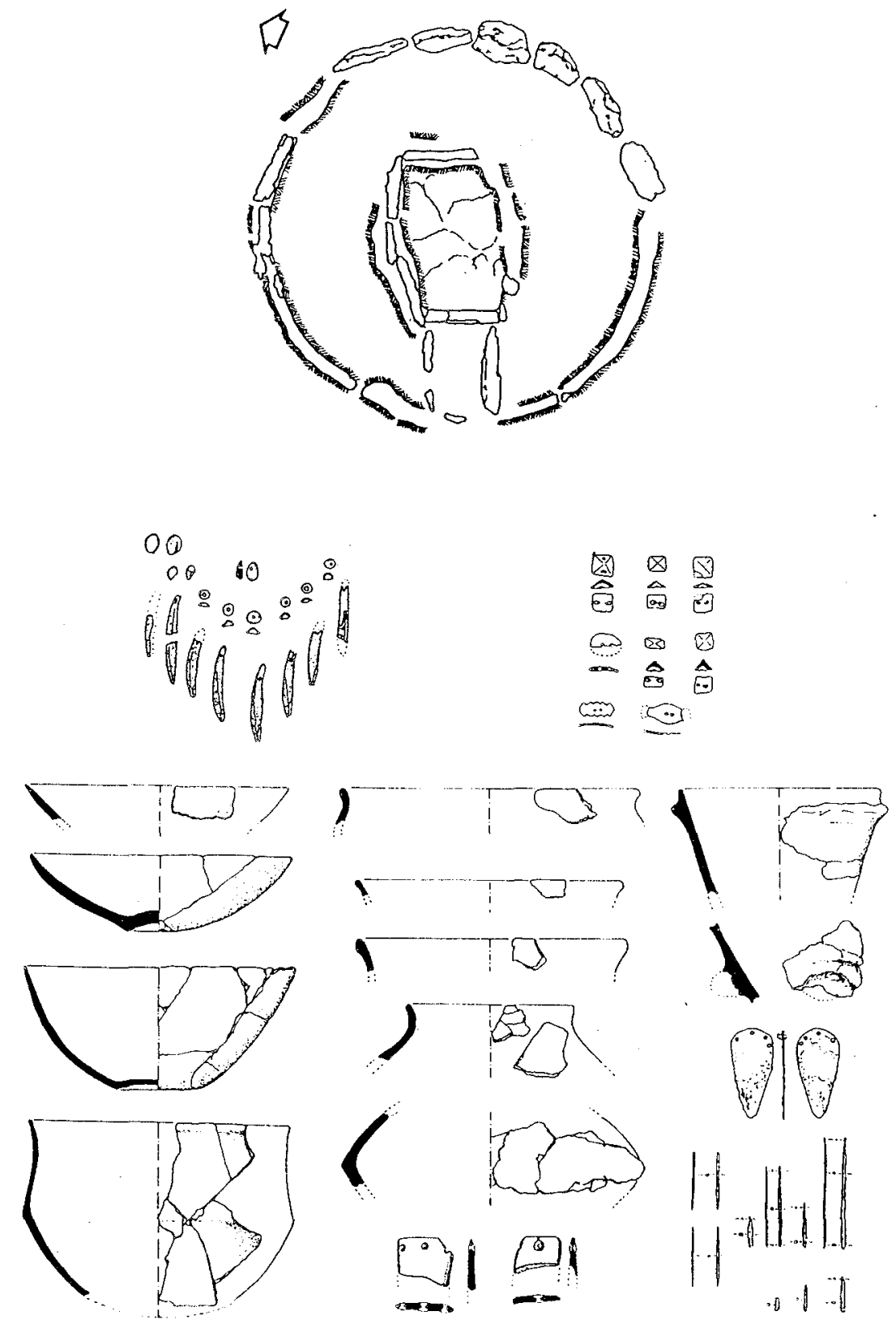

Figura 18. Sepulcro megalítico de S'Aigua Dolça (Artà) (según M. Calvo, J. Coll y V. M. Guerrero). 
senta un claro paralelo con las pocas cerámicas pretalaióticas halladas en las navetas de habitación. En Menorca, el único fragmento con forma que se ha podido identificar, procedente de Son Mercer de Dalt (Ferreries) presenta boca abierta y cuerpo esférico, forma también frecuente en las navetas de habitación menorquinas (Plantalamor, L. y Rita Larrucea, M.C., 1982).
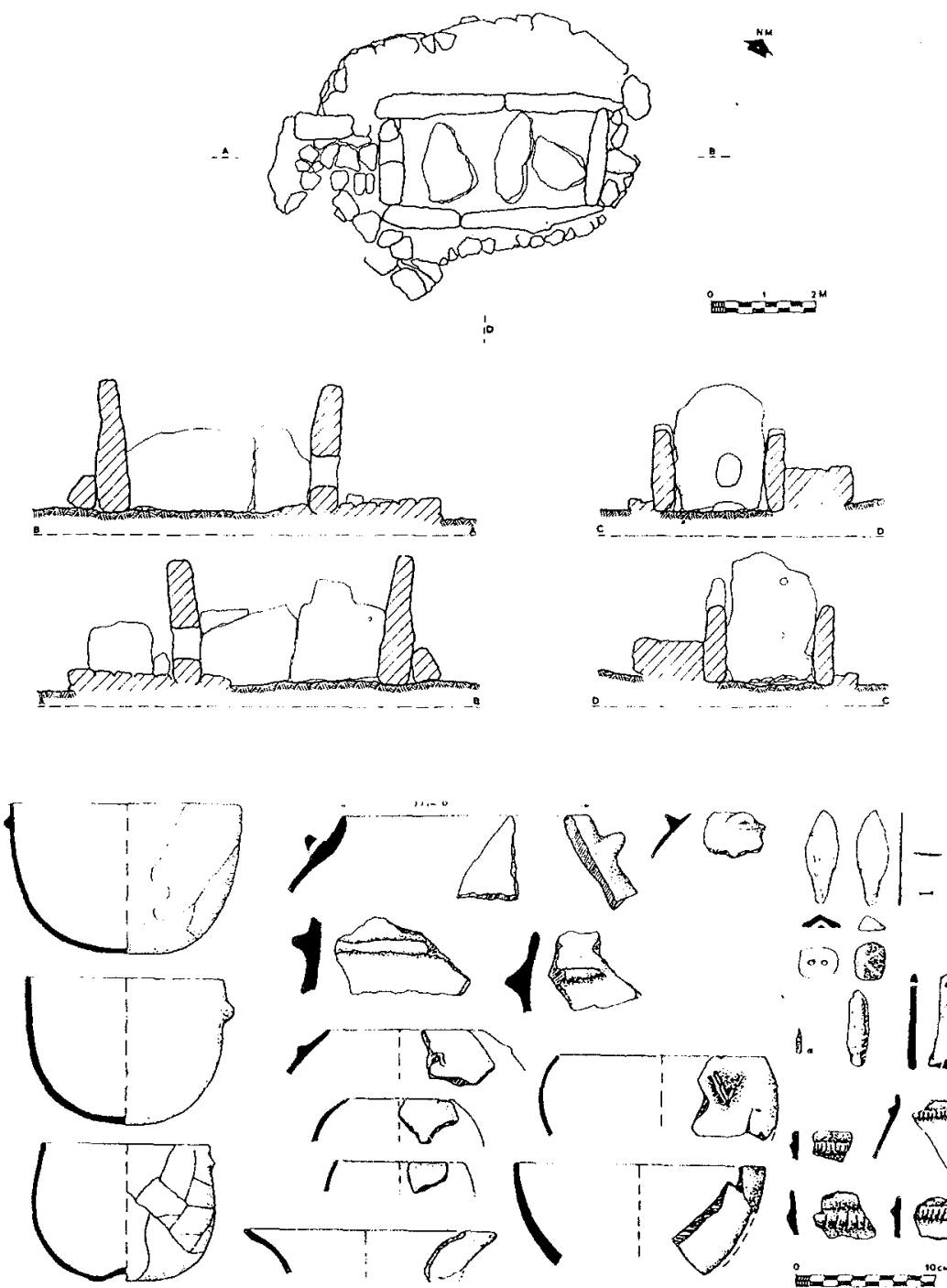

(c)
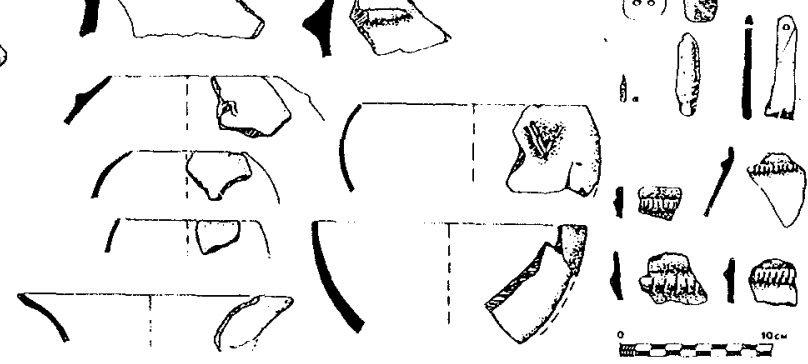

Figura 19. Sepulcro megalítico de Ses Roques Llises - Torre den Gaumés (Alaior) (según G. Rosselló Bordoy, L. Plantalamor, y A. López). 
Más escasos son los sepulcros megalíticos, que según se deduce de los ajuares hallados son coetáneos a los hipogeos funerarios del grupo anterior.

En Mallorca conocemos dos ejemplares en la zona oriental, en la Bahía de Alcudia: Son Bauló de Dalt (Santa Margarita) (fig. 17) (Rosselló Bordoy, G., 1966) y S'Aigua Dolça (Artà) (fig. 18) (Calvo Trías, M., Coll Conesa, J. y Guerrero Ayuso, V.1997). Ambos presentan antecámara y camara rectangulares, separadas por una losa perforada y el conjunto se halla contenido en un circulo de piedras colocadas en posición vertical. De sus ajuares puede deducirse que el primero corresponde a una fase calcolítica y el segundo al inicio de la edad del bronce, al menos en el momento de uso final.

En Menorca, al sudeste de la isla, se encuentra un grupo compacto de estos megalitos, con características similares a los encontrados en Mallorca (Plantalamor, L., 1976-77). Se trata de Ses Roques Llises de Torre den Gaumés (Alaior) (fig. 19) (Rosselló Bordoy, G., Plantalamor, L. y López Pons, A., 1980), Binidalinet (Maó) (Plantalamor, L., 1975) Montplé (Maó) y Alcaiduset (Alaior) (Flaquer, J., 1953). Estas estructuras posiblemente evolucionarán más tarde hacia estructuras ya ciclópeas (navetas de tipo intermedio) y posteriormente a las navetas de inhumación de estructura absidal alargada.

Al norte de Menorca se encuentran otros dos sepulcros que presentan rasgos similares, pero la documentación sobre ellos es escasa y su expoliación no permite una estudio definitivo. Por los datos conocidos podemos suponer que su uso fue posterior al del grupo anterior (Gornés-Hachero, J.S., Gual Cerdo, J, López Pons, A. y Nicolás Mascaro, J.C. de, 1992).

Un ejemplo de naveta de tipo intermedio se encuentra en la naveta Occidental de Biniac L'Argentina (Alaior) (fig. 20) (Plantalamor, L. y López Pons, A., 1983), cuya excavación permitió situar el yacimiento en la fase pretalaiótica. Posteriores análisis por el método de la termoluminiscencia han documentado el uso de este rnonumento en la segunda mitad del III milenio A.C. y el primer cuarto del II A.C. (García Orellana, J., I AL., 1996). Se trata de una construcción que mantiene la estructura del sepulcro megalítico pero presenta paramentos de tipo ciclópeo. En el termino municipal de Alaior y en la misma zona geográfica que ocupan los sepulcros megalíticos del primer grupo, se encuentran otros monumentos con características comunes: Biniac L'Argentina Oriental, Torralbet, Cotaina, Llumena den Montañés o Torrellisá, aunque ninguno de ellos ha sido excavado.

Es muy probable que monumentos como el de Sa Torreta de Tramontana (Maó) (fig. 21) [excavado por M. Murray (Murray, M.1934)] 

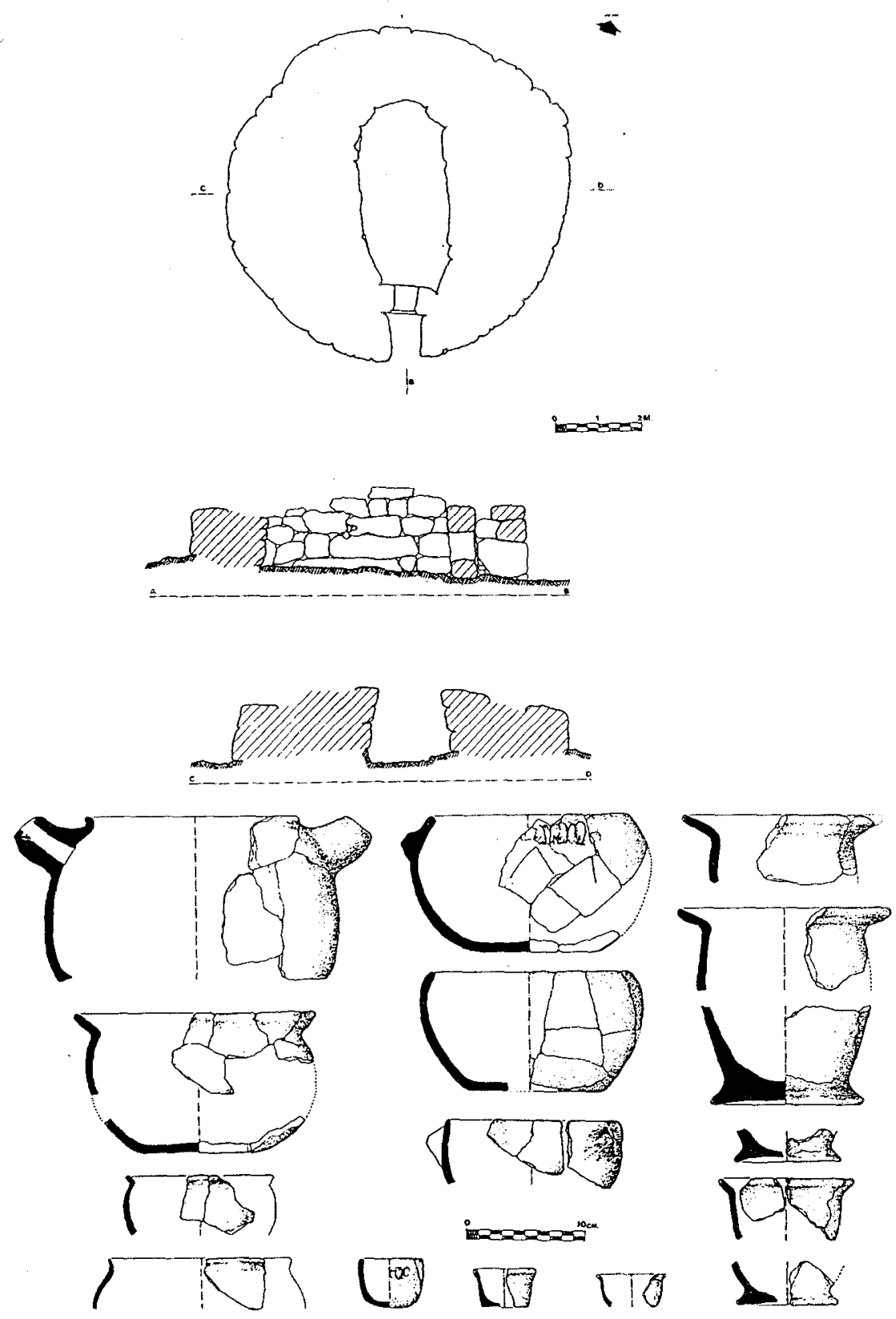

Figura 20. Naveta Occidental de Biniac - L'Argentina (Alaior) (según L. Plantalamor y A. López). 

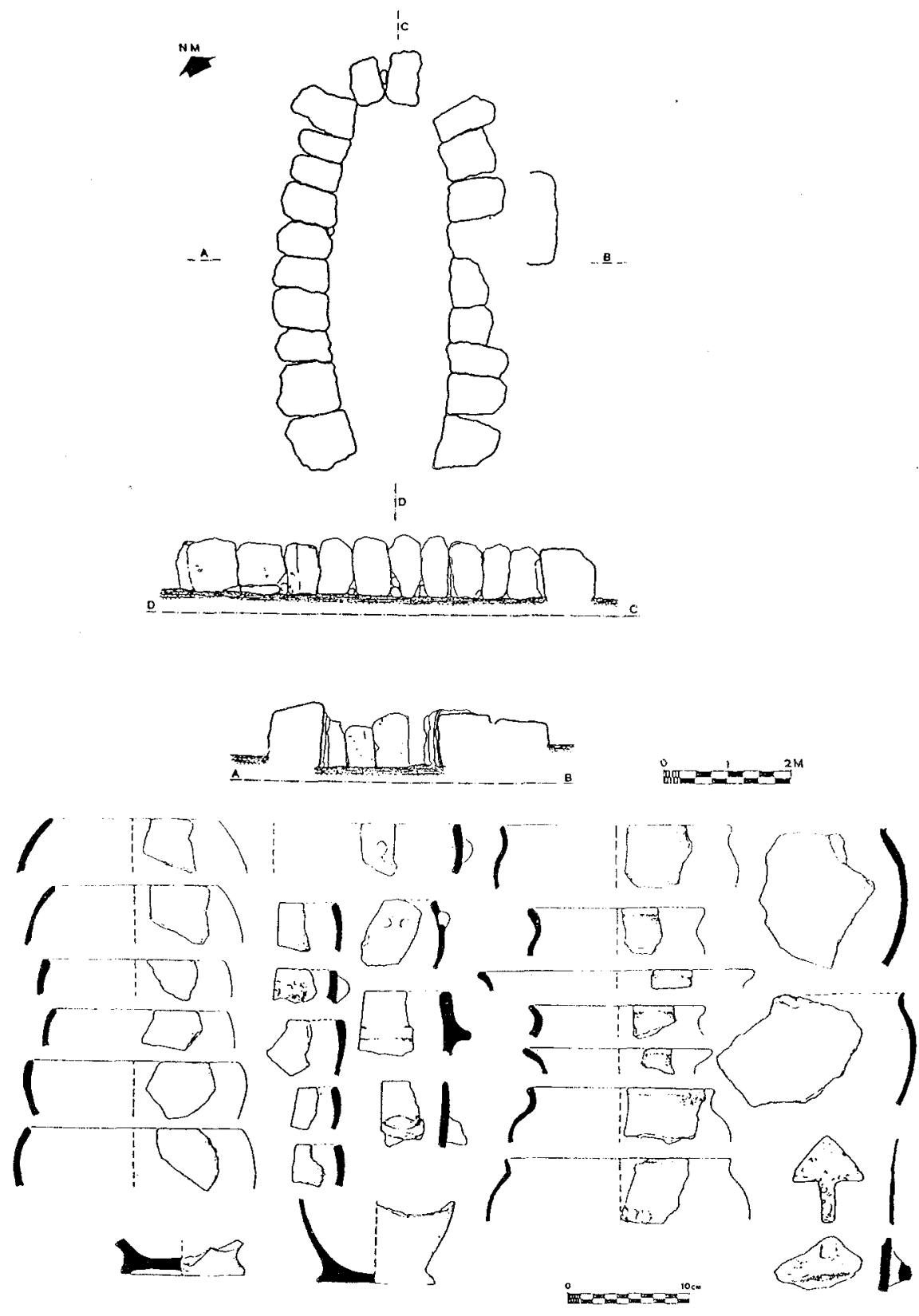

Figura 21. Naveta de Sa Torreta de Tramuntana (Maó). 

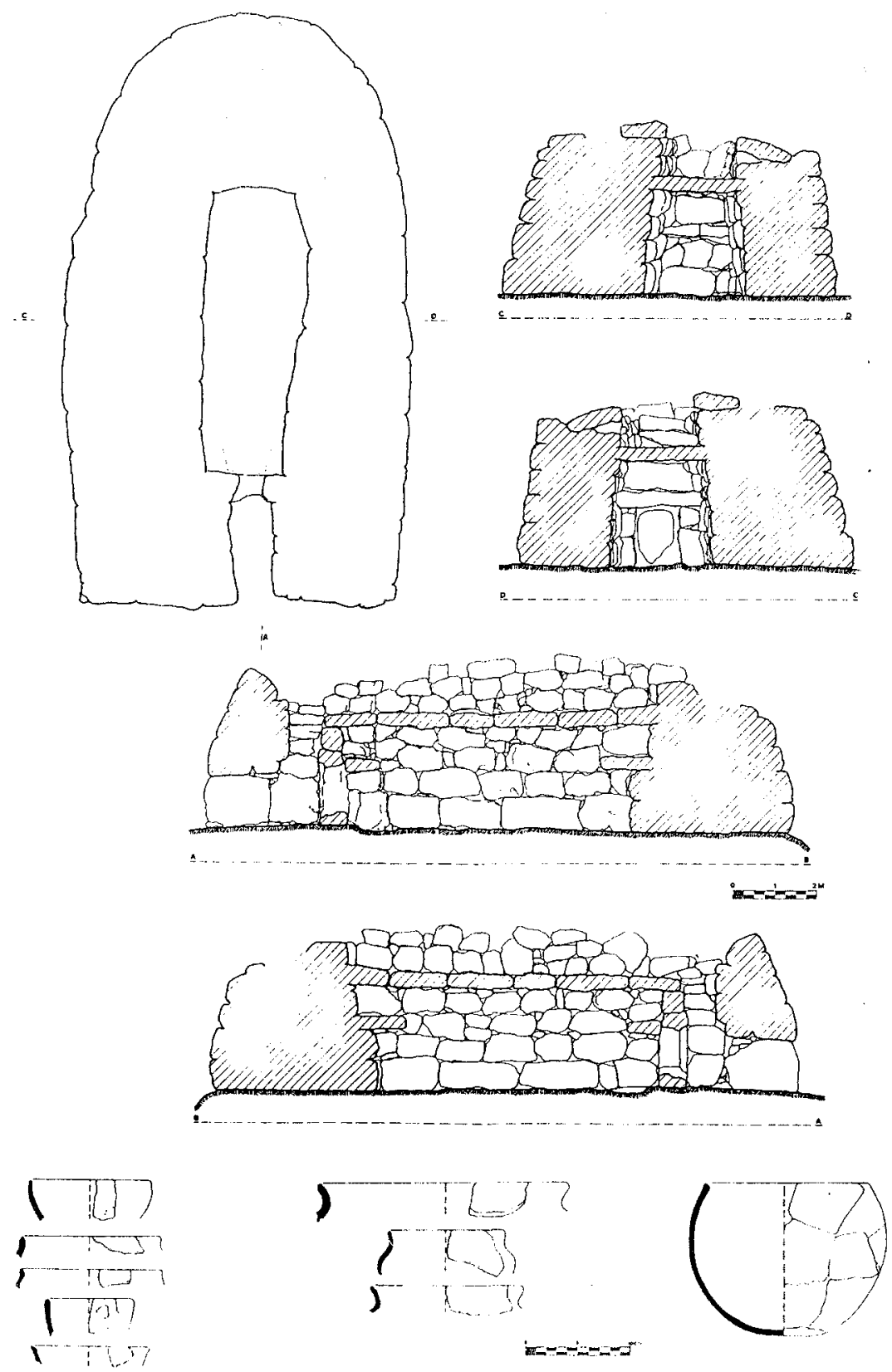

Figura 22. Naveta Meridional de Rafal Rubí (Alaior) (segün G. Rosselló Bordoy y L. Plantalamor). 
Prehistoria de las islas Baleares
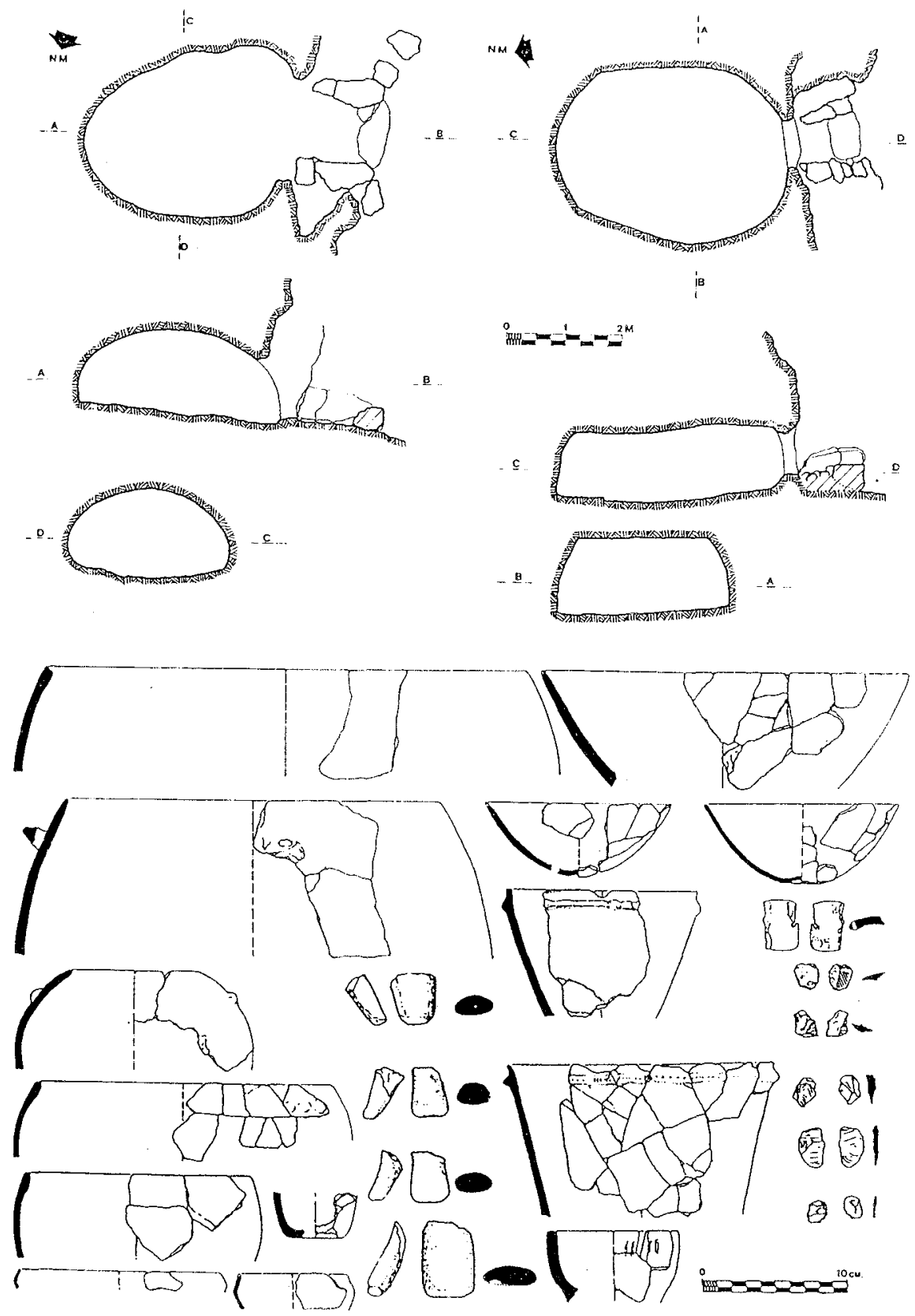

Figura 23. Cuevas 11 y 12 de Cala Morell (según G. Juan y L. Plantalamor).

353 
sean el prototipo de lo que se conoce como «naveta de planta alargada», aunque aún no ha adoptado la estructura interna del sepulcro megalítico y de la naveta de tipo intermedio. El reestudio de los materiales confirma que se trata de un monumento arcaico (Topp, C. y Plantalamor, L. En prensa).

Las navetas de inhumación de planta alargada, más evolucionadas, debían haber alcanzado, ya en la fase pretalaiótica, cierta complejidad estructural, como se demuestra del estudio de los materiales, claramente pretalaióticos, de los yacimientos de Rafal Rubí Meridional (Alaior) (fig. 22) (Rosselló Bordoy, G., 1971) o Binimaimut (Maó) (Veny, C., 1987). En algunos casos, cómo Es Lloc Nou des Fasser (Alaior) (Plantalamor, L., 1991), por encima de la naveta se ha construido un talaiot, reutilizando parcialmente la estructura y las piedras de la primera edificación.

Estas construcciones corresponden al momento final de la cultura pretalaiótica, y posiblemente a este mismo momento corresponde la construcción de la primera naveta de planta alargada en Menorca Occidental, La Cova (Ciutadella) (Veny, C., 1982) dónde se ha localizado algunos fragmentos cerámicos de esta época.

Otros monumentos de uso funerario presentan una cámara, más o menos globular, y estructura de fachada y corredor construidas bien con técnicas megalíticas [Biniai Nou 1 y 2 (Maó), y Sant Tomas (Migjorn) (Plantalamor, L., 1993)] bien con técnicas de muretes de piedras de tamaño reducido [cuevas 11 y 12 de Cala Morell (Ciutadella) (fig. 23) (Juan Benejam, G. y Plantalamor, L., 1996)]. El estudio de los materiales permite situar el origen de estos monumentos en un momento impreciso del III Milenio, en un estadio cultural calcolítico.

\section{EL INICIO DE LA CULTURA TALAIÓTICA EN MALLORCA Y MENORCA}

Hacia la mitad del segundo milenio A.C., se aprecia un gran cambio en todos los elementos que definen un grupo cultural. A grandes rasgos es posible afirmar que frente a una población dispersa, que no explota de forma intensiva el territorio, de forma paulatina se observa una concentración de esta población, con funciones sociales diferenciadas y una ocupación total del territorio.

Se ha querido explicar el paso de la cultura pretalaiótica a la talaiótica como el producto de una evolución interna, pero los cambios observados son radicales y abarcan la practica totalidad de los elementos culturales que hoy conocemos, por lo que una evolución interna no parece una explicación suficiente. 
No existe una uniformidad de elementos en el ámbito de la cultura talaiótica, más bien hemos observado diferencias notables entre Mallorca y Menorca, e incluso entre zonas de la misma isla. No es comparable un talaiot menorquín a uno mallorquín, en Mallorca no hay taulas, y la casa de planta de estructura rectangular, abundante en Mallorca, representa un concepto de hábitat radicalmente opuesto a las plantas circulares abundantes en Menorca.

Es por esta razón que intentaremos en primer lugar analizar los diversos elementos culturales y observar su incidencia en las diversas áreas y, dada la limitación temporal del presente estudio, abarcando las fases culturales del bronce medio y final. Este período, ya definido como talaiótico la, lb y II, es el de formación, cohesión y consolidación de la cultura talaiótica, anterior a la progresiva incidencia de la presencia colonial y de la edad del hierro en el Mediterráneo Occidental (talaiótico III y IV).

\section{LA ARQUITECTURA TALAIÓTICA}

La ocupación del territorio, así cómo la forma en que se explota o se controla, son elementos que definen y determinan un grupo humano. Aún hoy es patente la trasformación paisajística que produjo la cultura talaiótica, y los asentamientos talaióticos han sido referencia topográfica hasta la actualidad.

La compleja organización social de este grupo cultural queda reflejada en su arquitectura, con edificios con funcionalidad diferenciada y ligados entre sí por una trama urbana y de núcleos subsidiarios.

\section{El talaiot}

La palabra talaiot, o la más usada a nivel popular talaia, define en términos científicos un tipo de torre construida con técnicas ciclópeas propia de las Islas Baleares y que presenta característica comunes con los nuraghes de Cerdeña y las torri Corsas.

Hoy esta fuera de duda que nos hallamos frente a una estructura dominante bien por su carácter militar real o disuasorio. Ello no elimina funciones secundarias variadas a lo largo de su largo uso: hábitats, almacenes, lugares de reunión, centros de prestigio... que pueden haber cambiado a lo largo de su dilatado uso.

Pueden presentarse de forma aislada, sobre el territorio que controlan o integrados en un núcleo de población, al que dominan y protegen a la vez. 

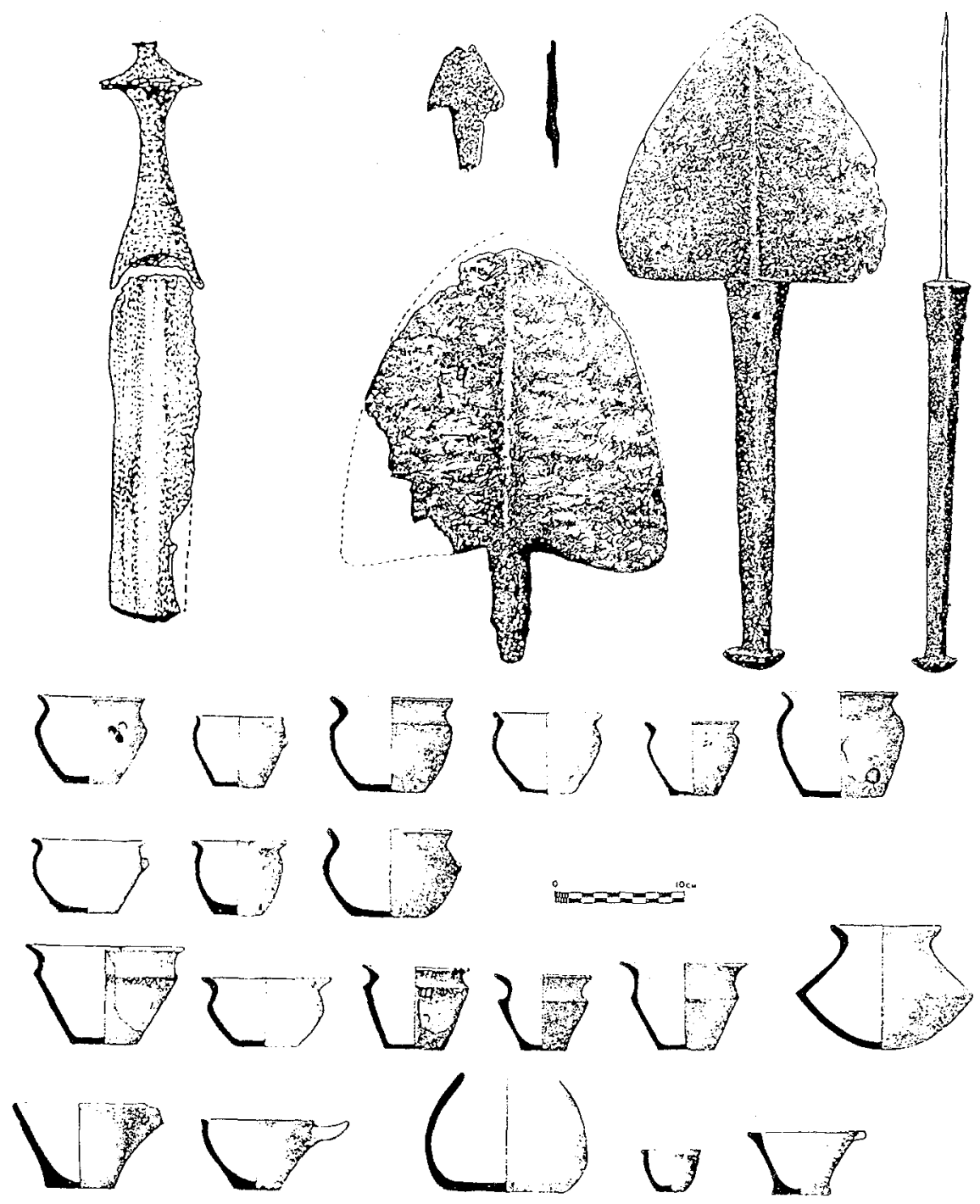

Figura 24. Materiales talaióticos de jas inhumaciones de Son Matge (Valldemossa) (según G. Rosselló Bordoy y W. H. Waldren).

A simple vista podemos observar diferencias formales entre los talaiots, tanto en su estructura interna como en su aspecto exterior, con independencia de su tamaño. El análisis de estas estructuras, a falta de excava- 

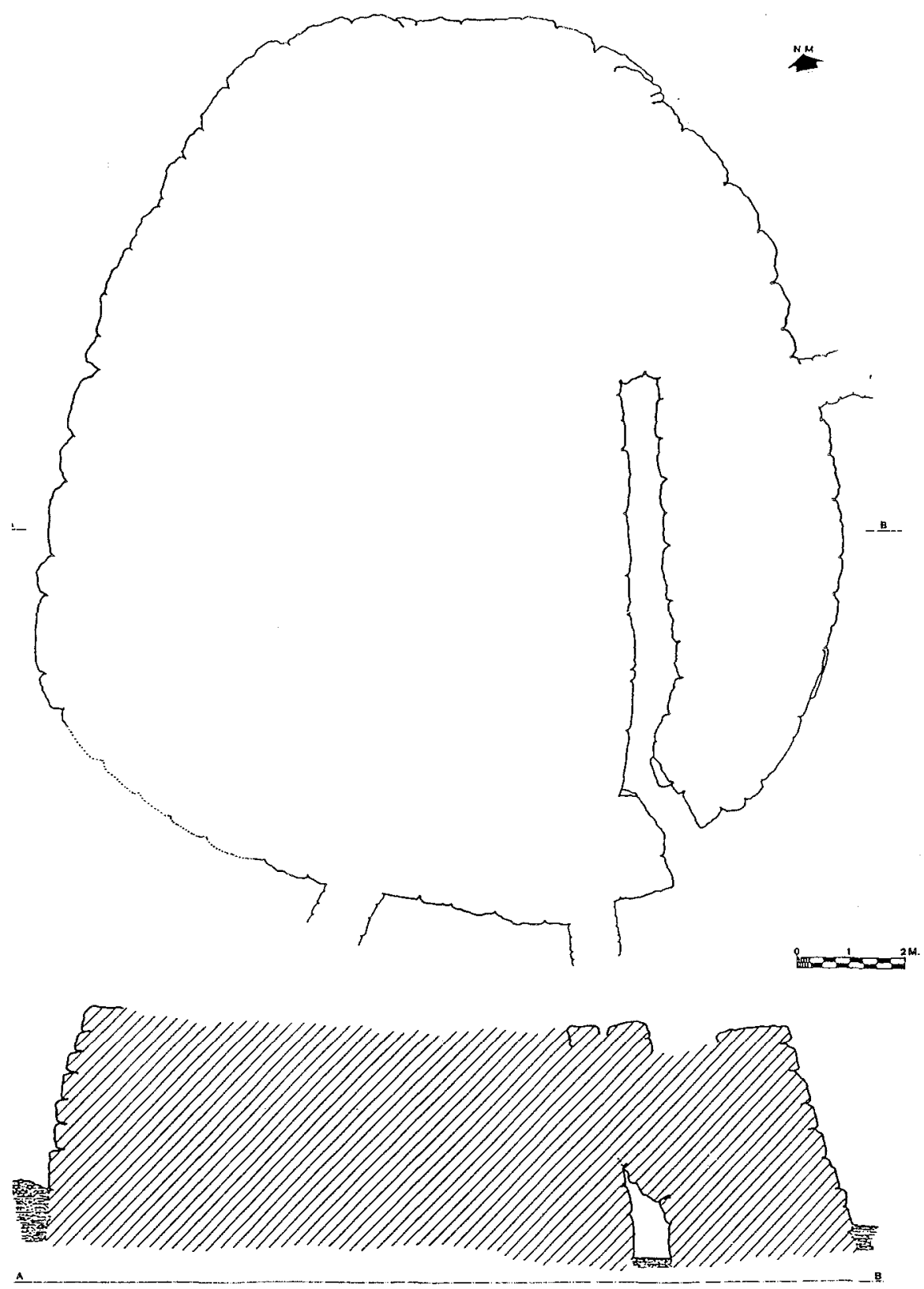

Figura 25. Talaiot superpuesto a una naveta de inhumación en Son Vitamina (Alaior). 
ciones, puede ayudarnos a formular una hipótesis sobre su cronología, mediante el análisis comparado y las estratigrafías murarias.

En Menorca, en general, tienen planta externa circular, aunque algunos (como el de Clariana, Ciutadella), presenten planta rectangular.

Distinguimos dos grandes grupos: los talaiots estructurados a partir de un eje de simetría longitudinal horizontal y los estructurados a partir de un eje de simetría vertical. Dentro del primer grupo observamos formas diversas, lo que puede ser indicio de una evolución hacia el segundo grupo.

El primero de estos grupos posiblemente se desarrolla hacia la mitad del II milenio, y seguramente se iniciaría en la zona oriental de la isla, donde se localizan los únicos ejemplos de estructuras a modo de plataforma, corredor y galería.

El talaiot de Trebalúger (Es Castell) (Gual Cerdo, J.M., López Pons, A. y Plantalamor Massanet, L., 1991) y el de Es Lloc Nou des Fasser (Alaior) (Plantalamor Massanet, L., 1991) corresponden a este primer grupo, y ambos pueden ser situados entre los más antiguos de la isla de Menorca. En los dos casos se aprovecharon estructuras anteriores (en el primer caso un hábitat pretalaiótico, y en el segundo una naveta de inhumación). Son similares a las estructuras de la Isla de Cerdeña, conocidas con el nombre de Protonuraghes a cielo abjerto y Protonuraghes de corredor (Manca Demurtas, L. y Demurtas, S., 1991) respectivamente. Otros talaiots, cómo Binicalsitx, Ses Fonts Redones de Baix y Bínicudrell [en el termino de Migjorn (Plantalamor, 1991)] presentan también una estructura similar a la de los protonuraghes de corredor.

Un segundo tipo estaría representado por los talaiots de galería, que permiten un espacio útil en planta baja, aunque reducido. Dentro de este grupo incluimos talaiots como el de Curnia Oriental y Sa Cudia Cremada (Maó) (fig. 26).

Talaiots como Sant Agustí Vell Oriental (Migjorn) (fig. 28) (Plantalamor, 1996) (con la cubierta sostenida mediante pilares y columnas polilíticas) y Torrevella den Lozano Nord Ciutadella) estructuran ya un espacio útil en planta baja, utilizando en ambos casos soluciones arquitectónicas ya utilizadas en las navetas de habitación.

Rafal Roig (Mercadal) (fig. 27) (Manca Demurtas, L. y Demurtas, S., 1986) alcanza cierta complejidad estructural, a partir de más de un eje de simetría horizontal, y servirá de enlace con talaiots estructurados entorno a un macizo central, como el de Torelló Occidental (Maó) y Montefi Meridional (Ciutadella) (fig. 33). 

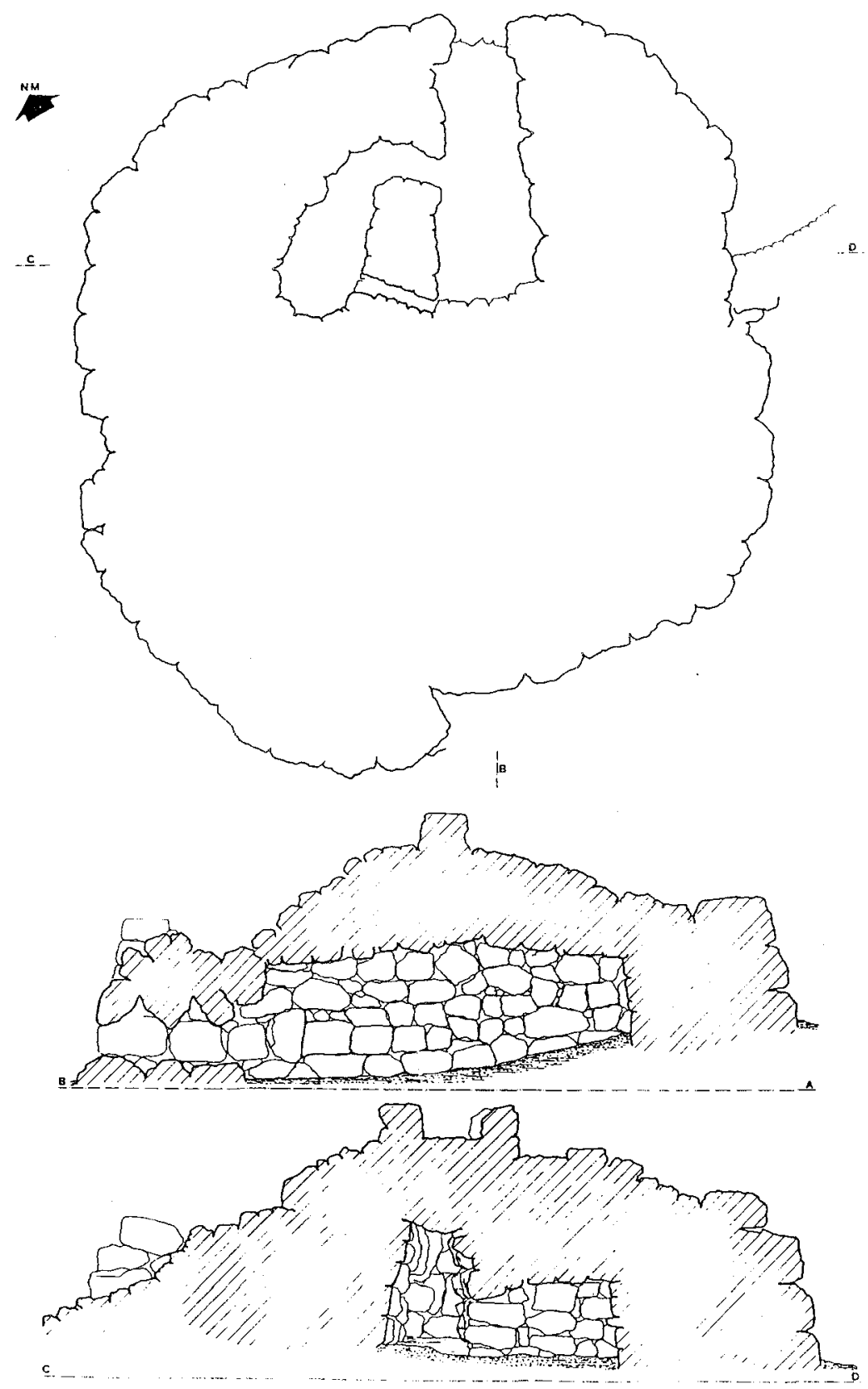

Figura 26. Talaiot oriental de Curnia (Maó). 

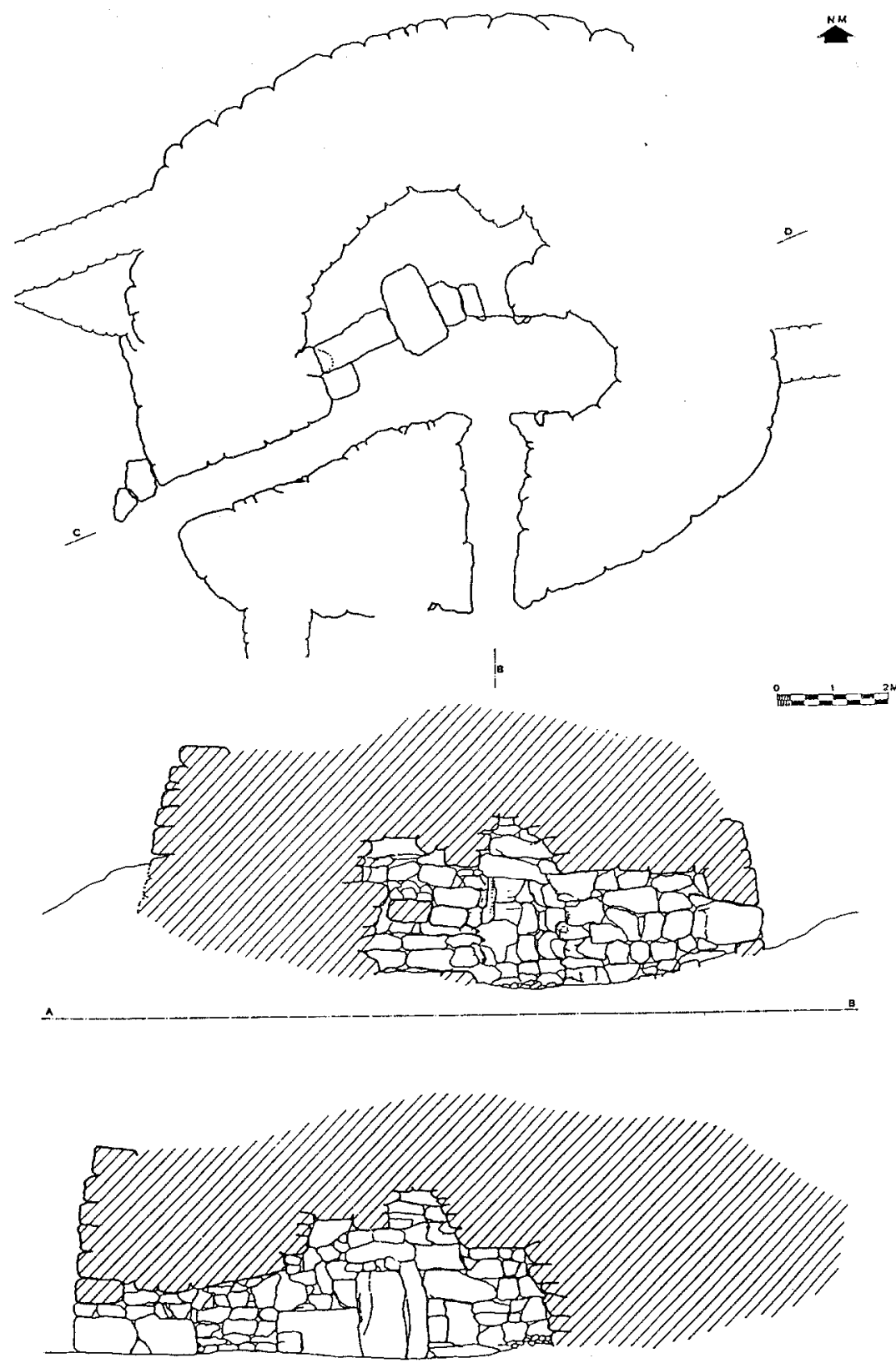

Figura 27. Talaiot de Rafal Roig (Mercadal). 


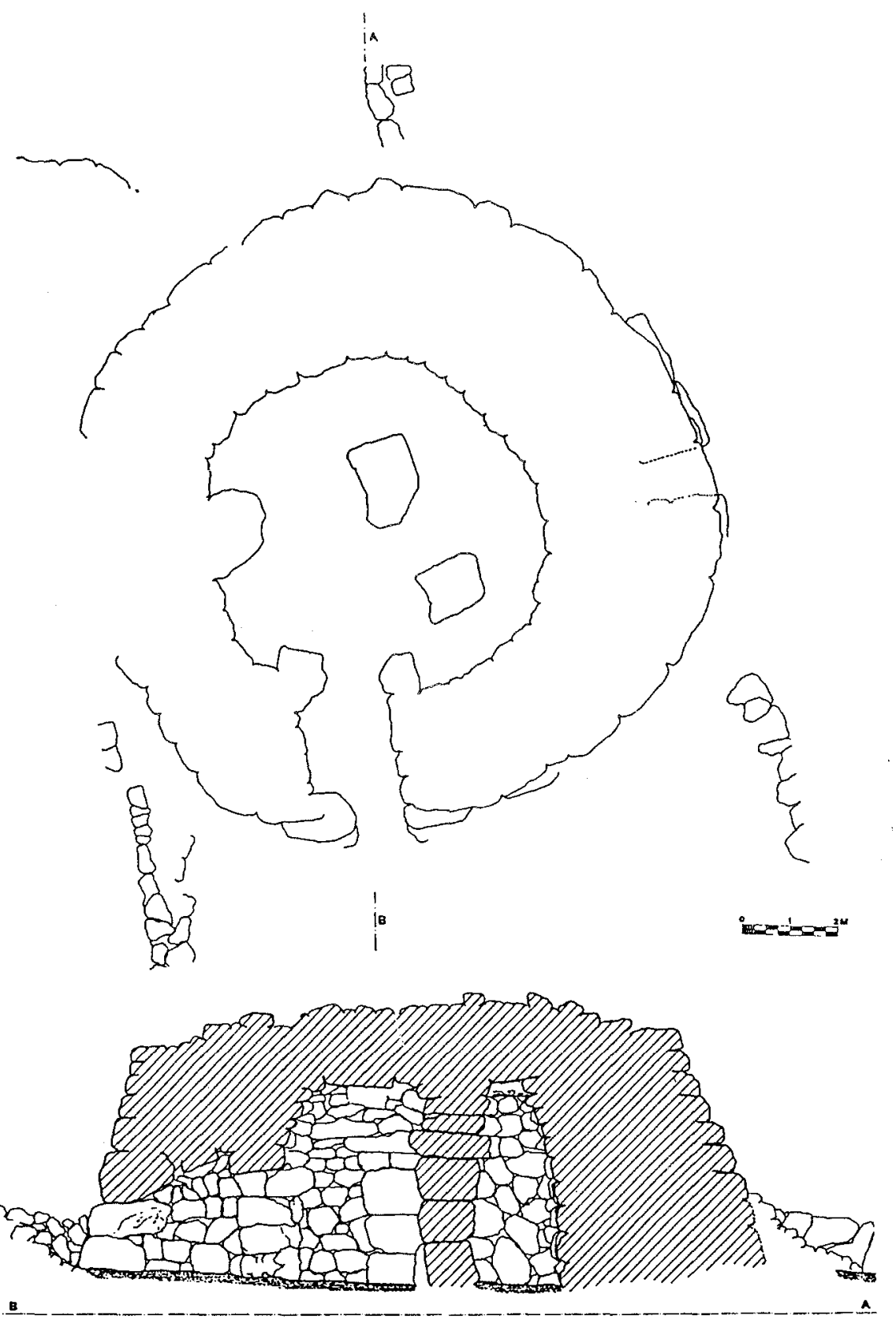

Figura 28. Talaiot oriental de Sant Agustí Vell (Migjorn). 
El segundo gran grupo de talaiots, que creemos posterior al anterior y propio del talaiótico lb y II, presentaría un eje central de simetría vertical. En este grupo incluimos los talaiots en los que el relleno interior de los paramentos está dispuesto en forma anular (lo que podría responder a una estructura de cúpula central) y los que presentan en el centro una columna polilítica.

En Mallorca son poco conocidos los talaiots que presentan características parecidas a los del primer grupo, aunque entre ellos pueden incluirse talaiots como el de Son Fred (Sancelles) o el monumento central de Ses Païsses (Artá) (Lilliu, G., 1960), entre los que presentan corredor, o los de Son Burguet (Puigpunyent) y Comasema (Orient) (fig. 30) (Plantalamor Massanet, L. y Murillo Orfila, J., 1993). Estos últimos presentan ya una columna polilítica central, elemento que se generalizará en la isla.

También presentan características arcaizantes los talaiots de Rafal Cogolles (Amorós, L. y Sancho, J., 1929), desgraciadamente desaparecido, los talaiots A y B de Capocorb Vell (Lucmajor) (Font Obrador, B. y Rosselló Bordoy, G., 1969), el Monumento central de S'lllot (Rosselló Bordoy, G. y Frey, O.H., 1966), Es Pagos (Porreres) o el monumento D de Son Oms (Palma de Mallorca) (Rosselló Bordoy, G., 1973), todos ellos con planta exterior rectangular.

Son muy conocidos los talaiots que presentan un eje de simetría central ocupado por una columna, algunos de planta circular: Son Oms B (Palma de Mallorca), Talaiots nordeste y meridional de Capocorp Vell (Llucmajor), Son Fornés (Montuiri) (Díez, T., Gasull, P., Lull, V. y Sanauja, E., 1980), Son Serralta (Puigpunyent) (Rosselló Bordoy, G., 1971), Son Pou Vell (Villafranca de Bonany)....y otros que presentan planta rectangular: Son Serra de Marina o S'Hospitalet (Rosselló Bordoy, G., 1983).

Es probable que el resultado de la evolución de estos monumentos se encuentre en talaiots como Sa Canova (Artá) o Talaia Joana- Antigors (Ses Salines) (entre los de planta circular) y Sa Gruta (Manacor) (entre los de planta rectangular). Excepcionalmente talaiots cómo el de Son Noguera (Llucmajor) presentan cámara circular sin columna central (Plantalamor, L. y Murillo, J., 1992) (fig. 31).

\section{Monumentos elevados}

Construidos con una técnica similar a la de los talaiots, estas construcciones presentan una rampa externa que facilita el acceso a una plataforma superior. Esta características descartan una función militar, y la locali- 


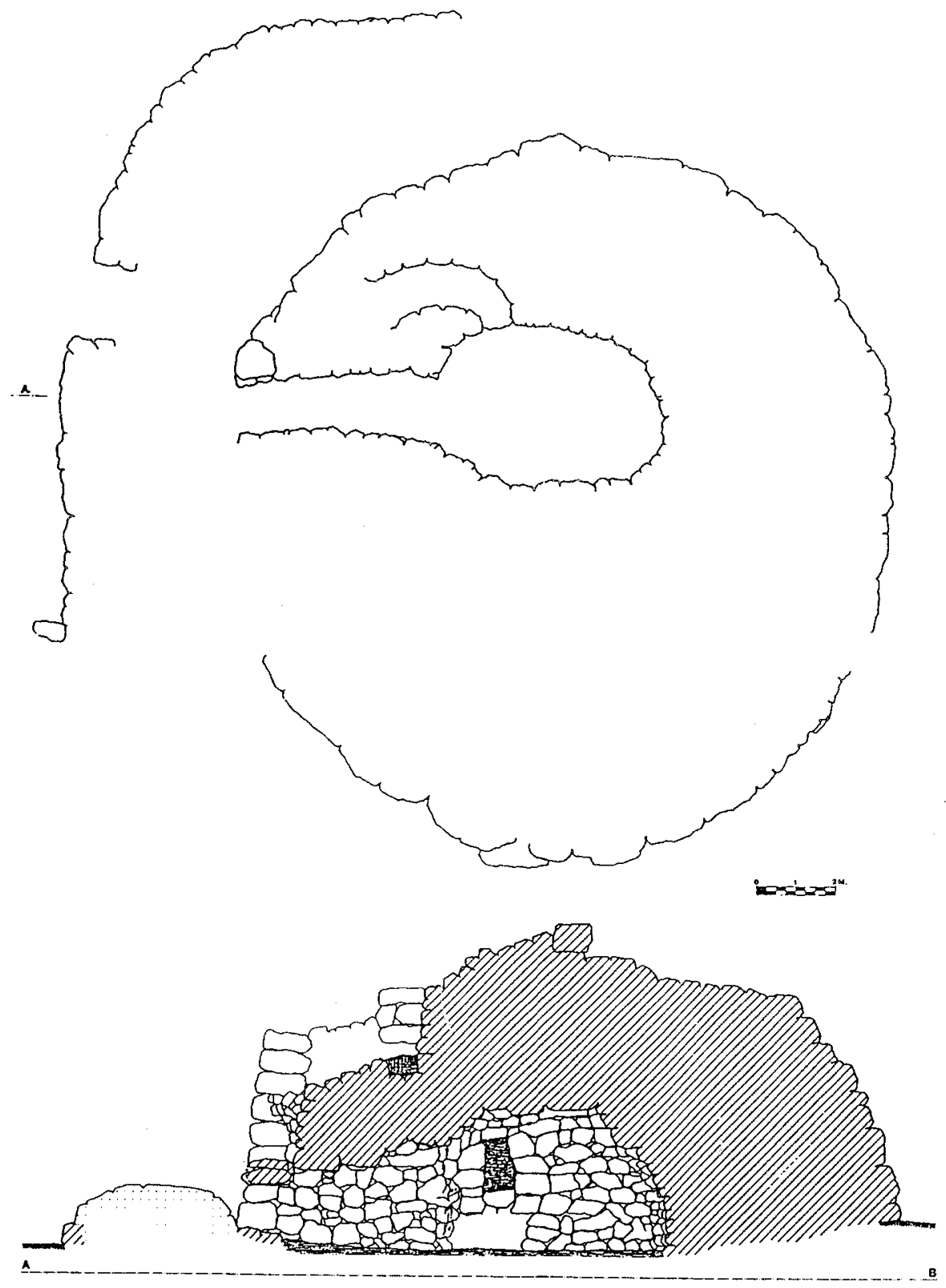

Figura 29. Talaiot Norte de Torrevella den Lozano (Ciutadella). 

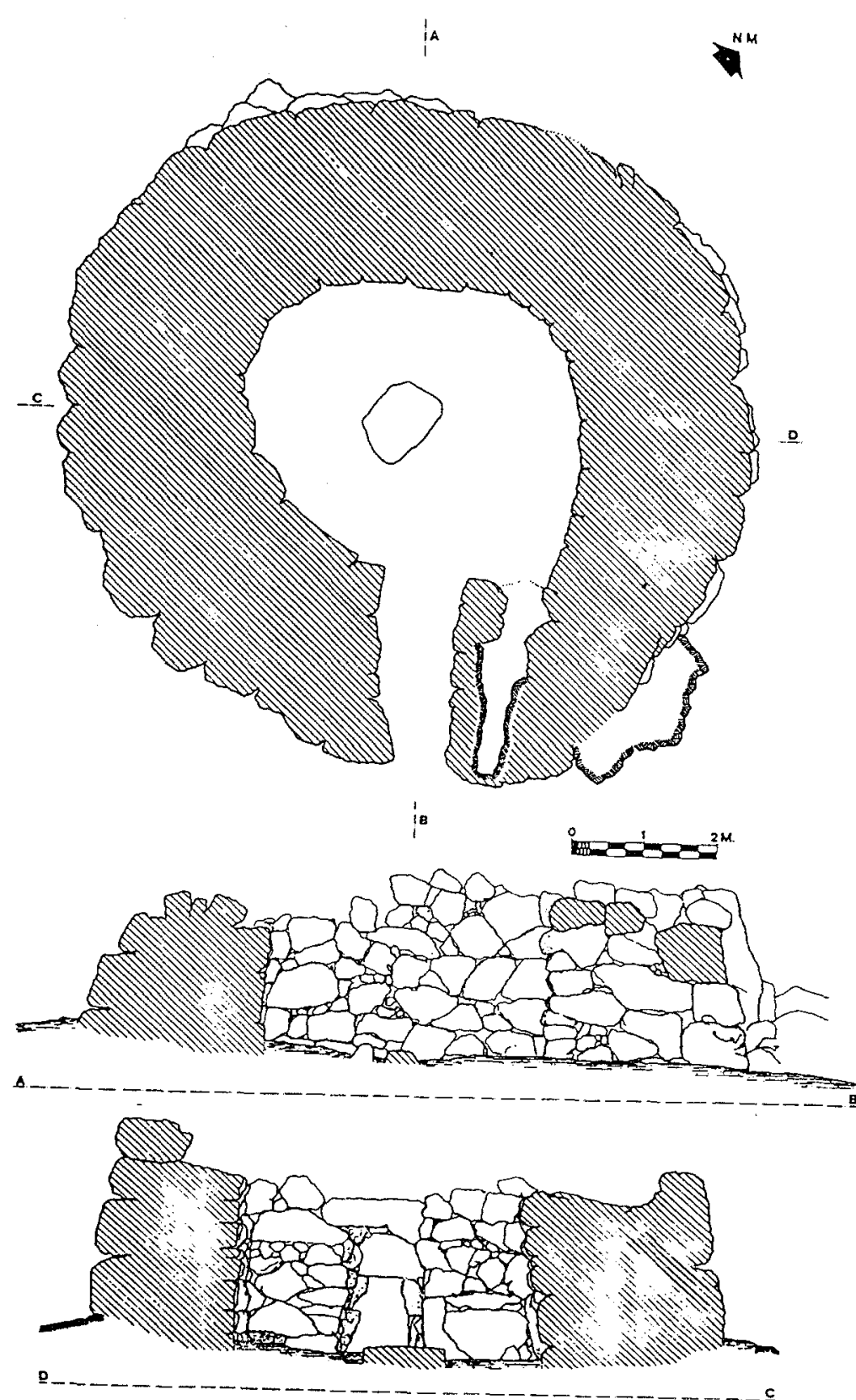

Figura 30. Talaiot de Comasema (Orient) (según L. Plantalamor y J. Murillo). 


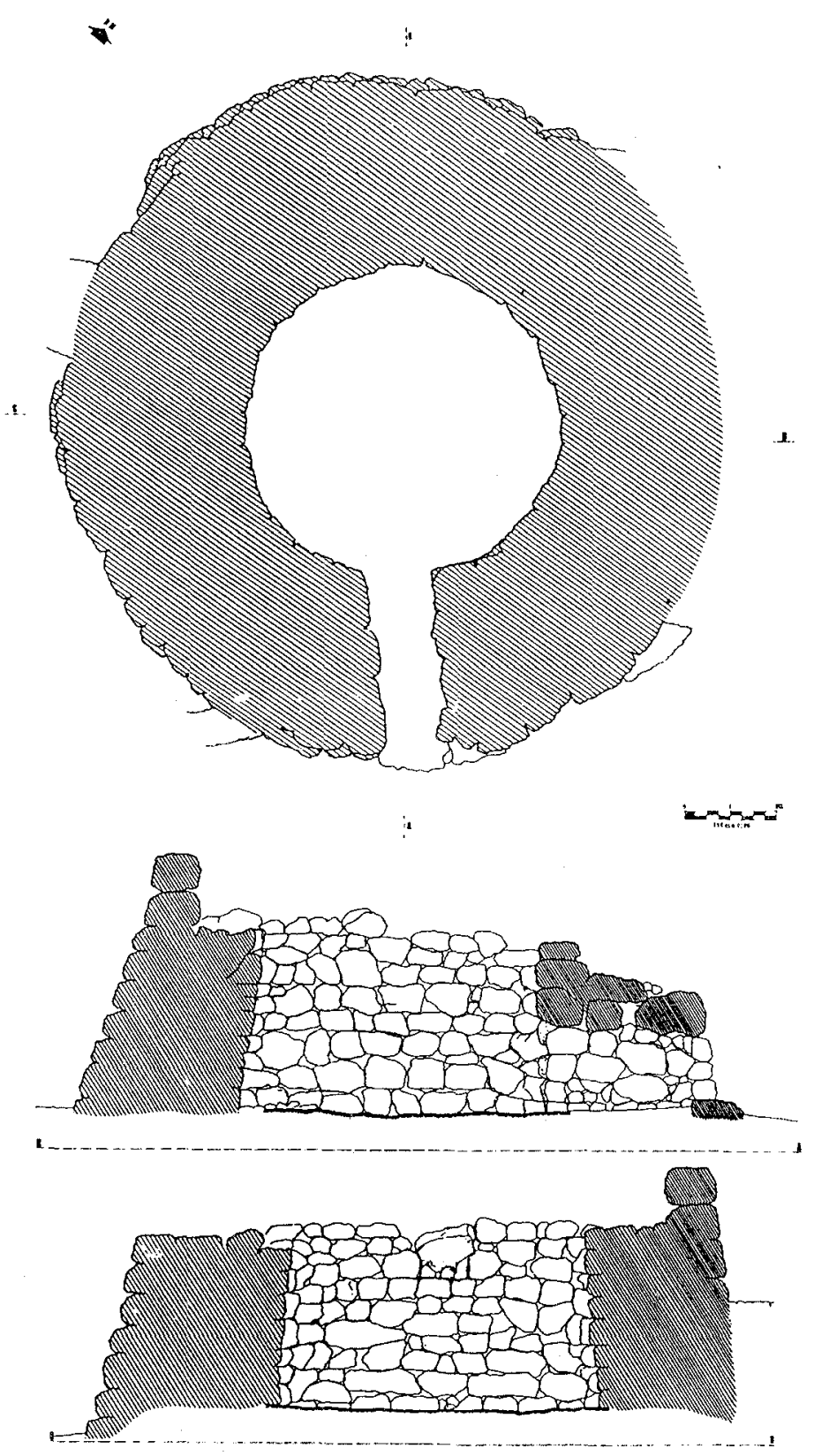

Figura 31. Talaiot de Son Noguera (Llucmajor) (según L. Plantalamor y J. Murillo). 

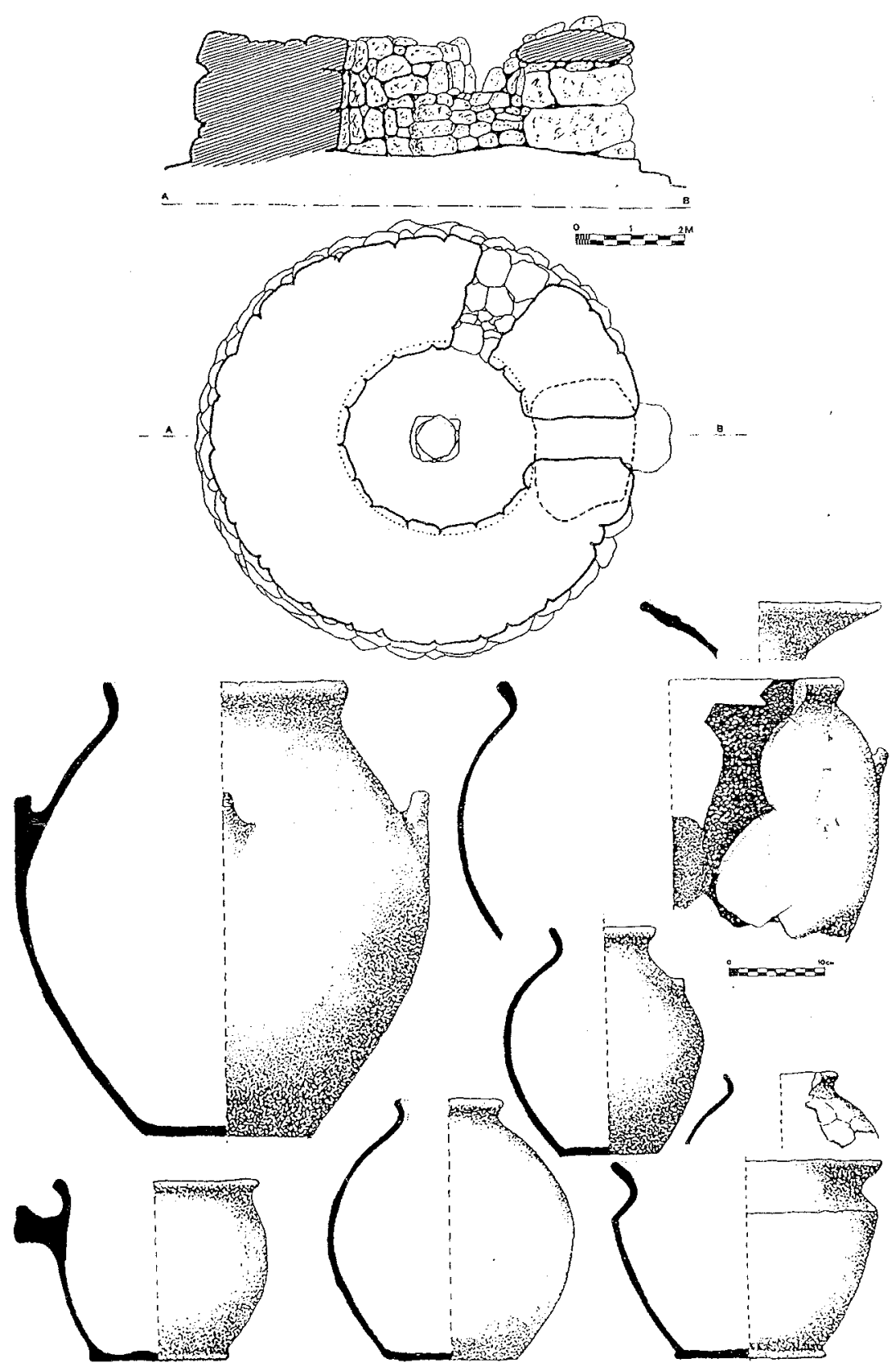

Figura 32. Talaiot de Son Serralta (Puigpunyent) (según J. Camps y G. Rosselló Bordoy). 


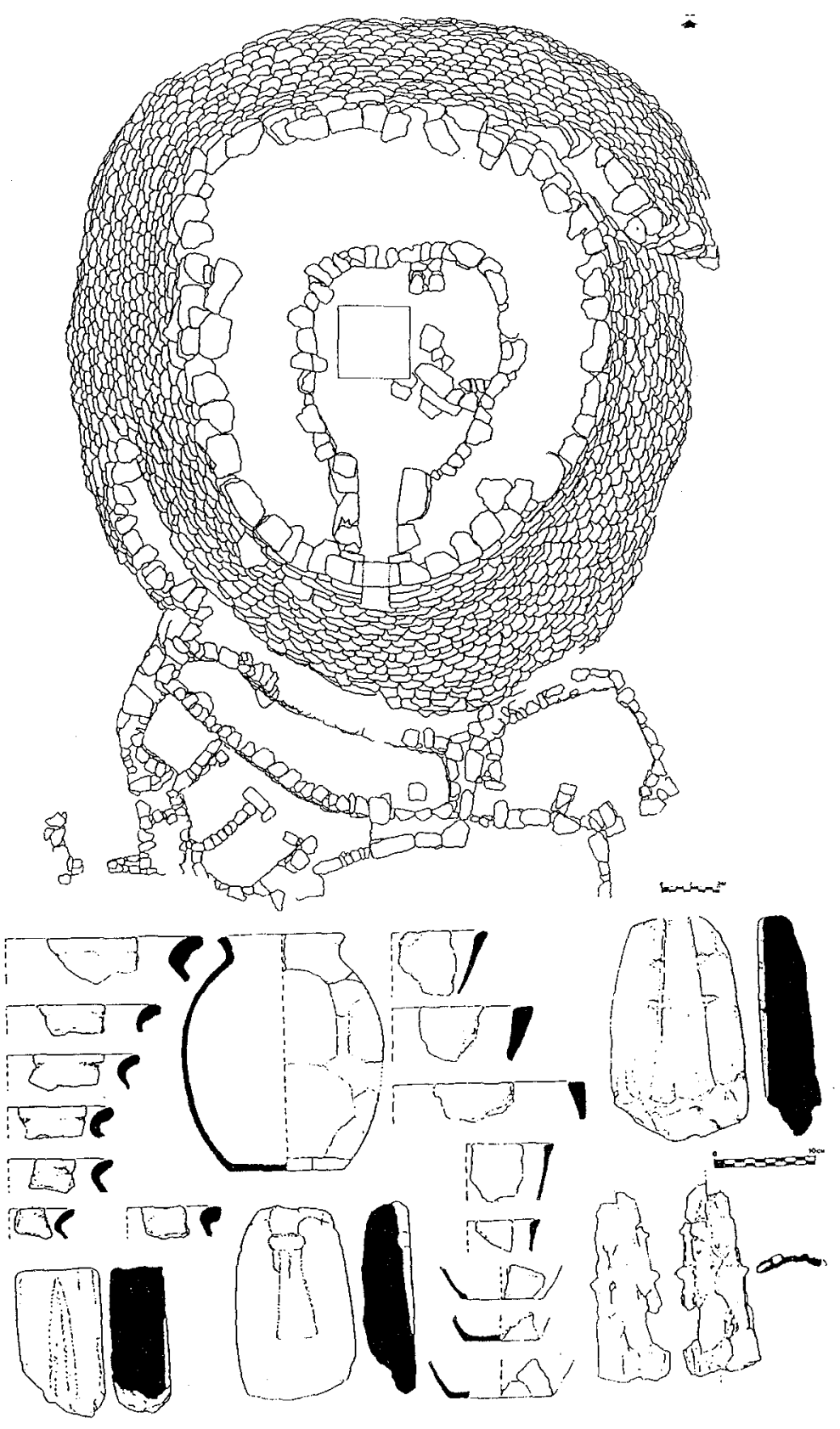

Figura 33. Talaiot de Torelló (Maó). 
zación de un hipogeo de triple cámara bajo el monumento $\mathrm{C}$ de Son Oms (Palma de Mallorca) (Rosselló Bordoy, G.) o de una posible ara con laberinto grabado en Toraixa (Es Castell) nos inclina a pensar que se trataría de un edificio con una función sacra.

El Monumento de Pula (Son Servera) ya estaba en uso en la mitad del II milenio A.C. y parecida cronología podría deducirse para el monumento de Toraixa (Es Castell). En ambos casos, al monumento se adosan hábitats al parecer abandonados en épocas posteriores (en el talaiótico II y III respectivamente). La construcción del monumento $\mathrm{C}$ de Son Oms, sobre unas navetas de habitación, es sin ninguna duda posterior.

\section{Santuarios y taulas}

Independientemente del uso de espacios naturales como lugares de culto destacamos el hecho de que la cultura talaiótica usa un tipo de lugar de culto específico, construido básicamente con planta externa absidal, excepcionalmente cuadrada, y con técnicas que recuerdan la arquitectura megalítica evolucionada (concretamente los llamados templos malteses) (Evans, J.D., 1971) y no la ciclópea. Estos monumentos pueden emplazarse, bien en el interior de la zona urbana, bien en el exterior, e incluso excepcionalmente, como en So $\mathrm{Na}$ Caçana (Alaior) se han identificado diversas unidades concentradas en un mismo recinto, lo que lleva a suponer que se trataría de una zona de culto común a varias comunidades. (Plantalamor Massanet, L., 1986).

En la zona oriental de Menorca algunas de estas construcciones presentan una distribución interior polilobular, con eje de simetría longitudinal (Curnia Maó, So Na Caçana 4 y 7 , Alaior, Sant Agustí Vell, Migjorn). No se conocen por el momento monumentos de estas características ni en Menorca Occidental ni en Mallorca (Plantalamor Massanet, L., 1995).

También en la zona oriental se hallan la taulas más arcaicas, como las de Trepucó (Maó) y Torre den Gaumés (fig. 35), que han proporcionado materiales pertenecientes claramente al talaiótico I. Los paramentos internos de estas taulas presentan aún características megalíticas, y pueden ser consideradas el prototipo de estos monumentos, las taulas, que se generalizan posteriormente a toda Menorca.

En Mallorca se encuentra un tipo de monumento similar, con columnas interiores, que ha sido generalmente situado al final de la cultura talaiótica, como lo fue también la taula. No se puede descartar que futuras excavaciones permitan situar este tipo de monumento en épocas mas ar- 


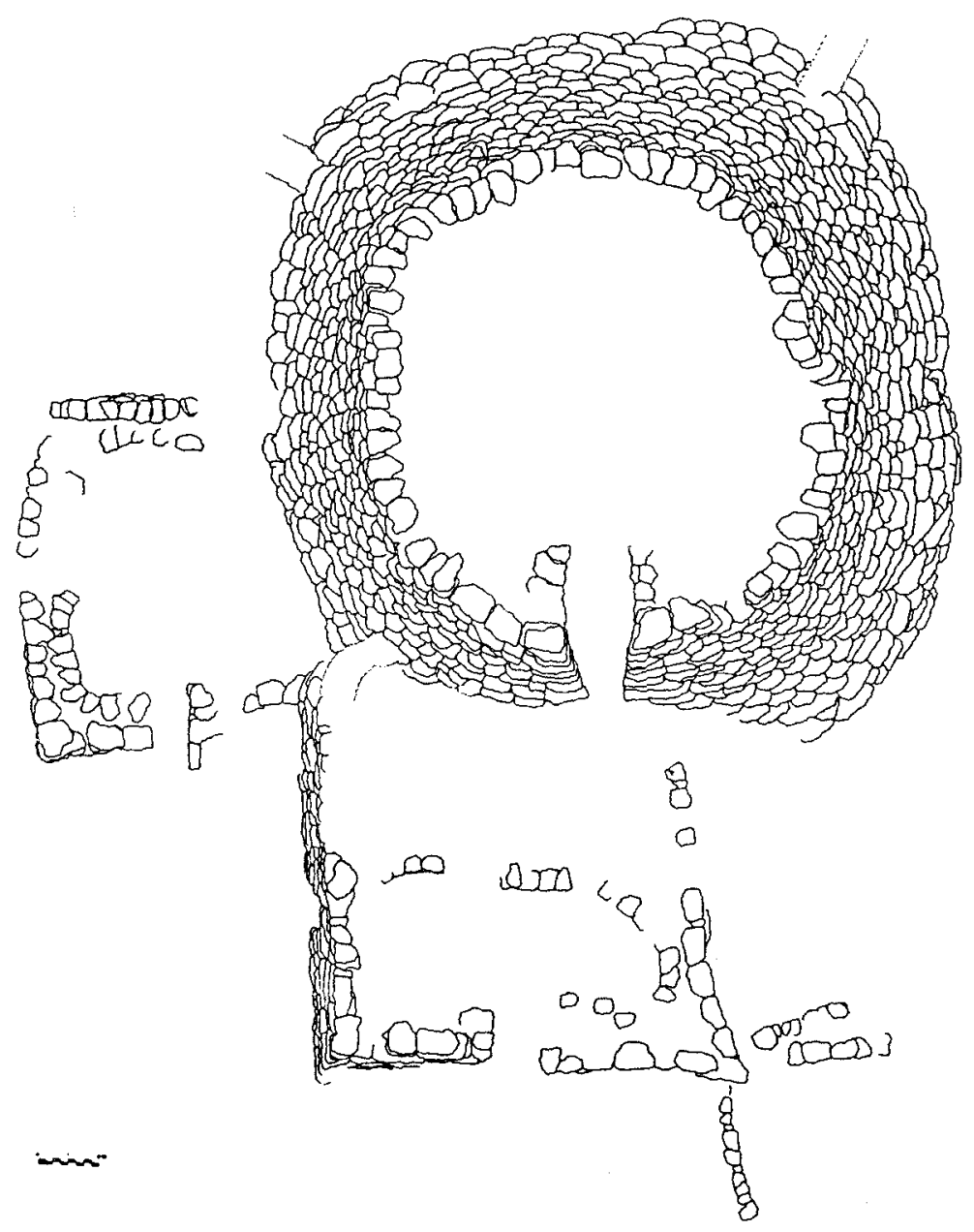

Figura 34. Santuarios absidales y talaiots superpuestos en la zona occidental de Curnia (Maó).

caicas, como parecen indicar la excavación de Son Mas (Valldemossa) (Waldren, W.H. y Strydonck, M. Van, 1993) y algunos fragmentos cerámicos correspondientes al talaiótico inicial aparecidos en la excavación del subsuelo del Monumento A de Son Oms (Palma de Mallorca). 


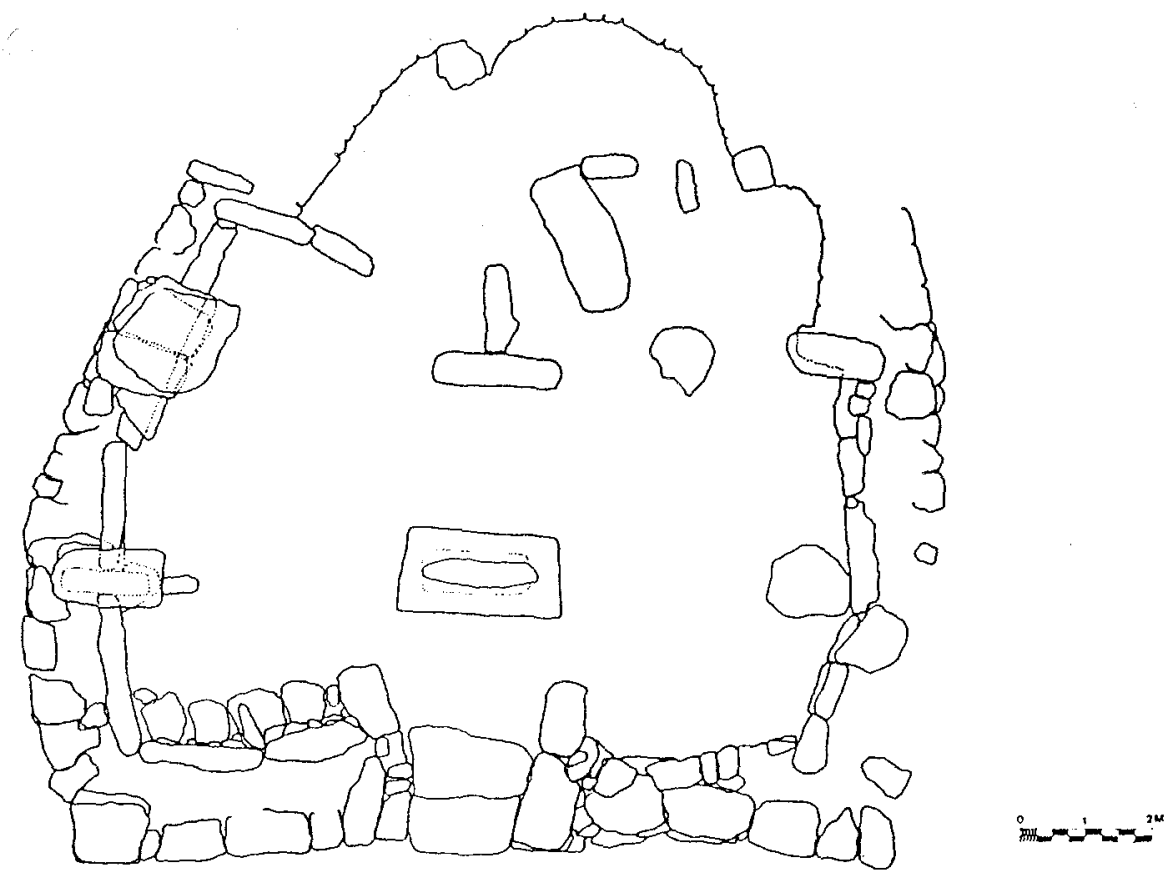

Figura 35. Taula de Torre den Gaumés (Alaior) (según G. Rosselló Bordoy y L. Plantalamor).

Casas y estructuras adjetivas

Es indudable la continuidad de uso de las navetas de habitación en la fase talaiótica inicial en Menorca occidental y en Mallorca, y es frecuente la construcción de un talaiot dominante en los poblados de navetas de habitación o en sus proximidades, como vemos en Clariana (Ciutadella), Santa Mónica (Migjorn), Son Mercer de Baix (Ferreries), Hospitalet (Manacor) o Son Oms (Palma de Mallorca). En los hábitats de Menorca Oriental también observamos fenómenos parecidos en establecimientos como Curnia (Maó) o Trebalúger (Es Castell).

El cambio entre las fases talaiótico IA y IB representa un abandono de muchos de estos hábitats, entorno al siglo XIV A.C., y la concentración de la población en núcleos urbanos.

En la cultura talaiótica, tanto en Mallorca como en Menorca, se generalizan dos tipos de estructuras urbanísticas, inicialmente partiendo de un monumento central (frecuentemente un talaiot): casas distribuidas de forma radial (Son 


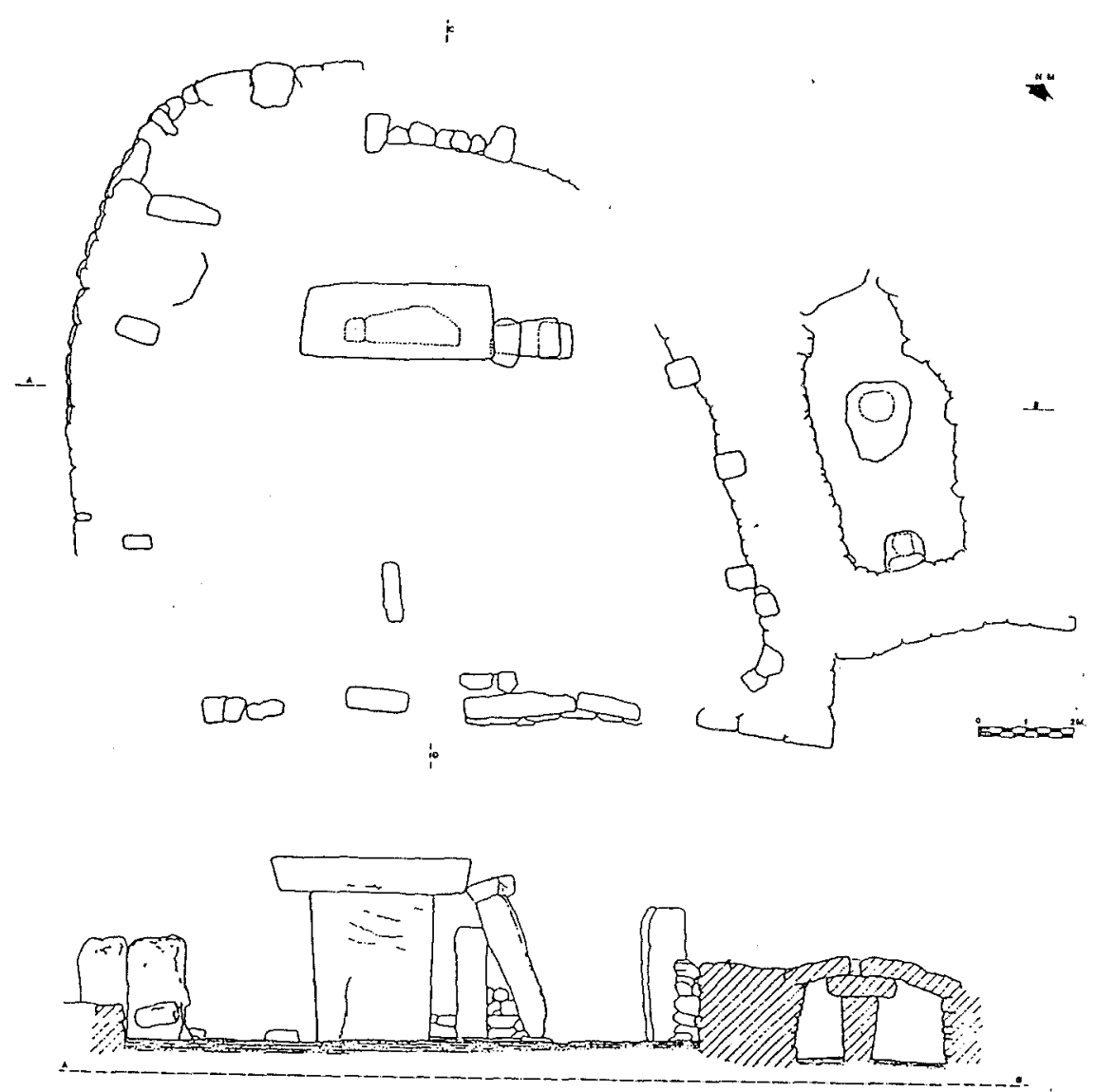

Figura 36. Taula de Talatí de Dalt (Maó).

Oms C, Son Favar, Sant Agustí Vell Oriental, Trepucó N.O.) y casas circulares adosadas (Son Oms B, Sant Agustí Vell Oeste, Torre den Gaumés).

Pero la estructura interna de los hábitats responde a formas distintas: mientras en Mallorca presentan en general estructuras simples, en Menorca observamos una estructura de casa compleja entorno a un patio central (a modo de impluvium) y con ámbitos específicos como hogar, almacenes, habitaciones, telar... exponente de distintas formas de estructura familiar.

Se encuentran también, aunque son menos frecuentes, estructuras absidales tal vez porticadas, aunque con una distribución similar a las anteriores [S'lllot, (Sant Llorenç des Cardessar) (fig. 39), Torre den Gaumés (Alaior), Torelló (Maó)] y que es probable que tengan su origen ya en la fase del hierro. 
En Mallorca se encuentran además estructuras cuadrangulares, en especial adosadas al interior de ámbitos amurallados [Capocorp Vell (Llucmajor) (fig. 38), Son Fornés (Montuiri), Hospitalet (Manacor)].
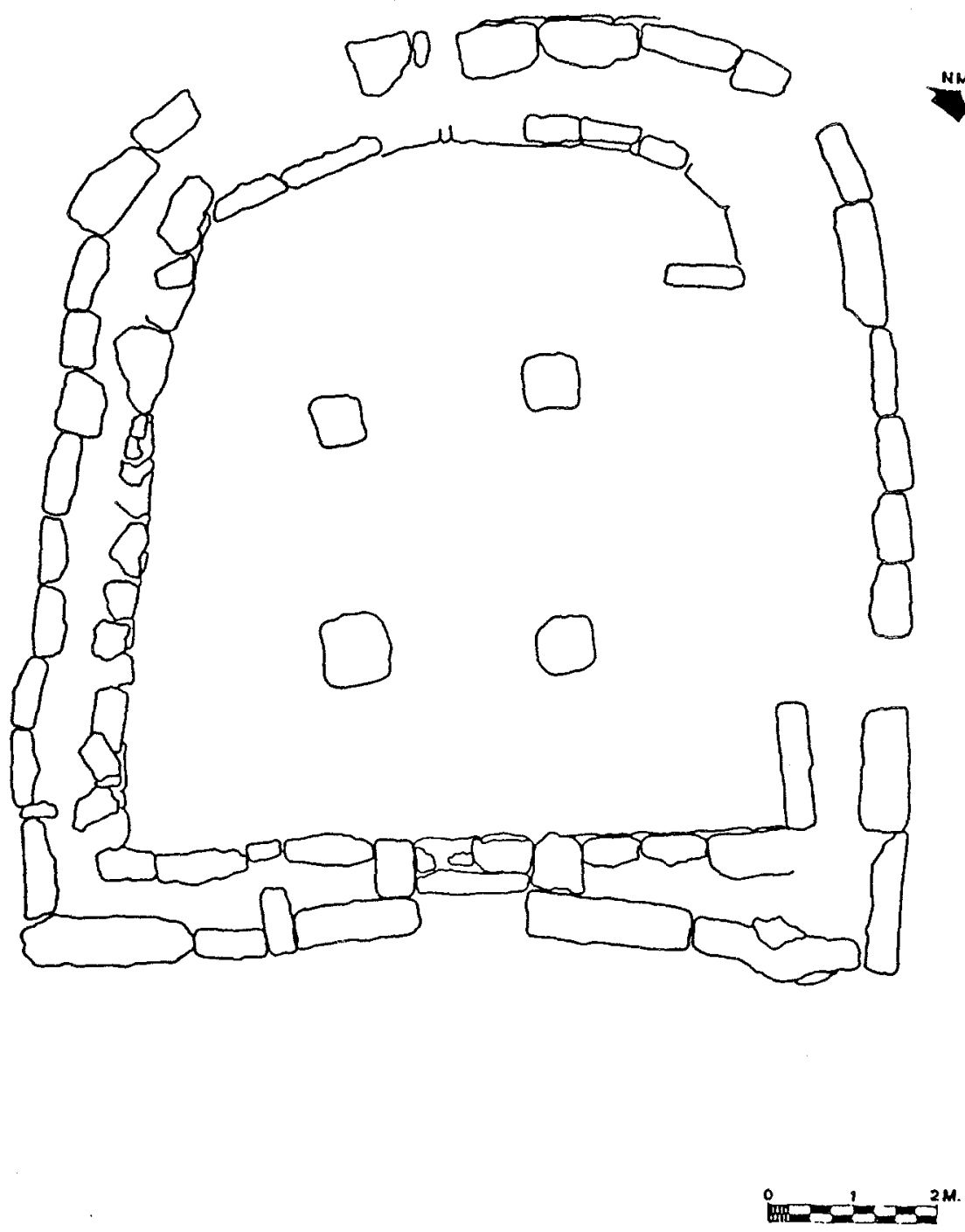

Figura 37. Santuario de Son Marí (Santa Margalida) (según G. Rosselló Bordoy y L. Plantalamor). 


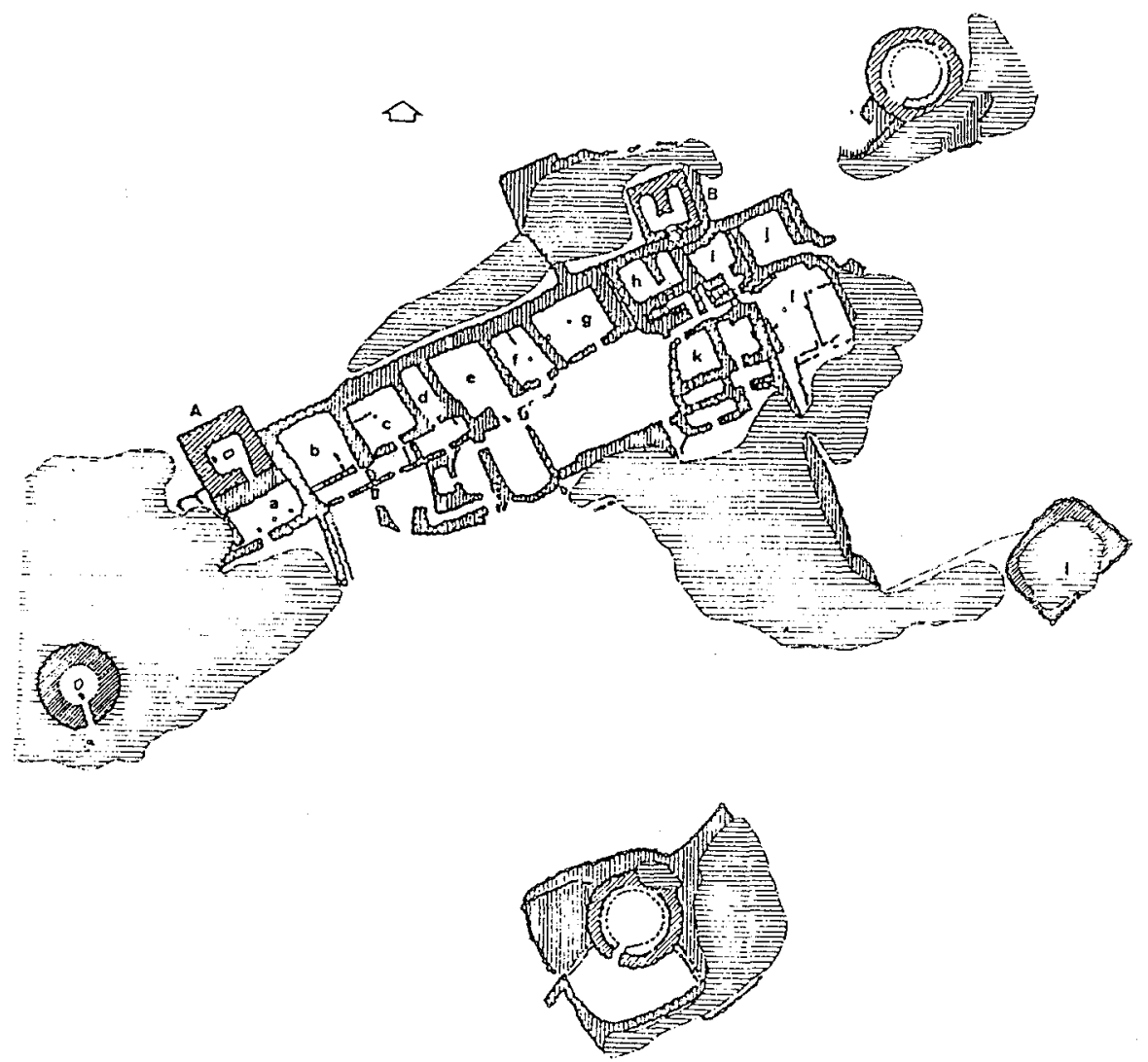

Figura 38. Capocorp Vell (Llucmajor) (según J. Mascaró Pasarius).

\section{Arquitectura funeraria}

En la cultura talaiótica se han utilizado distintas formas de inhumación, en general con rituales de inhumación primarios y deposiciones secundarias.

En Menorca oriental está claro que al inicio de la cultura talaiótica siguieron en uso, hasta los primeros siglos del I milenio, las navetas de inhumación de la fase anterior. Este uso conllevó el vaciado de las inhumaciones pretalaióticas (Nav. Occidental de Biniac-La Argentina (Alaior), Sa Torreta, Binimaimut (Maó).

Algunos fragmentos cerámicos de la naveta de la Cova podrían indicar que la construcción corresponde a la fase pretalaiótica, aunque también es 


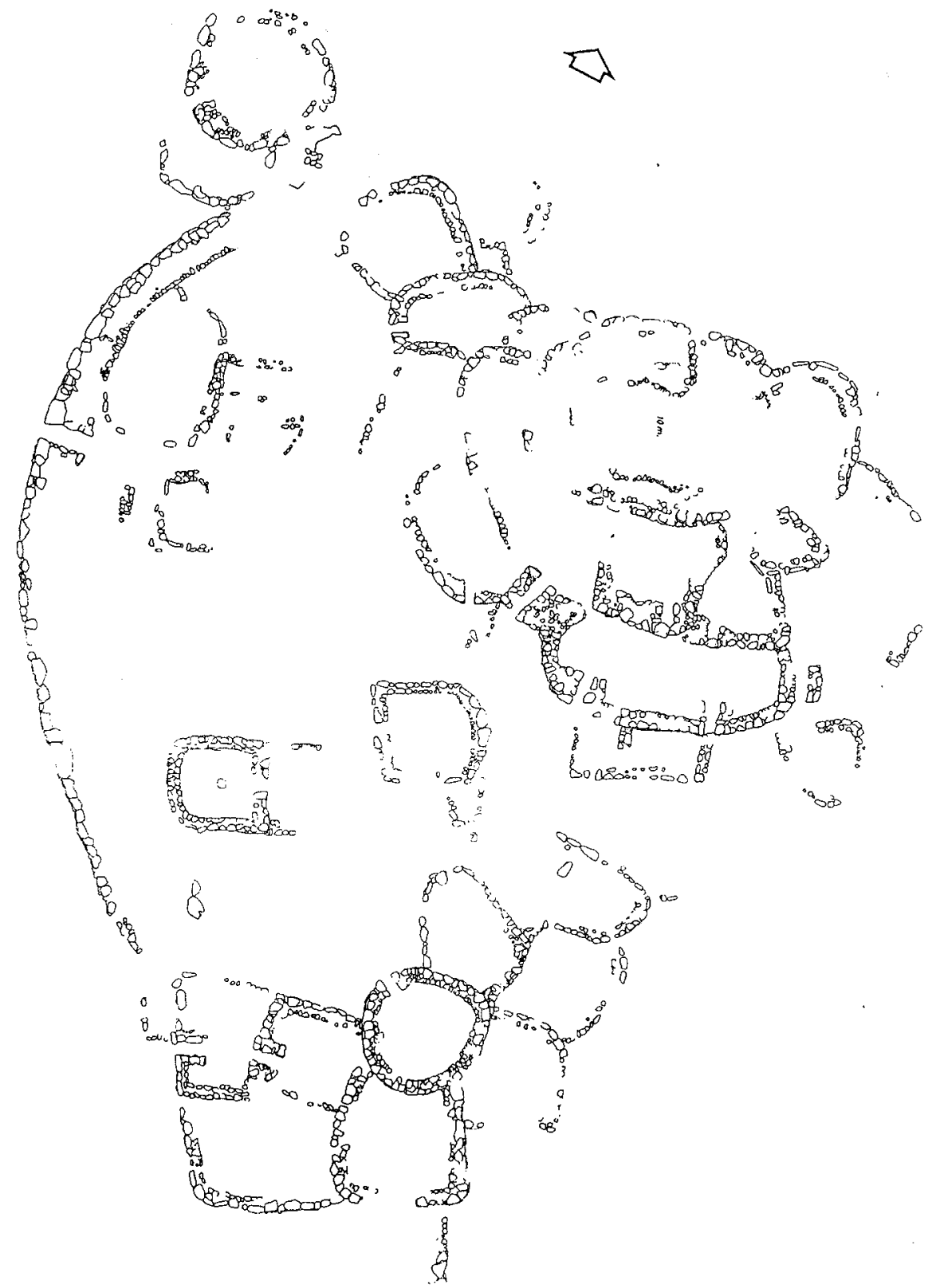

Figura 39. S'lllot (Sant Llorenç des Cardessar) (según O. H. Frey y G. Rosselló Bordoy). 


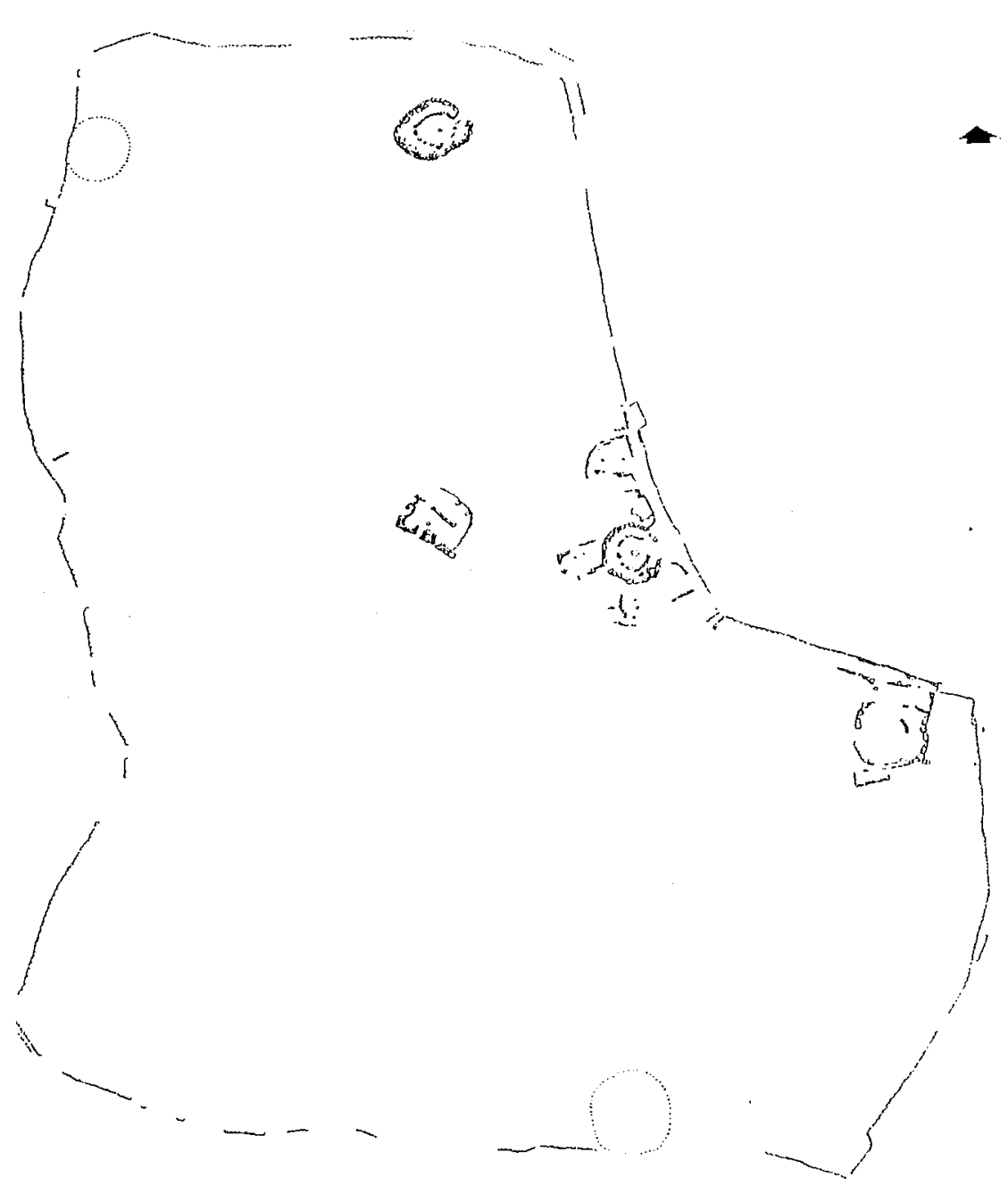

Figura 40. Son Catlar (Ciutadella).

posible que corresponda al momento inicial de la cultura talaiótica, en él que pensamos que se inicia la construcción de navetas de enterramiento en la zona occidental de Menorca. En esta parte de la isla, en las fases precedentes no se utilizaban este tipo de construcciones para la inhumación, y esto podría ser un indicio del desplazamiento a esta zona de población antes asentada en la zona Oriental. El uso de navetas como Binipati Nou, Son Morell, Es Tudons... perdurará hasta entrado el I Milenio. 
Además del enterramiento en navetas aparecen en Menorca otros dos tipos de inhumación: las cuevas de cámara lobular o polilobular con corredor de entrada y los abrigos cerrados por un muro ciclópeo. Estas formas de inhumación representan una ruptura con formas tradicionales en Menorca Oriental y presumiblemente puedan atribuirse a una fase arcaica de la cultura talaiótica, como puede deducirse de Curnia (Maó), Torre den Gaumés (Alaior) o Sant Agustí Vell (Migjorn).

Es difícil definir el momento en que se inicia el uso de estructuras similares en barrancos, muy abundantes, pero la observación de algunos materiales parecen indicar que necrópolis como la de Cales Coves (Alaior) ya estaban en uso a inicios del primer milenio.

En cuanto a Mallorca, carecemos de datos que permitan situar cronológicamente las inhumaciones en cuevas artificiales, por lo que no se conoce en que momento de la cultura talaiótica se inicia su uso. De hecho son escasísimos los materiales talaióticos hallados en hipogeos, y parece evidente una ruptura entre los enterramientos pretalaióticos y los talaióticos.

Los primeros enterramientos claramente talaióticos se encuentran en Son Matge (Valldemossa) (Rosselló Bordoy, G. y Waldren, W.H., 1973). Posteriormente, alguno materiales ya conocidos, procedentes de diversos yacimientos, fueron identificados con el mismo grupo, por su similitud con los materiales procedentes de Son Matge [Es Coval de En Pep Rave (Sóller) (Coll Conesa, J., 1991), Son Oms (Palma de Mallorca) (Rosselló Bordoy, G.1965), Sa Cometa des Morts (Escorca) (Veny, C., 1981)]. Las dataciones obtenidas por el C14 para el inicio de los enterramientos talaióticos (Fernández Miranda, M. y Waldren, W.H., 1974) y las memorias de excavación (Rosselló Bordoy, G. y Waldren, W.H., 1973 y Waldren, W.H. y Plantalamor, L, 1976) plantean algunas contradicciones que dificultan precisar el momento de inicio de las inhumaciones talaióticas.

\section{Industria Mueble}

El inicio de la cultura talaiótica está marcado por una ruptura total con los elementos culturales anteriores y muy pocos de estos elementos sugieren una adaptación a una nueva tecnología.

La uniformidad de los distintos e!ementos indica la existencia de talleres especializados, con producciones que van mas alla del ámbito familiar y local. Salvo casos muy concretos (las cuentas bicónicas en Menorca o el uso de vasos-incensarios troncocónicos en Mallorca y de fondo esférico en Menorca) no se observan diferencias notorias ni regionales ni insulares 


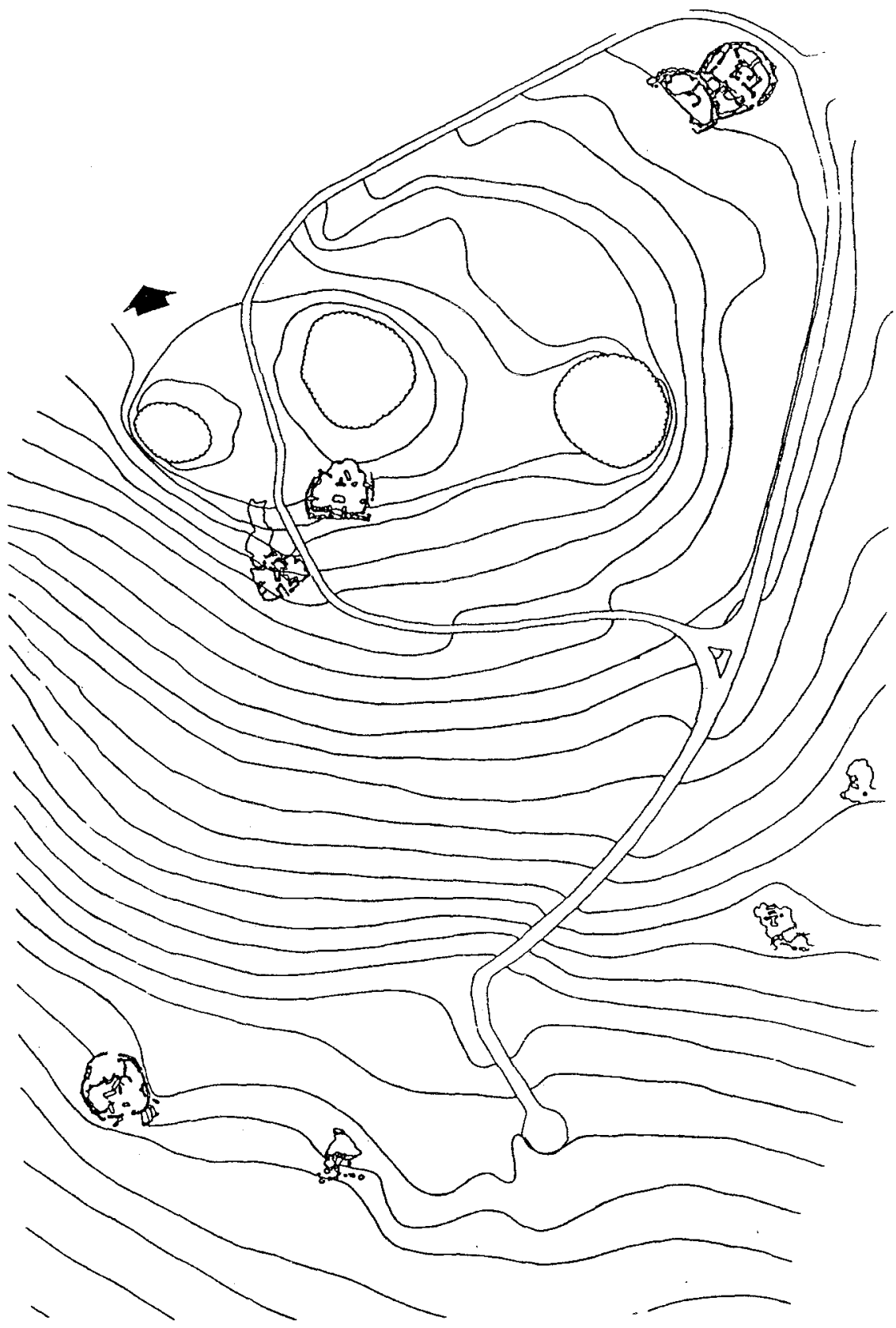

Figura 41. Torre den Gaumés (según G. Rosselló Bordoy y L. Plantalamor). 


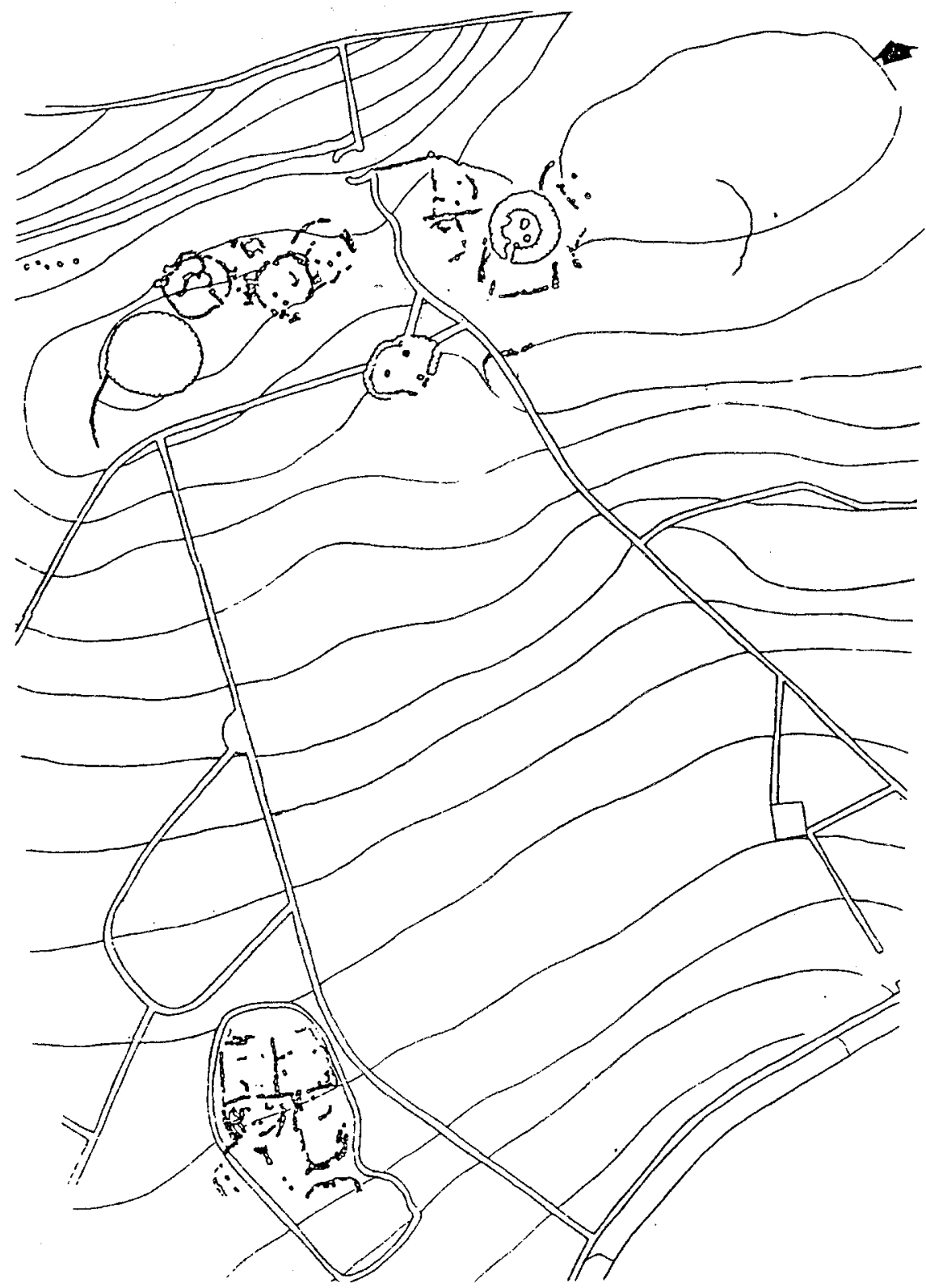

Figura 42. Sant Agustí Vell (según L. Plantalamor). 
en el material mueble que se encuentra en los distintos yacimientos. A partir del primer milenio, en cambio, se acentuarán notablemente estas diferencias.

\section{Metalurgia}

El inicio de la cultura talaiótica está marcado por un uso generalizado de las técnicas del bronce medio y final. El uso de aleaciones de cobre y estaño es general y la producción demuestra un dominio de las mismas. Se han hallado moldes de fundición, lo que demuestra un comercio intenso dado que los yacimientos de cobre son escasos en Mallorca y Menorca (S'Hospitalet, Rosselló Bordoy, G., 1987, Torelló), e inexistentes los de estaño.

Son relativamente abundantes las espadas, de pomo o a modo de sable, las puntas de lanza foliáceas, y especialmente un tipo de hoja semilunar o semiesférica apuntada que sugiere algún tipo específico de alabarda (fig. 24).

En cuanto a las herramientas, destacamos la frecuencia de hachas planas de filo semilunar y escoplos (Ripoll Perelló, E. y Rosselló Bordoy, G., 1963), que sugieren su uso sistemático en trabajos de cantería, y que progresivamente serán substituidas por hachas con nervadura y tubulares con asa central.

También son frecuentes los adornos personales, especialmente aros, y con menor frecuencia pectorales y torques, que tendrán un gran desarroIlo en el talaiótico II y III.

\section{Cerámica}

Con la cultura talaiótica se generaliza el uso de desgrasantes calcáreos (García Orellana, J., 1998) en la confección del barro, lo cual da un carácter tosco a las piezas pero a la vez permite la confección de contenedores de gran tamaño.

En líneas generales observamos que cada forma tiene usos específicos, tanto las que se utilicen en los hábitats cómo las que se utilicen en rituales de inhumación. Estas últimas son en general de tamaño reducido.

El uso generalizado en el talaiótico IA de grandes contenedores, de forma cilíndrica o de bota con borde ensanchado, indica una sociedad en la que la acumulación de excedentes alimentarios es un hecho económico 


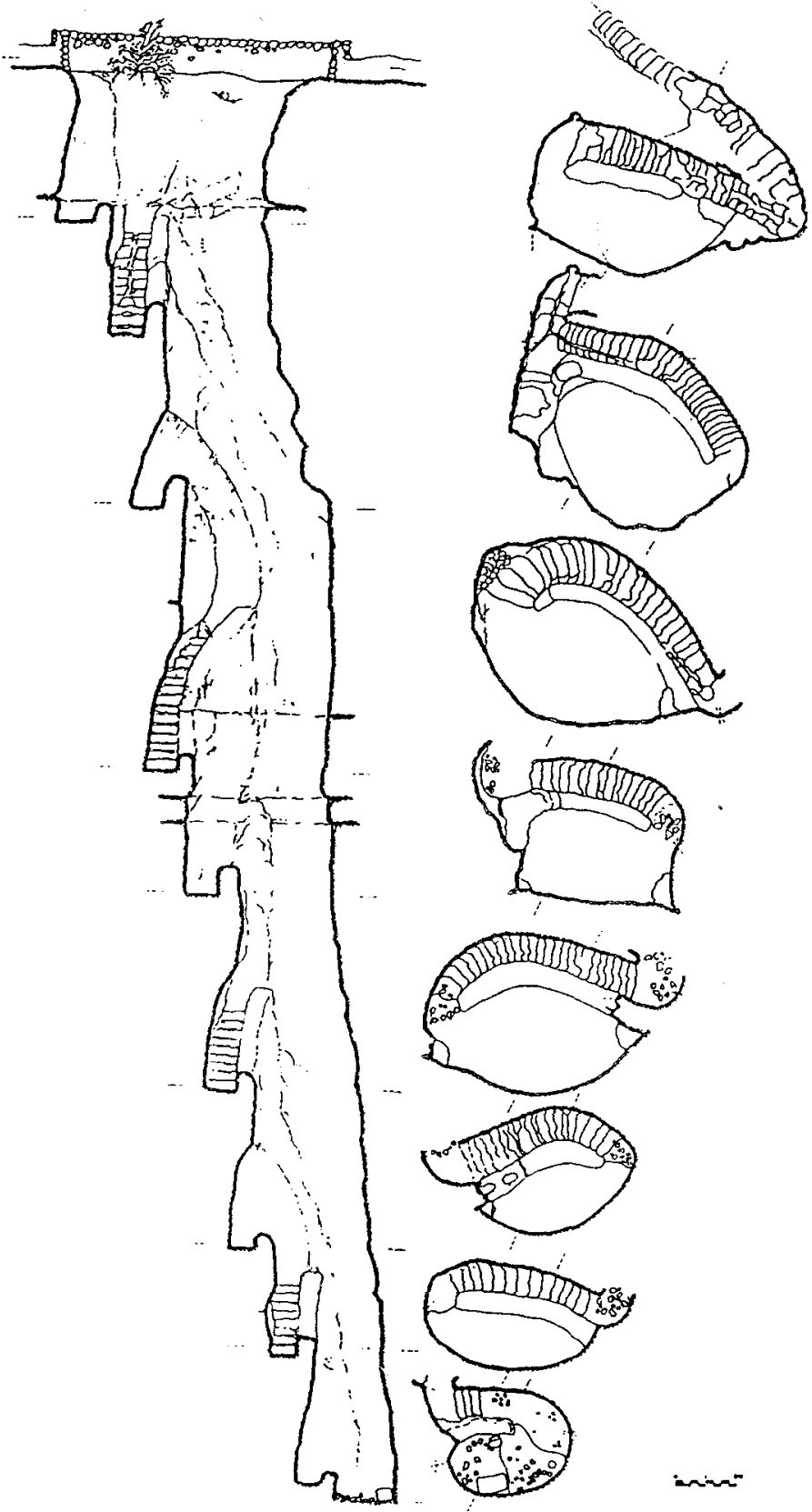

Figura 43. Pozo de Na Patarrà (Alaior) (según M. Tries). 
y social determinante. Este tipo de recipientes serán paulatinamente substituidos por las formas Ilamadas pitoide y carenada (Talaiótico IB), que serán las únicas formas usadas en el talaiótico II.

Las grandes ollas de diversos tipos (globulares, carenadas, troncocónicas y esféricas), siempre con base plana, estaban sin duda destinadas a su uso en la cocina. El ajuar doméstico se completaba con vasos troncocónicos y excepcionalmente con platos y copas (en Mallorca).

Piezas formalmente idénticas, pero siempre de tamaño reducido, son frecuentes en los yacimientos funerarios de la época, siendo excepcionales las piezas de tamaño mediano y grande.

Hueso

Como material duro, especialmente en islas en las que predominan los terrenos calcáreos, el hueso ha sido utilizado en la confección de punzones y mangos de leznas metálicas, muchas veces endurecido al fuego.

Bien de hueso, bien confeccionados con dientes de animales domésticos, son frecuentes los botones, sobre todo triangulares perforados en $\mathrm{Vo}$ transversalmente. Se ha visto en ellos una perduración de la fase precedente aunque en general los botones talaióticos presentan un trabajo más elaborado y su tamaño suele ser reducido. Además es común el uso de decoración incisa de círculos.

Excepcionalmente se han encontrado también pequeños tubos y punzones con asa en el extremo que tal vez se utilizasen para la elaboración de fibras y tejidos.

\section{Piedra}

La piedra, el material más abundante, ha sido utilizada para la fabricación de instrumentos. En todos los hábitats talaióticos es frecuente una gran variedad de percutores y alisadores. Hay que destacar en especial el uso de molinos de vaivén, conocidos popularmente en Menorca como "molons", que sugieren una economía en la que es importante el cultivo de cereales. En Mallorca estos molinos suelen ser aplanados, mientras que los menorquines son más voluminosos y pesados y están confeccionados con greses rojos del norte de la isla, lo que demuestra la existencia de rutas terrestres abiertas para facilitar su transporte. 
Los hallazgos de un núcleo de obsidiana procedente de la excavación de la cámara del talaiot de Torelló (Maó) y de un percutor de granito de la naveta de Cotaina (Alaior) demuestran sin ninguna duda contactos extra insulares, dada la inexistencia de estos materiales en Baleares

\section{LAS BALEARES Y PITIUSAS EN EL MEDITERRÁNEO OCCIDENTAL}

Los geógrafos de la antigüedad clásica distinguían entre Baleares y Pitiusas, y parece que esta distinción responde a hechos culturales con origen en las primeras poblaciones establecidas, y no a determinantes físicos o geográficos.

Los contactos entre Mallorca y Menorca parecen claros y ambas islas están relacionadas a su vez con el ámbito del Mediterráneo central y noroccidental en la primera fase de la metalurgia, esto es, en las fases calcolítica y bronce inicial.

Ya es clásica la comparación entre los hipogeos de las Bouches-duRhône (Audibert, J., 1958) con los de Mallorca y la parte occidental de Menorca. El análisis comparativo entre los distintos grupos de hipogeos indica que debían existir contactos entre las distintas zonas. Los hipogeos de las Bouches-du-Rhône, como otros grupos de hipogeos de Cerdeña (Santoni, V., 1976) o Sicilia (Tusa, S., 1983) presentan formas de ingreso con características similares a los de Mallorca y Menorca, aunque las cámaras suelen presentar una estructura diferente (cómo los hábitats).

Sepulturas megalíticas de corredor, con muro de contención simple, son frecuentes en el Languedoc Oriental (Arnal, J., 1963), Córcega (Cesari, J., 1985) y Cerdeña (Atzeni, E., Contu, E. y Ferrarese Ceruti, M.L., 1987) y presentan estructuras similares a los megalitos de Mallorca y Menorca.

Otras estructuras, como las tumbas de antenas o Tombes en ruche del Languedoc oriental (Martín, H. y Arnal, J., 1975), son similares a las llamadas prototombe di giganti de Cerdeña [Su Cuveccu-Bultei o S'Ena'e Vacca-Omzai (Moraveti, 1985)] y también a la naveta de Sa Torreta de Tramuntana (Maó).

En Menorca se encuentran tumbas con cámara excavada y corredor construido, frecuentemente con técnicas megalíticas (Biniai Nou, Sant Tomás, o Cala Morell 11 y 12), muy parecidas a tumbas de estilo similar de Cerdeña [Canudedda-Dorgali (Ferrarese-Ceruti, M.L., 1980), Cúccuru Craboni-Maracalagonis (Atzeni, E., 1973), Su Tiriarzu-Pulilatino (Demurtas, 
S., Manca Demurtas, L. y Sebis, S., 1987)] y de Sicilia [Salaparuta-Pergola y Santa Margherita Belice (Mannino, G., 1971)].

Las casas de planta alargada de la cultura de Fontbouisse (Gasco, J., 1976) muestran elementos comunes con las navetas de habitación, y en especial con hábitats como los localizados en Cala Morell (Ciutadella). Los recintos cerrados como Es Filicomís (Lloseta) son también similares a los de la Cultura de Fontbouisse (Gutherz, G., Jallot, L., 1989), del golfo de Liguria (Bretaudeau, G., 1996), Cerdeña (Manca Demurtas, L. y Demurtas, S., 1990-1991) o Córcega (Cesari, J., 1989). En este último caso es frecuente en la edad del bronce la construcción de torres sobre sus estructuras, como también ocurre en Curnia (Maó) (Plantalamor, L., 1991).

En cuanto a la prehistoria de las Pitiusas, los pocos datos disponibles hacen difícil precisar los posibles contactos, pero algunos indicios permitirían relacionar el sepulcro de $\mathrm{Ca} \mathrm{Na}$ Costa (Formentera) con los de Lacs y Bays (Minerve) (Rouldín, J.L., 1978), a través de ejemplares cómo El Cementiri dels Moros (Gabarras) (Esteva Cruañas L., 1970) o Mas Pla (Valldosera-Querol) (Mestres, J., 1979-80). Es posible que nos encontremos dentro de la influencia de la cultura de Veraza, sobre la que incidirán las influencias del levante peninsular.

Hipotéticamente podemos pensar que Mallorca y Menorca, hasta el momento fuera de las rutas de navegación, entran en contacto, al inicio de la metalurgia, con el sur de Francia y en concreto con la zona del Ródano (Culturas de Ferrieres y Fontbouisse), y poco después con la isla de Cerdeña (Subotzieri, Monteclaro).

Al final de la fase Calcolítica-bronce inicial el grupo de Bonnanaro A presionaría, especialmente en Menorca y en menor grado en Mallorca (cerámicas pretalaióticas de pasta negra compacta). Coetáneamente observamos la introducción de las cerámicas incisas $A$ (identificadas como campaniformes por algunos autores) que tal vez puedan relacionarese con el arco geográfico del levante catalán $y$ del Languedoc Occidental, y que incidirá sobre Mallorca y las Pitiusas.

Entendiendo la cultura talaiótica como el resultado de diversos factores en el que indudablemente el desarrollo de los grupos precedentes es importante, pero también lo es la presión que se ejerce sobre estos grupos desde el Mediterráneo Central, esto podría explicar el posible retraso del inicio de la cultura talaiótica en Mallorca respecto a Menorca.

El inicio de la cultura talaiótica va ligado a nuevas forma de vida cuyos exponentes arquitectónicos más visibles son los talaiot y los santuarios. Pero también es muy significativa la acumulación de excedentes, que 
queda evidenciada por la utilización de contenedores cilíndricos o en forma de bota y de ollas pitoides.

La comparación de los llamados protonuraghes de Cerdeña con los talaiots de características arcaicas (en especial los de Menorca Oriental), permite suponer que los grupos que construyen estos edificios tienen unos conocimientos similares, y utilizan las mismas soluciones arquitectónicas pese a las diferencias medioambientales y sobretodo geológicas. No es hasta el talaiótico IB, coetáneo con el nurágico I y la fase posterior, que evolucionan dichos monumentos por vías diferenciadas, como los talaiots con columna central en Mallorca y los Nuraghes con cúpula Sardos, si bien carecemos de elementos suficientes para precisar cual sería la evolución de estos edificios en Menorca.

La comparación entre talaiots y nuraghes puede extenderse a las Torri corsas (Virili, F.L. et Grosjean, J. 1979). Los Sessi de Panteleria (Orsi, P. 1899) y la torre maltesa de Borg-In-Nadur (Murray, M. 1923) podrían pertenecer al mismo tipo de construcciones, pero carecemos de datos recientes que hagan factible la comparación.

Los usos funerarios en las culturas talaiótica y nurágica son también similares: inhumaciones colectivas, utilización de lugares elegidos exprofeso para esta función (enterramientos colectivos en abrigos con un muro de contención) y reutilización y perduración de formas arcaicas (como las Navetas y las tombe di giganti).

En esta misma época se construyen los primeros santuarios de planta absidal, polilobulados y con un eje de simetría longitudinal perpendicular a la fachada, que podrían compararse con los llamados Templos Malteses en cuanto a sus estructuras. Hay que destacar que el inicio de este tipo constructivo en Menorca coincide con la reutilización de los templos malteses por el grupo del cementerio de Tarxien (Trump, 1995-96).

Este tipo de monumento evolucionará en Menorca hacia los SantuariosTaula y en Mallorca hacia los santuarios con cubierta sostenida por varias columnas.

Esta variedad de paralelismos nos inclina a pensar que el inicio de la cultura talaiótica ocurre en un momento de inestabilidad y de expansión de los grupos culturales del Mediterráneo occidental y central.

Es posible que, en torno al final de la primera mitad del II milenio, existiera una vía marítima comercial de la que formarían parte los asentamientos costeros de las Baleares y las Pitiusas con anterioridad a las rutas del comercio fenicio - púnico y griego. 
Asentamientos costeros como El Cap de Forma (Maó), Llucalari (Alaior), Macarelleta y la última ocupación del cap de Cala Morell (Ciutadella) en Menorca (Plantalamor Massanet, L. 1991), Islotes como S'llla des Porros (Santa Margarita) (Tarradell, M. 1964), Na Moltona (Ses Salines) y Sa Galera (Palma de Mallorca) y asentamientos costeros como S'Almunia y Es Baus (Santanyi), S'lllot (Sant Llorenç des Cardessar), Cala Morlana (Manacor), Cala Pi (Llucmajor), ocuparían un puesto clave de escalas de esta ruta comercial, como también Es Puig de $\mathrm{Na}$ Jondal (Ibiza) (Ramón Torres, J. 1985, Gómez Bellard, C. y San Nicolás Pedraz, P. 1988) o Sa Cala en La Mola de Formentera (Fernández, J.H. 1977).

En algunos de estos yacimientos se han localizado contenedores cilíndricos o en forma de bota de borde de sección triangular, al igual que ocurre en algunos lugares de Cerdeña como el Área del Campidano (Santoni, V. y Sebis, S. 1984, Sebis, S. 1987), o San Antíoco (Usai, L., 1990).

\section{BIBLIOGRAFÍA}

AlCOVER, J.A. (1994). Eivissa: A Pleistocenic Oceanic-like Island in the Mediterranean. Research and exploration, pp. 236-248.

AlmagRo, M. (1941). Introducción a la Arqueología. Las culturas europeas. Ed. Apolo, Barcelona

Amorós, L.R. y SAncho, J. 1929. El talaiot de Rafal Cogolles (Manacor) B.S.A.L. 22. Palma de Mallorca.

ARnAL, J. (1963). Les dolmens du departament de l'Herault. París.

ATZENI, E. (1973). Nuovi idoli della Sardegna prenuragica. Studi Sardi XXIII. Sassari.

Atzeni, E., Contu, E. y Ferrarese Ceruti, M.L. (1987). L'età del rame nellitalia insulare: La Sardegna. Congreso internazionale. L'età del rame in europa. Viareggio.

AUDIBERT, J. (1958). Notes de préhistoire Provençale I. Les hipogées préhistoriques de Fontevielle. B. du Rh. Provence historique.

Binimelis, J. (1927). Nueva historia de la Isla de Mallorca y de otras Islas a ella adyacentes compuesta por el Dr. (1593). Palma de Mallorca. Imprenta de J.Tous.

Blanes i Blanes, C., Bonet i Rosselló, J., Font i Jaume, A. y Rosselló I Callejas, A.M. (1990). Les Illes a les fonts clàssiques. Palma de Mallorca.

Bosch Gimpera, P. (1932). Etnología de la Península Ibérica. Barcelona. Ed. Alpha.

Bretaudeau, G. (1996). Les enceintes des Alpes-Maritime. Ed. Institut de Préhistoire et d'archeologie Alpes Mediterranée. Nice.

Calvo Trias, M., Coll Conesa, J. y Guerrero Ayuso, V.M. (1997). El dolmen de S'aigua dolça. Sepulcro colectivo del pretalayótico. Rev. Arqueología. Madrid.

Cantarellas Camps, C. (1972). Cerámica incisa en Mallorca. Palma de Mallorca.

Cantarellas Camps, C. (1972). Excavaciones en Ca Na Cotxera(Muro, Mallorca). N.A.H. Prehistoria I. Madrid, pp. 177-228.

CAÑIgueral, J. (1951). Los primeros habitantes de Mallorca. La cueva de Sa Canova d'Ariany. Ibérica XIII. Barcelona.

CARTAILHAC, E. (1892). Monuments primitifs des lles Baleares. Toulouse.

CESARI, J. (1985). Les dolmens de la Corse. Archeologia N1 205. Dijon, pp. 33-45.

Cesari, J. (1989). Contribution a l'étude des habitats de l'âge du bronce de la Corse du sud.Habitats centurés, sites perchés du neolithique au bronce ancien dans le sud de la France et de les regions voisines. Montpellier, pp. 69-82.

COLl Conesa, J. (1991). Seriación cultural de los materiales del coval den Pep Rave (Sóller, Mallorca). Elementos calcolíticos y talayóticos. Trabajos de Prehistoria 48. Madrid. 
Costa, B. i Fernández Gómez, J.H. (1992). Les Illes Pitiüses: de la Prehistòria a la fi de l'època Púnica. Prehistòria de les Hles de la Mediterrània Occidental. Palma de Mallorca, pp. 277355.

Demurtas, S., Manca Demurtas, L. y Sebis, V. (1987). Domu de Janas di Du Tiriarzu A (Paulilatino, Oristano). Quaderni della Soprintendenza archeologica per le province di Cagliari e Oristano. Cagliari, pp. 35-47.

Díez, T., Gasull. P, Lull, V. y Sanauja, E. (1980). Excavaciones en el yacimiento de Son Fornés 1975-1978 (Montuiri-Mallorca) N.A.H. 9. Madrid, pp. 311-380.

Encinas, J. A. i Alcover, J. A. (1987). El jaciment fosilífer de la Cova Estreta (Pollença, Mallorca). Endins, Palma de Mallorca, pp. 83-92

ENSEÑAT ENSENAT, C. (1971). Excavaciones en el navetiforme Alemany. Magalluf, Calvià. N.A.H. 15. Madrid.

Esteva Cruañas, L. (1970). Los sepulcros megalíticos de las Gabarras (Gerona) III. Gerona.

Evans, J.D. (1971). The Prehistoric Antiquitis of the Maltese Islands. University of London. The Atholone Press. London.

Fernández Gómez, J.H. (1973). Nuevo depósito de hachas descubierto en Formentera. Pyrenae 9. Barcelona, pp. 177-83.

FERNÁNDEZ GÓMEZ, J.H. (1974). Hachas de bronce halladas en lbiza y Formentera. VI Symposium de Prehistória. Palma de Mallorca, pp. 64-71.

Fernández Gómez, J.H., Plantalamor Massanet, L. y Topp, C. (1976). Excavaciones en el sepulcro megalítico de $\mathrm{Ca} \mathrm{Na}$ Costa (Formentera). Mayurqa, 15. Palma de Mallorca, pp. 64-71.

FERnÁNDEZ GómEZ, J.H. (1977). Últimos descubrimientos prehistóricos en la isla de Formentera. XIV C.C.N. Vitoria.

FERNÁNDEZ GÓMEZ, J.H. (1984). The prehistory of Eivissa and Formentera. Biogeography and Ecology of the Pityusic Islands. La haya, pp. 565-595.

Fernández Gómez, J.H., Plantalamor Massanet, L. y Topp, C. (1987). El sepulcro megalítico de Ca Na Costa (Formentera). Eivissa.

Fernández Miranda, M. y Waldren, W.H. (1974). El abrigo de Son Matge (Valldemossa) y la periodización de la prehistoria mallorquina mediante los análisis de carbono 14. Trabajos de prehistoria 31. Madrid, pp. 297-304.

Fernández Miranda, M. y Waldren, W.H. (1979). Periodizacion cultural y cronologia absoluta en la prehistoria de Mallorca. Trabajos de Prehistoria 36. Madrid, pp. 349-377.

FERnANdez MiRAnda, M. (1991). La transición hacia la cultura talayótica en Menorca. Trabajos de Prehistoria 48, p. 37-50.

Ferrarese Geruti, M.L. (1980). La domus de janas di Mariughia e Canudedda, e il dolmen di Motorra. Sassari.

Flaquer i Fabregues, J. (1953). Alaior, Menorca. Torre d’En Gaumés. Excavaciones 1943. N.A.H. 1. Madrid, pp. 118-120.

Font Obrador, B. y Roselló Bordoy, G. (1969). El poblado prehistórico de Capocorp Vell (Llucmayor). Llucmayor.

Garcia Orellana, J., Fernández Moreno, F., Sánchez Cabeza, J.A., Plantalamor Massanet, L. i TrIPIER, J. (1996). Datació absoluta de ceràmica pretalaiòtica de l'illa de Menorca. Pyrenae 27. Barcelona, pp. 21-29.

García OrellanA, J. (1998). Caracterització de la ceràmica pretalaiòtica de Menorca mitjançant la datació de la termoluminiscència. Treballs del Museu de Menorca 18, Maó.

Gasco, J. (1976). La communauté paysanne de Fontbouisse. Archives d'Ecologie Préhistorique 1. Toulouse.

Gómez Bellard, C. y San Nicolás Pedraz, M.P. (1988). La Prehistoria de lbiza y Formentera: Estado actual de la investigación. Trabajos de Prehistoria 45, pp. 201-228.

Gornes Hachero, J.S., Gual Cerdo, J.M., López Pons, A. i Nicolás Mascaró, J. de (1992). Nous monuments funeraris del mon pretalaiòtic de Menorca. La prehistòria de les llles de la Mediterrània Occidental. Palma de Mallorca, pp. 419-440.

Gual Cerdo, J.M., López Pons, A. i Plantalmor Massanet, L. (1991). Trebalúger: un exemple de la perduració de l'habitat a la prehistòria de Menorca. Meloussa 2. Maó, pp. 157-162.

Guthertz, X., Jallot, L., Colarou, J., Colomer, A. ET Escalón, G. (1989). Les habitats chalcolithiques ceinturés de l'Hérault oriental. Enceintes, habitats ceintures, sites perchés du neolithique au bronze ancien. Montpellier, pp. 111-126.

Juan Benejam, G. i Plantalamor Massanet, L. (1996). L'aixecament planimètric del cap costaner de Cala'n Morell (Ciutadella-Menorca). Treballs del Museu de Menorca 15. Maó. 
Juan Benejam, G. i Plantalamor Massanet, L. (1996). Les coves 11 i 12 de Cala Morell (Ciutadella-Menorca). Maó.

Juan BenejaM, G. i Plantalamor Massanet, L. (1997).

LEWTHWAITE, J. (1981-82). La cultura des castelli de la Corse, dernier temoin d'une genre de vie ouest-mediterranéen d'autrefois. Archeologia Corsa.

LILLIU, G. (1960). Primi scavi del vilaggio talaiotico di ses Païsses (Artà, Mallorca). Rev. dell'istituto Nazionale d'Archeologia e Storia dell'Arte. Nuova Serie A.IX. Roma.

LÓPEZ PONS, A. (1977). El poblament inicial i els grups culturals pretalaiòtics. Enciclopèdia de Menorca. Maó.

Manca Demurtas, L. y Demurtas, S. (1986). Di un tipo architecttonico mediterraneo (Talaiot Rafal Roig-Mercadal Minorca). La Sardegna nel Mediterraneo tra il secondo e il primo miliennio a.C. Selargius-Cagliari, pp. 493-503.

Manca Demurtas, L. y Demurtas, S. (1990-91). II complesso fortificato di Crastu-soddi (Oristano) Saggio di analisi sulle structture di fortificazioni in Sardegna. Le chalcolithique en languedoc. Ses relations extra-regionales. Saint-Mathieu -de-tréviers (Hérault), pp. 315321.

Manca Demurtas, L. y Demurtas, S. (1991). Elementi di iconografia mediterranea (protonuraghi a camera naviforme). Trabajos de Prehistória 48. Madrid, pp. 145-163.

Mannino, G. (1971). La tomba di Contrada Pergola. Sicilia Archeologica. Trapani, pp. 52-56.

martín Granel, H. y Aanal, J. (1952). Les tombes a antenes du Bas-Languedoc. Acte du premier Congreés inter. d'études ligures, pp. 48-51.

MerCADAL, B. (1959). Breve noticia sobre el hallazgo de un incisivo de Myotragus en una cueva menorquina junto a cerámica neolítica. Bol. soc. de His. Natural de Baleares. Tom V. Palma de Maliorca, pp. 57-59.

Mestres, J. (1979-80). El sepulcre megalític de Mas Pla (Valldossera), Querol, Tarragona. Pyrenae 15-16. Barcelona, pp. 125-141.

MorAVETI, A. (1985). Le tombe e l'ideologia funeraria. Civiltà Nuragica. Milano, pp. 132-180.

Murray, M. (1923). Excavations in Malta. London.

OrSI, P. (1899). Pantelleria. Risultati di una missione archeologica. Monumenti antichi vol. IX 1. Roma, pp. 1-92.

Pericot García, L. (1972). The Balearic Islands. Thames and Hudson. London.

Plantalamor Massanet, L. (1974). Avance al estudio de la cueva de Son Maiol d'Establiments (Palma de Mallorca). Prehistoria y arqueología de las Islas Baleares. Barcelona, pp. 89-99.

Plantalamor Massanet, L. (1976-77). Algunas consideraciones sobre los sepulcros megalíticos de Menorca. Santuola II. Santander, pp. 153-173.

Plantalamor Massanet, L. i ANGLADA GomilA, J. (1978). Excavacions a les navetes d'habitació de Clariana- Ciutadella (Menorca). Fonaments 1. Barcelona, pp. 205-208.

Plantalamor Massanet, L. i Rita Larrucea, M.C. (1982). Tres cuevas de la edad del bronce en la zona occidental de Menorca. Ampurias 44. Barcelona, pp. 1-16.

Plantalamor Massanet, L. i López PONS, A. (1983). La naveta occidental de Biniac-Argentina (Alaior, Menorca).N.A.H. 15. Madrid, pp. 159-381.

Plantalamor Massanet, L. (1986). El santuario de So Na Caçana y las relaciones con el MediterrÁneo central y occidental. La Sardegna nel Mediterraneo tra il secondo e il primo milennio a.C. Selargius-Cagliari, pp. 533-546.

Plantalamor Massanet, L. (1991). L'arquitectura prehistòrica i protohistòrica de Menorca i el seu marc cultural. Treballs del Museu de Menorca 12. Maó.

Plantalamor Massanet, L. (1991). El conjunt de Curnia (Maó) i l'evolució cultural a Menorca Oriental al II Mil.lenari A.C. B.S.A.L. 47. Palma de Mallorca, pp. 3-18.

Plantalamor Massanet, L. (1991). Los asentamientos costeros en la isla de Menorca. Congresso Internazionale di Studi Fenici e Punici. Roma, pp. 1152-1160.

Plantalamor Massanet, L. i Murillo OrfILA, J. (1992). Aixecament planimètric del talaiot de Son Noguera (Llucmajor). B.S.A.L. 48, Palma de Mallorca, pp. 17-24

Plantalamor Massanet, L. i Murillo Orfila, J. (1993). El talaiot de Comasema.B.S.A.L. 49. Palma de Mallorca, pp. 3-8.

PlantAlAmOR MASSANET, L. (1995). Ubicació topogàafica de les taules i santuaris menorquins. EI seu significat econòmic i social. Ritual, Rites and Religion in Prehistory. BAR Internationa Series 611, pp. 281-294.

Plantalamor Massanet, L. i Strydonck, M.Van. (1997). La cronologia de la prehistòria de Menorca (Noves datacions de 14C. Treballs del Museu de Menorca 20. Maó. 
Ramis I Ramis, J. (1818). Antigüedades célticas de la isla de Menorca desde los tiempos más remotos hasta el siglo iv de la era cristiana. Mahón.

Ramón Torres, J. (1985). Els monuments antics de les Illes Pitiüses. Conselleria de Cultura. Consell Insular d=Eivissa i Formentera. Eivissa 1985.

Ripoll Perelló, E. y Roselló Bordoy, G. (1963). El lote de bronces talayóticos de Cas Corraler (Felanitx-Mallorca). Ampurias XXV. Barcelona, pp. 192-197.

RitA LARRUCEA, M.C. (1886). Evolución de la cultura pretalaiótica menorquina a través de los yacimientos de Morellet y Son Mercer de Baix. La Sardegna nel Mediterraneo tra il secondo e il primo millenio a.C. Selargius Cagliari. 1986, pp. 547-555.

RoMÁN, C. (1913). Antigüedades Ebusitanas. Barcelona.

Roselló Bordoy, G. (1962). Excavaciones en la Necrópolis de cuevas artificiales de So'n Sunyer (Palma de Mallorca). Exc. Arqu. en Esp. 14. Madrid.

Roselló Bordoy, G. (1963). El túmulo escalonado de So'n Oms (Palma de Mallorca). Barcelona.

Roselló Bordoy, G. (1965). Excavaciones en el conjunto talayótico de Son Oms (Palma de Mallorca) (Campañas de 1959, 1961 y 1962). Ex. Arq, en Esp. 35. Madrid.

Rosello BordoY, G. y FreY, O.G. (1966). Levantamiento planimétrico de S'lllot (San LorenzoMallorca). Exc. Arq. en Esp. 48. Madrid.

Roselló Bordoy, G. (1966). Excavaciones en el círculo funerario de Son Bauló de Dalt (Mallorca). Mem. Ex. Arq. en Esp. № 51. Madrid.

Roselló BordoY, G. (1966). Las navetas en Mallorca. Studi Sardi. Cagliari, pp. 2-66.

Rosello Bordoy, G. (1967). Es closos de Ca'n Gaià. Trabajos del Museo de Mallorca 2. Palma de Mallorca.

Roselló Bordor, G. y CAMps Coll, J. (1971). Excavaciones en los talaiots de «Son Serralta» (Puigpuñent, Mallorca). N.A.H. XV. Madrid, p. 32.

Roselló Bordoy, G. y Serra Belabre, M.L. (1971). Excavación y restauración de la naveta meridional de Rafael Rubí (Alaior, Menorca). N.A.H. XVI. Madrid, pp. 51-86.

Roselló Bordoy, G. y CAMPS COLL, J. (1972). Excavaciones en el complejo noreste de «Es Figueral de Son Real». Santa Margarita (Mallorca). N.A.H. prehistoria 1. Madrid, pp. 109166.

Roselló Bordoy, G. y Waldren, W.H. (1973). Excavaciones en el abrigo del bosque de Son Matge (Valldemosa, Maliorca) N.A.H. Prehistoria II. Madrid, pp. 1-76.

Roselló Bordoy, G. (1973). La cultura talayótica en Mallorca. Bases para el estudio de sus fases iniciales. Palma de Maliorca.

Roselló BORDOY, G. (1973). Materiales pretalaióticos en navetiformes mallorquines. XII C.N.A. Zaragoza, pp. 295-300.

Roselló Bordoy, G. y Camps Coll, J. (1976). Excavaciones en Canyamel. Capdepera (Mallorca). N.A.H. prehistoria 5. Madrid, 235-240.

Roselló Bordor, G., Plantalamor Massanet, L. y lópez Pons, A. (1980). Excavaciones arqueológicas en Torre den Gaumés (Alaior-Menorca). Sepultura Megalítica de Ses Roques Llises. N.A.H. (Madrid), pp. 71-138.

Roselló Bordoy, G. (1983). El poblado prehistórico de Hospitalet Vell (Manacor). Ins. Est. Balearics. Palma de Mallorca.

Roselló Bordoy, G. (1987). Mallorca en el bronce final. La Sardegna nel Mediterraneo tra il bronzo medio e il bronzo recente (XVI-XII sec. a. C.) Selargius, Cagliari, pp. 421-442.

Roselló Bordoy, G., Plantalamor Massanet, L. y Murillo Orfilla, J. (1995). Cala de Sant Vicenç: una necrópolis de cuevas artificiales de tipo mediterráneo en Mallorca. B.S.A.L. 50. Palma de Mallorca, pp. 3-56.

Rouldín, J.L. (1978). Circonscription du Languedoc-Roussillon. Gal. Pr. Tom 21, fasc. 2, París, pp. 682-683.

SANTONI, V. (1976). Nota preliminare sulia tipologia delle groticelle funerarie in Sardegna. Arc. Sto. Sardo. Vol XXX. Cagliari 1976, pp. 1-49.

SANTONI, V. y SEBIS, S. (1984). Il complesso nuragico "Madonna del Rimedio" (Oristano). Nuovo Bullettino archeologico Sardo, vol. 1.

TARRAdelL, M. (1964). La necrópolis de "Son Real» y la «lla dels Porros». Mallorca. Exc. Arq. en Esp. 24. Madrid.

Topp, C., Fernandez Gómez, J.H. y Plantalamor Massanet, L. (1976). Ca Na Costa: A megalithic chamber tomb on Formentera, Balearic Islands. Bull. 13 of institute of Archaeology. London, pp. 139-174. 
Topp, C., Fernández Gomez, J.H. y Plantalamor Massanet, L. (1979). Recent archaeological activities in Ibiza and Formentera. Bull. 16 of institute of Archaeology. London, pp. 215-231.

TOPP, C. y Plantalamor MASSANET, L. (1992). Les ceràmiques pretalaiòtiques d'Ariant (Pollença) a l'University Museum of Archaeology and Antropolgy of Cambridge. B.S.A.L. 48. Palma de Mallorca, pp. 3-16.

Trías, M. i RocA, L. (1975). Noves aportacions al coneixement de les coves de Sa Mola (Formentera) i la seva importància arqueològica. Rev. Endins, N1 2. Palma de Mallorca, pp. 15-33.

TríAs, M. (1977). Cova Xives: Troballes prehistòriques a Eivissa. Rev. Endins, N1 4. Palma de Mallorca, pp. 49-52.

TRUMP, D. (1995-96). Radiocarbon dates from Malta. The Accordia Research Papers. Vol.6. London, pp. 173-177.

TUSA, S. (1983). La Sicilia nella preistoria. Palermo.

VENY, C. (1968). Las cuevas sepulcrales del bronce antiguo de Mallorca. B.P.H. IX. Madrid.

VENY, C. (1981). El complejo funerario de una galería subterránea de la Cometa dels morts, Lluc, Escorca (Mallorca). Trabajos de prehistoria 38, pp. 257-280.

VenY, C. (1982). La naveta de la Cova. Trabajos de Prehistoria. Madrid, pp. 73-136.

VENY, C. (1987). Las navetas de Menorca. La sardegna nel Mediterraneo tra il bronzo medio e il bronzo recente (XVI-XIII sec. a.C.). Selargius Cagliari, pp. 443-472.

VIRILI, F.L. et Gros.JEAN, J. (1979). Guide des sites Torréens de l=age du bronze corse. Ed. Vigros, París.

ViVES Escudero, A. (1917). Estudios de arqueología cartaginesa. La necrópolis de lbiza.

Waldren, W.H. y Plantalamor Massanet, L. (1976). Campaña de excavaciones en el abrigo d'Son Matge. Valldemosa (Mallorca). 1974. N.A.H. Prehistoria 5. Madrid, pp. 241-246.

WALDREN, W.H. y STRYDONCK, M. Van. (1993). Ferrandell-Oleza-Mas prehistoric settlement complex ysunger settlement Valldemossa. Mallorca, Baleares. Spain. Talaiot 1. Damarc 22. Deià.

WALDREN, W.H. (1994). Myotragus Balearicus an extinct pleistocene antelope from the Island of Mallorca. Damarc 21. Deià.

Waldren, W.H., Enseñat Alcover, J. y Cubi Grimalt, C. (1994). Ferrandell-Oleza calcolithic old settlement. Damarc 20. Deià. 